University of Louisville

ThinkIR: The University of Louisville's Institutional Repository

Electronic Theses and Dissertations

$12-2017$

\title{
Culturally relevant teachers : a critical beacon in the educational standards movement.
}

Angela Pleasant

University of Louisville

Follow this and additional works at: https://ir.library.louisville.edu/etd

Part of the Educational Leadership Commons

\section{Recommended Citation}

Pleasant, Angela, "Culturally relevant teachers : a critical beacon in the educational standards movement." (2017). Electronic Theses and Dissertations. Paper 2857.

https://doi.org/10.18297/etd/2857

This Doctoral Dissertation is brought to you for free and open access by ThinkIR: The University of Louisville's Institutional Repository. It has been accepted for inclusion in Electronic Theses and Dissertations by an authorized administrator of ThinkIR: The University of Louisville's Institutional Repository. This title appears here courtesy of the author, who has retained all other copyrights. For more information, please contact thinkir@louisville.edu. 


\title{
CULTURALLY RELEVANT TEACHERS: \\ A CRITICAL BEACON IN THE EDUCATIONAL STANDARDS MOVEMENT
}

By

\author{
Angela Pleasant \\ Bachelor of Science, University of Louisville, 1996 \\ Masters of Education, University of Louisville, 2001
}

\begin{abstract}
A Dissertation
Submitted to the Faculty of the

College of Education and Human Development of the University of Louisville in Partial Fulfillment of the Requirements

for the Degree of

Doctor of Education

in Educational Leadership and Organizational Development
\end{abstract}

Department of Educational Leadership, Evaluation, and Organizational Development University of Louisville

Louisville, Kentucky

December 2017 
Copyright 2017 by Angela Pleasant

All rights reserved 

CULTURALLY RELEVANT TEACHERS:

A CRITICAL BEACON IN THE EDUCATIONAL STANDARDS MOVEMENT

By

\begin{abstract}
Angela Pleasant
Bachelor of Science, University of Louisville, 1996

Masters of Education, University of Louisville, 2001
\end{abstract}

A Dissertation Approved on

November 28, 2017

By the following Dissertation Committee:

Meera Alagaraja (Dissertation Co-Director)

W. Kyle Ingle (Dissertation Co-Director)

Harrie Buecker

Georgia Hampton 


\section{DEDICATION}

This dissertation is dedicated to my son, Micah, my forever light and purpose - "act justly and to love mercy and to walk humbly with your God" (NIV Micah 6:8) 


\section{ACKNOWLEDGMENTS}

To my late father, LeRoy Pleasant, and my mother, Aldean Pleasant, thank you for instilling in me that education is the way for a better tomorrow. Little did I comprehend back then the depth of meaning behind those words. Your personal and professional guidance led me to where I am today.

To my husband, Cal, thank you for your unconditional love, steady belief, and unending patience. I appreciate you for being there for me when I struggled to be there for myself. Your words of, "So what do we need to do?" helped more than you ever will know. I so love how you stepped up and filled in when I could not.

To my son, Micah, all of this is for you. The words, "Mommy is working on her paper?" is instilled in my memories forever. We started this program together, when you were in my belly for only three months. All of this is for you and the dreams I have for your future in education.

To my friends, thank you for understanding my tight schedule and not forgetting that I exist. I appreciate the times where you let me sit and not talk, so I could think through what I was going to do next. It is wonderful to know that I constantly had a group of women who understand me when I am trying to find my way.

To my doctoral chairs, Dr. Alagaraja and Dr. Ingle, thank you for your support throughout this process. In addition, I appreciate all the classes that helped me understand, define, and articulate what I have tried to understand for 21 years. Thank you for pushing me and never accepting anything less than my absolute best. 


\title{
ABSTRACT \\ CULTURALLY RELEVANT TEACHERS: \\ A CRITICAL BEACON IN THE EDUCATIONAL STANDARDS MOVEMENT
}

\author{
Angela Pleasant
}

November 28, 2017

The purpose of this study was to describe culturally relevant teachers' beliefs and teaching practices as they implement the Reading CCSS. It was hypothesized that by exploring the beliefs and practices of teachers who practice a culturally relevant pedagogy, this research could provide evidence of the specific and identifiable practices that demonstrated high expectations, culturally competency, and critical consciousness. This research could provide evidence of effective strategies, which could be used to impact the literacy achievement of students of color while the teacher implements the Reading Common Core State Standards or any standards movement that follows.

A qualitative case study research design was used in this investigation to analyze elementary school teachers whose use of culturally relevant practices positively enabled students of color to engage in the Reading CCSS. Three teachers of grades four and five were chosen because of their professional development practices and understanding of cultural competency. A short answer question, interviews, classroom observations, and artifacts generated data that, when analyzed, showed that all three teachers made it a priority to create a positive and cooperative learning environment that enabled students to engage with the reading standards. Each teacher was committed to learning about all their 
students and utilizing their students' culture and interest to provide meaningful literacy instruction. Even though various literacy approaches were used, each teacher felt that working with their students and allowing students to work in small groups provided them the opportunity to have a positive impact on student engagement, which led to student achievement. In regards to culturally relevant pedagogy, the teachers in the study expected all students to be success with the standards in that they used formative assessments as a way to reflect on their own teaching. Next, the participants used events in the community to connect to the content being taught in the classroom. Finally, these participants expected students to look beyond the words on the page and to use their cultural knowledge to determine the purpose of the message being delivered by the author. These teachers welcomed student input that was against mainstream beliefs and encouraged students to build their arguments using facts.

It was recommended that school leaders should establish a vision where all students are expected to achieve at high levels. In this expectation, students are to be exposed to higher level thinking opportunities regardless of their current academic output. A school vision should embrace and use the communities in which students live in the classroom. Is up to school leaders to keep this clear and visible in materials used, lessons taught, and individual classroom communities. Lastly, a classroom teacher must reflect and analyze why their students are learning or why they are not. Historically, race has not been part of instructional decision-making; however, as the United States becomes more culturally diverse, students bring with them their beliefs. Classroom teachers should utilize and embrace students' individuality as an instructional strategy when developing learning opportunities for their students. 
TABLE OF CONTENTS

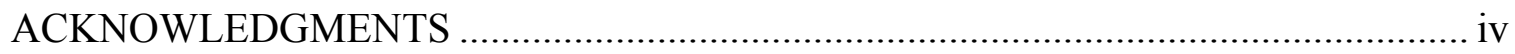

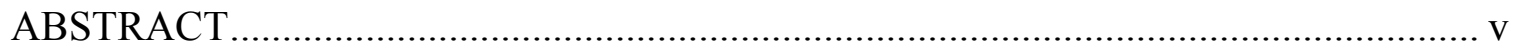

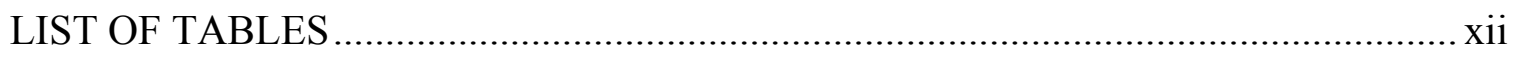

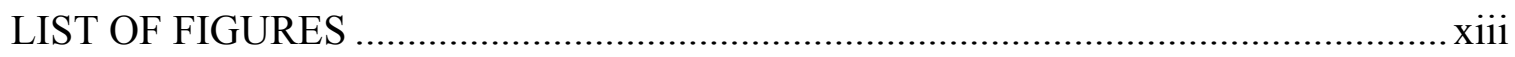

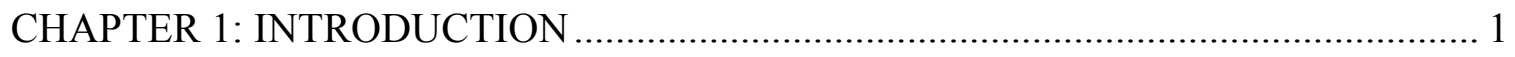

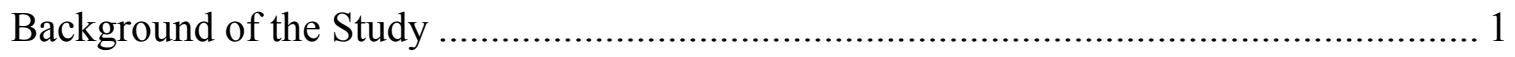

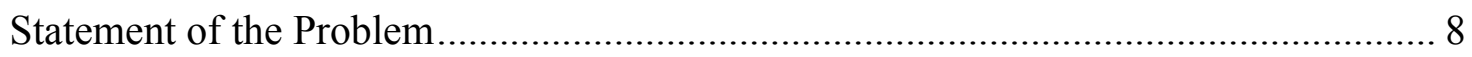

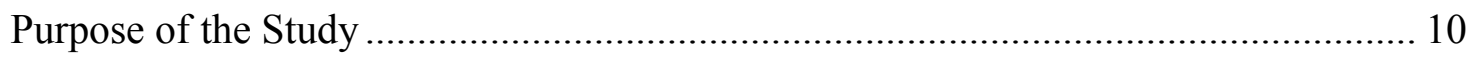

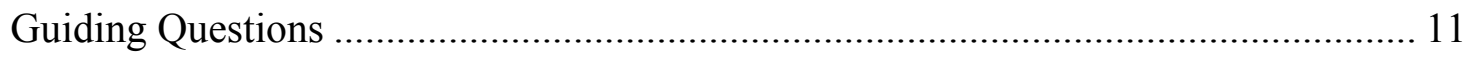

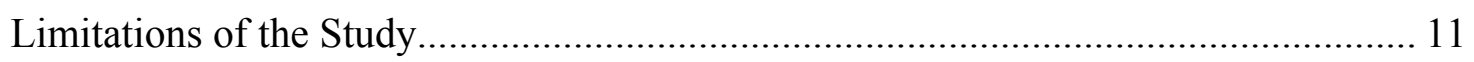

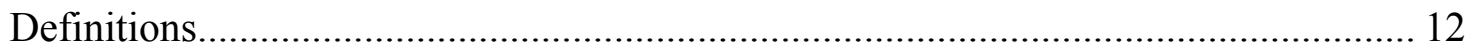

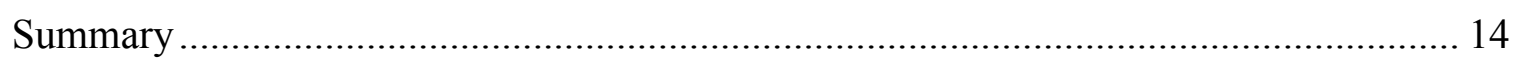

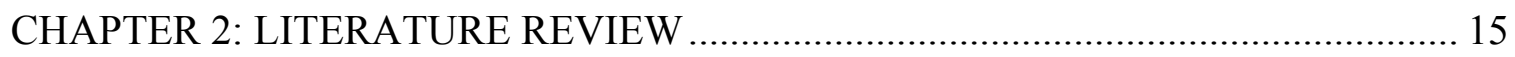

Culturally Relevant Teaching: Extracting Knowledge .................................................. 16

Criterion 1: Academic Success .......................................................................... 21

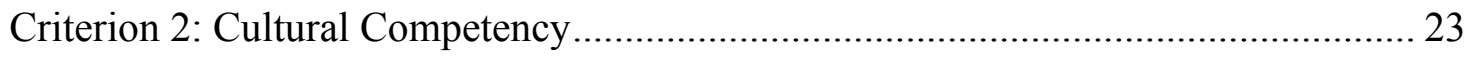

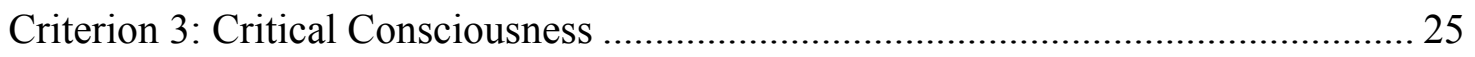

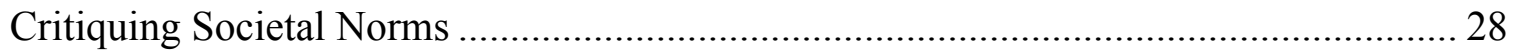


Critical Literacy: Empowerment through Literature ……………………………...... 33

Theory to Practice for Culturally Relevant Teachers ……............................................... 37

The Path to Becoming a Culturally Relevant Teacher...................................................... 41

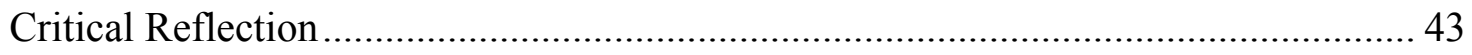

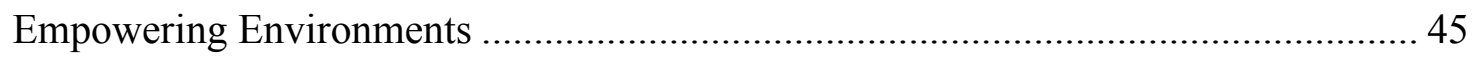

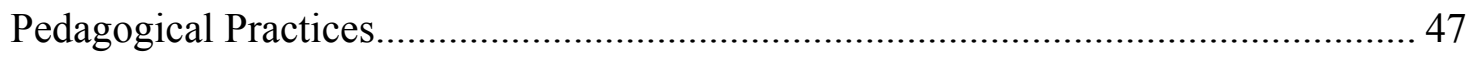

Changing Demographics within the United States …………………......................... 53

Education Reform Initiatives to Improve Student Achievement ..................................... 56

From NCLB to CCSS Reform: Continued Efforts to Improve Student Learning............ 61

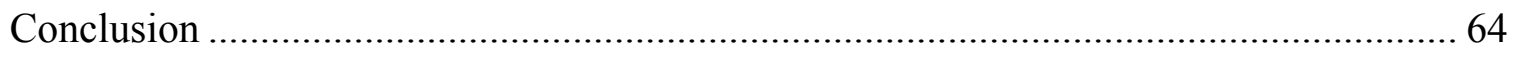

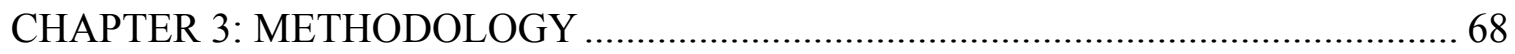

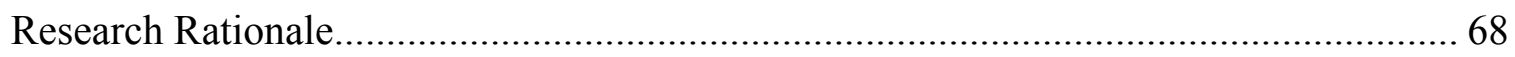

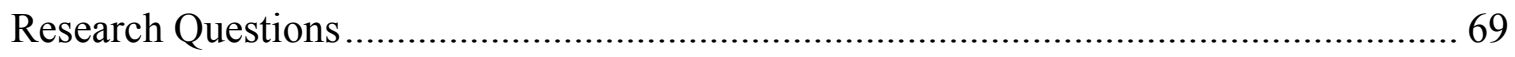

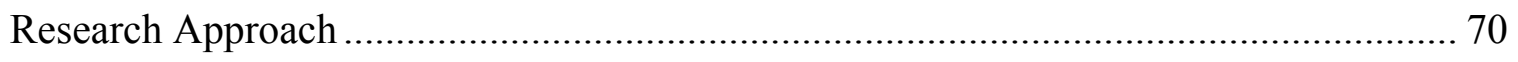

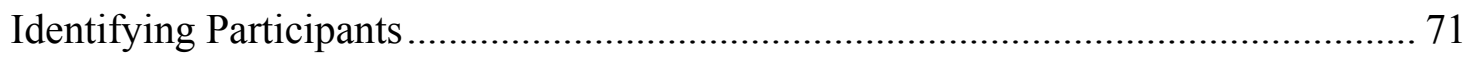

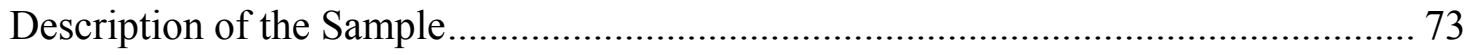

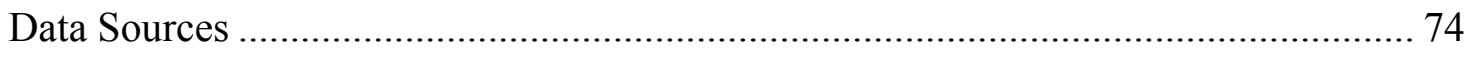

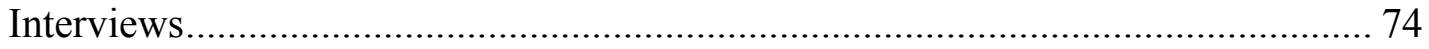

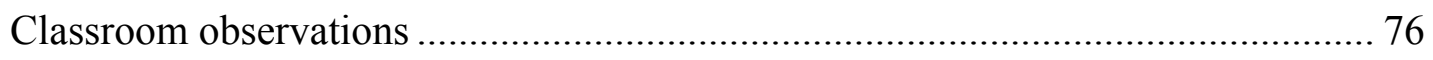

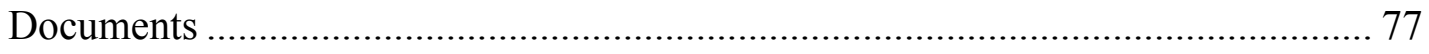

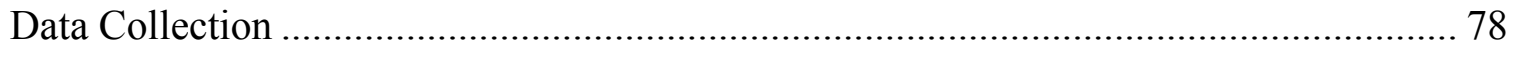

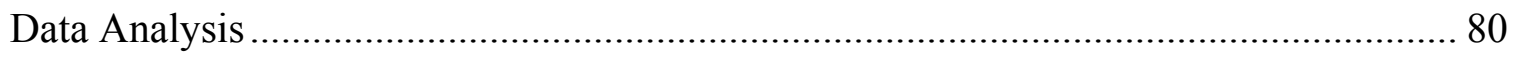

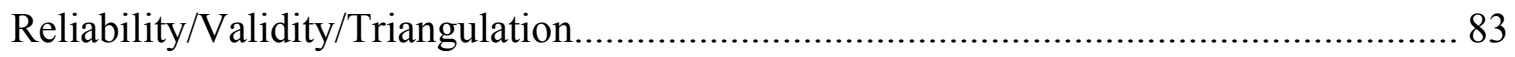




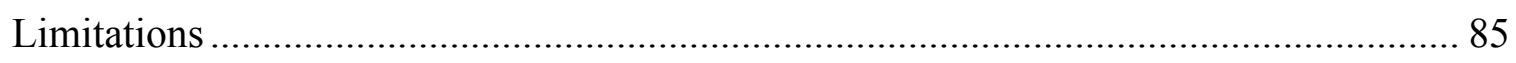

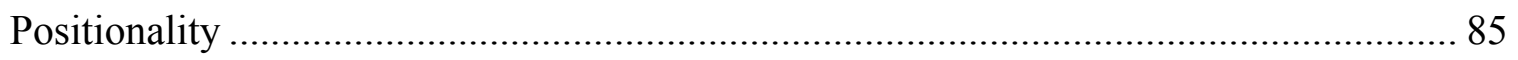

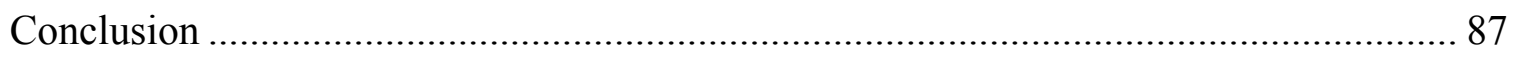

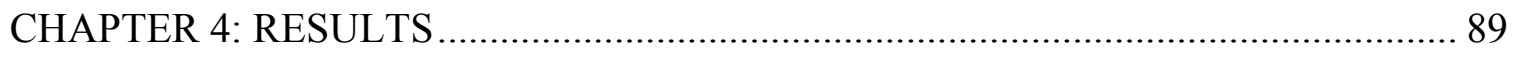

Stephanie: Fourth-Grade Teacher ............................................................................. 90

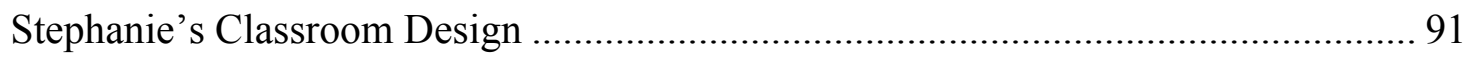

Stephanie's Culturally Relevant Pedagogy Analysis.................................................. 95

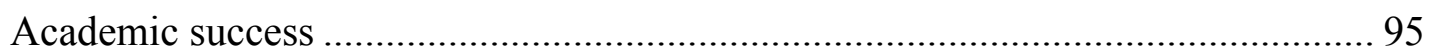

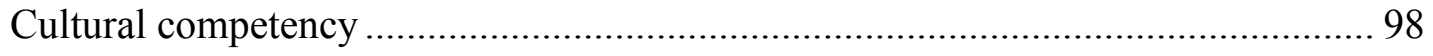

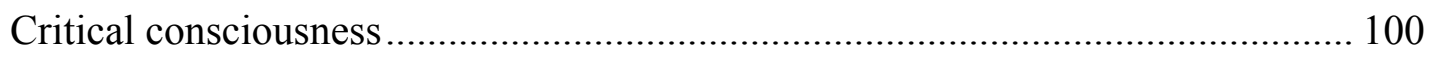

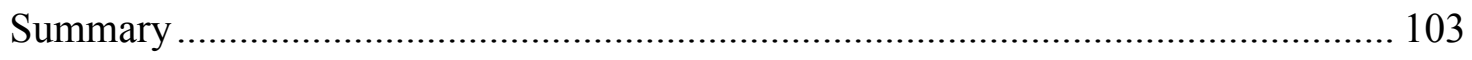

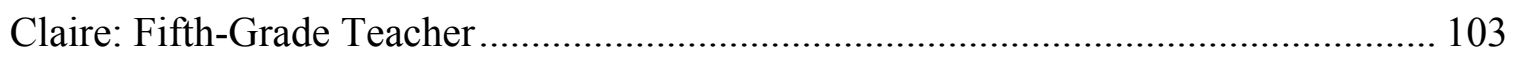

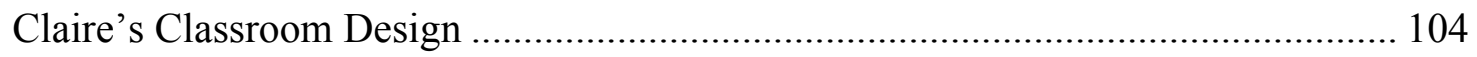

Claire's Culturally Relevant Pedagogy Analysis.................................................... 108

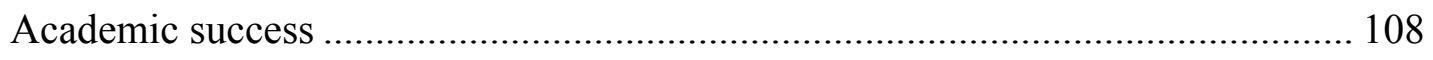

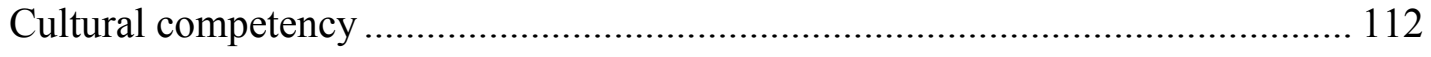

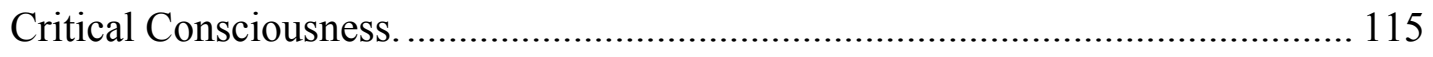

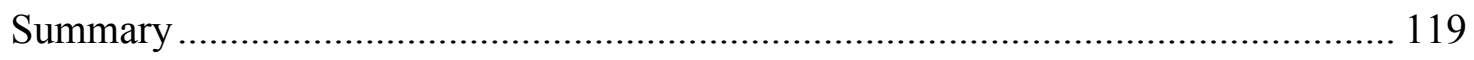

Charles: Fifth-Grade Teacher .............................................................................. 119

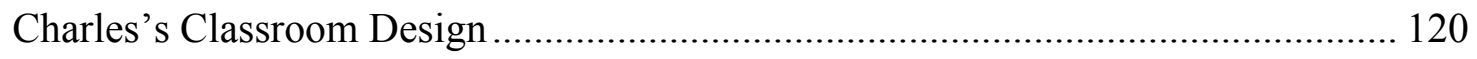

Charles's Culturally Relevant Pedagogy Analysis ................................................... 124

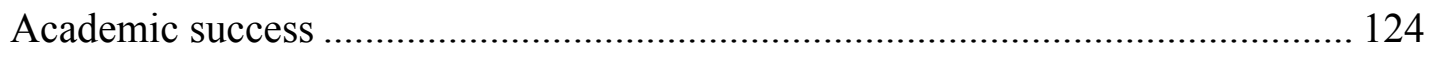

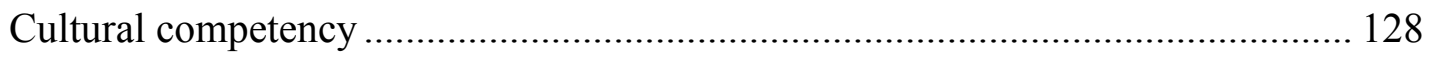


Critical consciousness

Summary

Practices of Culturally Relevant Teachers

Developing Critical Consciousness and Addressing Lack of Diversity in the CCSS ... 134

CHAPTER 5: DISCUSSION, CONCLUSION, AND RECOMMENDATIONS

Findings

Finding 1: Classroom culture is built upon relationships and respect for each student's

cultural background

Finding 2: Assessments are used to inform instruction, not classify students

Finding 3: Higher-order questioning and rigorous activities are used to engage students in learning environment.

Finding 4: Cross-curricular instruction is used to bring relevance to what is being taught

Finding 5: Reflection practices are used to question instruction effectiveness and

individual student needs.

Recommendations 156

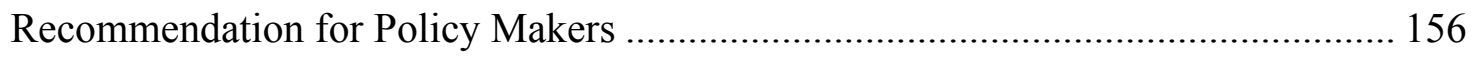

Recommendation for Schools of Education ...................................................... 158

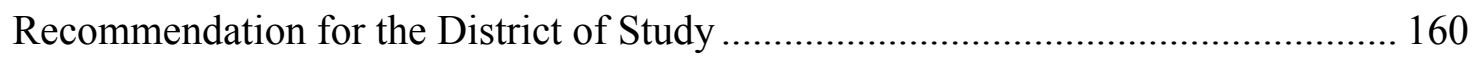

Recommendation for School Leaders' Practice........................................................ 163

Recommendation for Individual Teacher's Practice.................................................... 169

Recommendations for Future Research ................................................................... 172

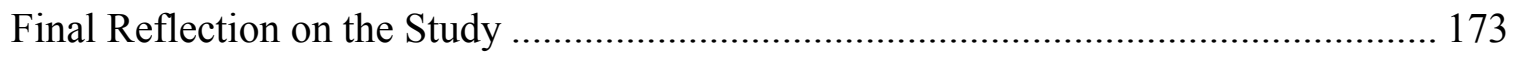




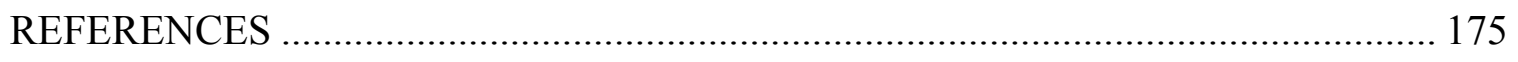

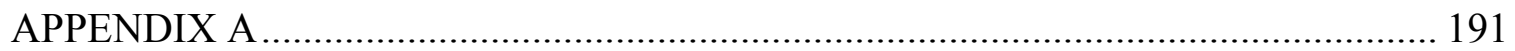

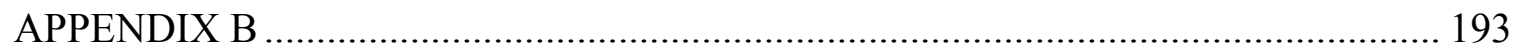

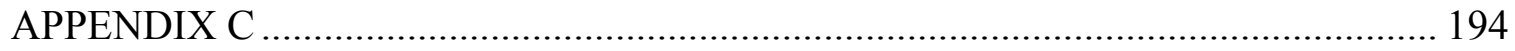

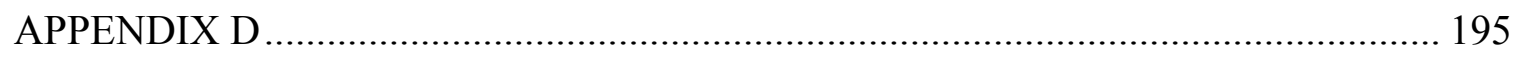

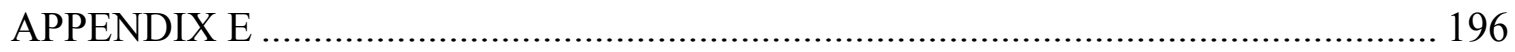

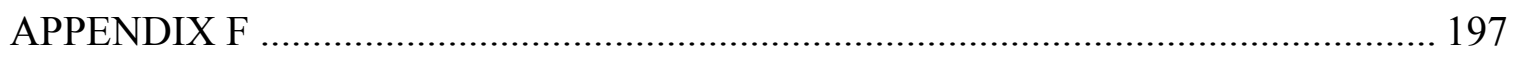

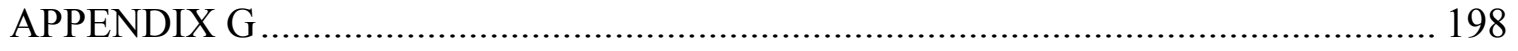

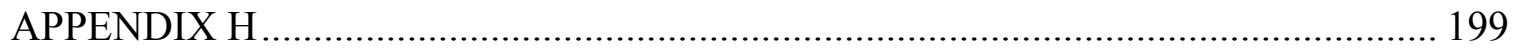

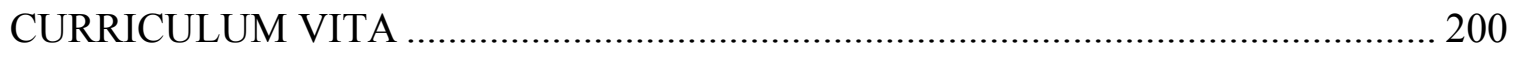




\section{LIST OF TABLES}

Table 1. Findings in Practice .................................................................................................144 


\section{LIST OF FIGURES}

Figure 1. The three components of a culturally relevant teacher according to LadsonBillings (2009): philosophy, pedagogy, and personal commitment................................ 16 


\section{CHAPTER 1: INTRODUCTION}

This study investigates the phenomenon of how teachers are able to practice culturally relevant teaching while complying with educational reform movements, particularly, the Common Core State Standards (CCSS). It examines a sample of elementary teachers, exploring their insights into how they use a culturally relevant pedagogical approach while implementing a new educational reform movement. The conclusions generated from this inquiry will add to Ladson-Billings' theory and supplement existing knowledge about culturally relevant teaching frameworks, specifically, providing insights for those designing professional development initiatives. To accomplish these goals, this study will use a qualitative research methodology.

This chapter introduces the study's focus, describing the federal standard reform CCSS initiative as well as a theoretical framework for culturally relevant teaching. In doing so, it briefly describes the framework, rationalizing its selection for addressing the current educational reform. The chapter closes by stating the problem, summarizing the purpose of the study, introducing guiding questions, and defining terms.

\section{Background of the Study}

The development and adoption of the CCSS constitutes a sweeping curriculum reform effort on an unparalleled scale (Porter, Fusarelli, \& Fusarelli, 2015; Ujifusa, 2013). The CCSS are not a "national curriculum", but rather are a guiding framework for states to use in developing curriculum and realigning testing (Kendall, 2011; McDonnell 
\& Weatherford, 2013; Porter et al., 2015). The CCSS attempt to standardize what students are learning and when while also bringing states to a uniform level of expectation regarding student learning. This is the first attempt by a national organization (i.e., National Governors Association Center for Best Practices) to originate solid, clear grade-level expectations and have them filtered through the state and district levels for ultimate implementation by classroom teachers (Kendall, 2011).

CCSS sought to delineate an irreducible set of knowledge and skills while ensuring equitable treatment of all students in terms of the educational expectations of their teachers (Kendall, 2011). Before CCSS, the No Child Left Behind Act (NCLB) tried to ensure equitable educational experiences for all children by requiring states to align tests with state academic standards and begin testing students on an annual basis in basic reading and math skills (Dee, Jacob, Hoxby, \& Ladd, 2010; Hursh, 2007). Legislative proponents of NCLB believed that standards-based education reform, when attempted after establishing measurable goals, could improve individual outcomes in education. But they did not define or detail a national achievement standard (Dee et al., 2010; Hursh, 2007). Under NCLB, students across the nation saw achievement improvements, but gaps persisted between races, ethnic groups, cultural groups, and socioeconomic groups (Dee et al., 2010; Hursh, 2007; National Assessment of Educational Progress, n.d.).

In the 1990s, Ladson-Billings (1992) developed a theory of culturally relevant teaching, seeking to capture what teachers should do when teaching diverse students. Ladson-Billings noted that teachers who were successful in teaching African American students succeeded because they held students to high academic standards, exhibited a high degree of cultural competence, and embodied a critical consciousness. Teachers who 
evaluate their views regarding its ability to function as a teaching platform have a positive efficacy about their ability to teach students of color, use their students' cultural capital, and influenced students' success (Goldenberg, 2014; Ladson-Billings, 2009; Love \& Kruger, 2005). Her book, The Dreamkeepers: Successful Teachers of African American Children (2009) reviewed findings of eight teachers whose students of color found academic success while the teacher navigated educational reforms.

Ladson-Billings' $(1994,1995,2009)$ found that efficacious teaching led students, regardless of race and socioeconomic status, to academic success. However, Sleeter (2011) notes that the theory of culturally relevant teaching is not a framework used regularly in the classroom, arguing that although culturally relevant pedagogy supports empowered learning for a diverse student population, three particular problems keep it from being common practice among educators. First, educators hold persistent and simplistic conceptions of its meaning. Although culturally relevant teaching is a cultural celebration, educators separate culture from academic instruction (Sleeter, 2011). Second, research does not directly connect culturally relevant teaching to student learning. Third, culturally relevant teaching prompts a political backlash prompted by the fear of upsetting the existing social order. An example of this was seen in Arizona when the Social Justice Education Project positively affected Chicano academic achievement more than it did that of their White counterparts. The districts' superintendent pledged to terminate the program (and did), having determined it to be an un-American curriculum for using issues relevant to the lives of students of color (Sleeter, 2011).

Ladson-Billings' teaching framework of incorporating students' cultural capital is an appropriate lens through which to view the current reform movement, for teachers 
who are culturally relevant find success in educating their students regardless of the initiative currently being pushed at the classroom level (2009). As Sleeter (2011) noted, when reform initiatives speak blatantly of race, the possibility of political backlash exists. The CCSS differ from NCLB, however, in that they are based on higher-order thinking skills instead of mastery of basic skills (Dee et al., 2010; Kendall, 2011). Culturally relevant teaching takes the view that students positively respond to instruction that is based on high expectations and higher-order thinking tasks (Ladson-Billings, 2009). Because a foundational CCSS stance is that higher-order thinking tasks help students excel, this common ground between CCSS and culturally relevant teaching helps eliminate the possibility of political backlash.

Another way that the CCSS differ from previous reform movements while sharing common beliefs with culturally relevant teaching is that students are expected to evaluate judgments, synthesize information within and across texts, develop a spoken or written presentation, and use metacognition strategies to manage their understanding of all they read - and are assessed on their ability to do so (Kendall, 2011). This is the same expectation that the teachers in Ladson-Billings (2009) had for their students. For example, a fifth-grade literacy standard expects that students will be able to integrate information from several texts on the same topic in order to write or speak about the subject knowledgeably. Even if a student of color does not have a culturally relevant teacher, he or she is exposed to high levels of academic expectation. Moreover, the reading standards encourage students to think critically about what they read.

Even though the CCSS and culturally relevant teaching share the common beliefs of setting high academic expectation of all students and teaching students to critically 
analyze text, CCSS does not explicitly state teachers should take students cultural identity into account when deciding on how use the standards in the classroom (Common Core State Standards Initiative, 2010; Fernandez \& Hauser, 2015; Ladson-Billings, 2009). Culturally relevant teaching views students' culture as essential to the engagement of students of color, whereas the CCSS neglect the use of students' cultural capital as a way to engage all students. Instead, the CCSS argue that a decrease in text complexity for $\mathrm{K}-$ 12 students is the reason for the declining numbers of students who are prepared for college and careers (Common Core State Standards Initiative, 2010). Accordingly, the 15 member English CCSS workgroup (i.e., composed from Achieve, ACT, College Board, assessment coordinators, professors and past educators) developed an "Appendix A" discussing the importance of text complexity, as well as an "Appendix B" to exemplify the level of complexity and quality of texts with which students are to engage in designated grade levels. The workgroup selected 171 author exemplars for $\mathrm{K}-12$ teachers to use. Only 18 of 171 authors were persons of color (Strauss, 2014). What is more, only a few of the texts addressed issues relevant to the lives of students of color (Strauss, 2014). Yet, according to the National Center for Educational Statistics (NCES), almost half of the members of the American student population are students of color (Add YEAR). Ladson-Billings (1992) found that students of color use their cultural experiences to make sense of what they read, regardless of its complexity. However, Appendix B of the CCSS ignored the lives, experiences, and needs of students of color (Strauss, 2014). Seeking to remedy this, the Collaborative for Equity and Literacy Learning suggested 150 multicultural titles to the Council of Chief State School Officers, all of which were sent to Stanford University's Understanding Language Program for 
validation of text complexity (Strauss, 2014). Considering that the CCSS are a national reform movement, the CCSS work group might have tried to include more culturally diverse sample of texts as exemplars to avoid the appearance of neglecting the life experiences of students of color as beneficial to the classroom (Goldenberg, 2014; Ladson-Billings, 2009; Strauss, 2014).

Traditionally, school reform movements have focused on instructional leadership, professional development, learning climate, family, and quality of instruction when seeking to improve student achievement (Payne, 2013). But these reforms have overlooked a major component of the educational process: the interaction between teachers and students (Goldenberg, 2014). When legislators, school districts, and schools maintain the belief that academics and culture are separate, we should not be surprised at teachers' attitudes toward and beliefs about cultural diversity and its place in the classroom (Gay, 2010; Sleeter, 2011). Ladson-Billings (1998) discusses the disconnect of culture and curriculum as a way to "maintain a White supremacist master script" (p. 18). Master scripting means silencing the voices and stories of various culture groups when they challenge the dominant culture authority (Ladson-Billings, 1998).

As already noted, culturally relevant teachers maintain high academic expectations of their students, exhibit high levels of cultural competence, and embody a critical consciousness regarding the materials they use - and they teach their students to have a critical consciousness as well (Ladson-Billings, 2009). For example, Ann Lewis, one of the teachers in Ladson-Billings study, required all of her fifth and sixth grade students to read from chapter books. Ann taught literacy and some of her students had not read from a chapter book until her class. When slower readers struggled, she encouraged 
and "urged other class members to help. 'Remember, we're all a team here. We've got to help each other" (Ladson-Billings, 2009, p. 118). Ann was also observed doing impromptu activities like role-playing characters to help with comprehension. Additionally, students were expected to find common themes in the different chapter books they read. Evidence of this was seen in character-attribute webs that hung around the room. Students found how different authors develop similar character traits in stories that take place in different places and times. Julia, a third grade teacher, was another participant in Ladson-Billings (2009) research. Julia believed in following the school's basal series but added additional resources to connect to her students. She used a Book of the Month Club to encourage students to read higher order comprehension texts. When she taught phonic lessons, she used above grade level words to build students confidence in their ability to read. Ladson-Billings (2009) spoke to a student with a history of being a reluctant reader. He shared how he became a good reader because if he wanted to be a good reader, “She [Julia] was going to help me want to. She said you can't stay in her class if you don't read. I want to stay" (p. 125). Both of these examples show teachers going beyond the school's curriculum and showing their students through their assignments the importance of the subjects they teach. Also, both teachers held their students accountable to each other and to their own learning. They did not see themselves as the sole person responsible for teaching but students teach each other and hold each other accountable.

Research using the framework of culturally relevant teaching has shown that even though teachers often value the cultural backgrounds of their students of color, they are inclined to consider basic skill instruction as a better means of instruction than was the 
use of students' culture as a conduit for engagement (Love \& Kruger, 2005; Song, 2006).

Research has also shown that teachers' instructional choices are sometimes influenced by colorblind or biased ideology (Bennett, 2012; Love \& Kruger, 2005; Natesan \&

Kieftenbeld, 2013; Siwatu, 2011; Song, 2006; Walker, 2011). When teachers use a curriculum that is not culturally relevant to students of color, those students' academic ability might not be optimized. Considering that CCSS also lacks cultural connection to students of color, these students might be facing similar outcomes as those produced by previous reform movements.

\section{Statement of the Problem}

Previous research on culturally relevant teaching has focused on teachers' cultural competency and on their belief in students' academic ability (Gay, 2000; Love \& Kruger, 2005; Watson, 2012). Researchers have studied teachers in the context of being a culturally relevant teacher as defined by Ladson-Billings (2009). However, when researchers call a participant culturally relevant, the focus has been on their cultural competency and/or high expectations pedagogical practices. Also, literature is lacking about how a culturally relevant teacher uses the CCSS when deciding how to teach a diverse classroom. So if, by definition, a culturally relevant teacher has a critical consciousness but the literature does not speak of teachers' critical consciousness, can that teacher be called culturally relevant? The dropping of critical consciousness connects back to the research of Sleeter (2011), who noted that culturally relevant teaching has been redefined so many times that the true framework has lost its purpose.

In 2014, Ladson-Billings reviewed the state of culturally relevant teaching. She discussed how her work on culturally relevant pedagogy had "taken a life of its own, and 
what I see in the literature and sometimes in practice is totally unrecognizable to me (Ladson-Billings, 2014, p. 82). She reported that:

Despite the apparent popularity of culturally relevant pedagogy, I have grown increasingly dissatisfied with what seems to be a static conception of what it means to be culturally relevant. Many practitioners, and those who claim to translate research to practice, seem stuck in very limited and superficial notions of culture. Thus, the fluidity and variety within cultural groups has regularly been lost in discussions and implementations of culturally relevant pedagogy ... . I could see teachers who had good intentions toward the students and wanted to embrace culturally relevant pedagogy. They expressed strong beliefs in the academic efficacy of their students. They searched for cultural examples and analogues as they taught prescribed curricula. However, they rarely pushed students to consider critical perspectives on policies and practices that may have direct impact on their lives and communities. There was no discussion of issues such as school choice, school closings, rising incarceration rates, gun laws, or even everyday school climate questions like whether students should wear uniforms. (pp. 77-78)

As Sleeter (2011) noted, this "static conception" of culturally relevant teaching arose from educators' simplistic conceptions based on limited reliable culturally relevant research, and as a result of political backlash. Although all students need to improve, without targeted interventions for students of color, improvement trends will continue to exhibit gaps between some groups of students. As long as teachers "just see children" when they make instructional decisions, students of color will continue to lag regardless 
of educational reforms (Ladson-Billings, 2009). The CCSS represents a reform movement focused on high expectations, sets high academic standards, and identifies a clear path, starting in Kindergarten, for students to prepare for their futures. But if teachers do not make use of students' cultural capital in a spirit of critical consciousness, the CCSS will not reach their full potential for all students.

\section{Purpose of the Study}

The implementation of CCSS affects students and educators by putting forth specific expectations of students' level of academic achievement in each educational stage (Kendall, 2011). Accordingly, this qualitative case study examines the beliefs and practices of culturally relevant teachers as they implement CCSS (Sleeter, 2011). In particular, it focuses on how teachers integrate these standards' expectations of higherorder thinking within a culturally relevant teaching framework in which teachers embody critical consciousness and teach it to their students (Ladson-Billings, 2014).

The study is designed to collect empirical data about culturally relevant teachers' beliefs and teaching practices as they implement the Reading CCSS. In doing so, it will add to the theory of culturally relevant teaching by providing extensive interviews of urban in-service teachers and digging deep into their understanding of how culturally relevant teachers teach reasoning skills. According to Sleeter (2011), if culturally relevant teaching is to be recognized as a valuable framework for teaching, supporting research must be specific and must elaborate on the explicit pedagogical practices of a culturally relevant teacher's classroom. Plus, research needs to measure academic achievement of culturally relevant teachers' students compared to teachers who focus solely on academic achievement. Accordingly, Debnam, Pas, Bottiani, Cash, \& Bradshaw (2015) have called 
for more research into culturally relevant teaching professional development, and specifically into ways of measuring the effectiveness of the frequency and quality with which these strategies are shared with teachers.

\section{Guiding Questions}

Teachers who reflect on their prejudices, bias, and beliefs about diverse student populations develop a more affirming pedagogy (Gay \& Kirkland, 2003; Howard, 2003). Critical research studies claim that current research is of small scale, diluted from the original study, and are fragmented which therefore produces a disjointed and somewhat tedious understanding and stagnant practice (Sleeter, 2011, 2012)

This study seeks to answer the following research questions:

1. What culturally relevant practices do elementary teachers use to ensure academic success, develop their cultural competency, and teach critical consciousness?

2. How do teachers working in an urban school district develop and use critical consciousness to better serve the needs of their diverse students?

3. How do teachers develop a critical consciousness to address the lack of diversity in the CCSS?

\section{Limitations of the Study}

This study has a few limitations that must be acknowledged. The sample was taken from the districts' diversity department's professional development rosters focused on developing teachers' cultural competency. Since this study focused on a specific type of teacher, and no two teachers are identical, it is difficult to apply the findings to wider populations in different contexts. Because the researcher works at an elementary school located in the district of the study and is a person of color, a certain degree of bias could 
exist. This could also have created an atmosphere among the participants that caused them to respond in a certain manner to avoid appearing to harbor racial prejudices. In other words, participants may have provided responses that painted them in a certain light, which might not reflect the reality of their decision-making priorities or pedagogical choices.

\section{Definitions}

The following key terms and definitions will be used in the context of this study: Academic achievement: "Students demonstrated an ability to read, write, speak, compute, and pose and solve problems at sophisticated levels — that is, pose their own questions about the nature of the teacher-or text-posed problems and engage in peer review of problem solutions" (Ladson-Billings, 1995, p. 475). Academic achievement is commonly measured through examinations or assessments that evaluates procedural knowledge or declarative knowledge (Ward, Stoker, \& Murray-Ward, 1996).

Anchor Charts: When a teacher writes during the lesson the lesson strategy tool or lesson reinforcement on chart paper. The chart is placed in the classroom so all students have access when they determine they need it. The anchor chart provides equitable academic support for students who thrive with visual representations of taught content.

Basal Series: textbooks used to teach reading.

Bloom's taxonomy: "A six-level classifications system that uses observed student behavior to infer the level of student achievement. Moving from simple to more complex, the taxonomy's levels include knowledge, comprehension, application, analysis, synthesis, and evaluation" (Athanassiou, McNett, \& Harvey, 2003, p. 535). 
CCSS: Common Core State Standards. Learning goals of what a student should know and be able to do at the end of each grade. These standards are designed to be robust and relevant to the real world, reflecting the knowledge and skills that young people need for success at both college and in their careers (Kendall, 2011, pp. 177-178).

Collaborative Learning: "An instruction method in which students at various performance levels work together in small groups toward a common goal. The students are responsible for one another's learning as well as their own. Thus, the success of one student helps other students to be successful"' (Gokhale, 1995, p. 2).

Colorblindness: Term used to describe individuals who seek to ignore race or to be “race-neutral" (Atwater, 2008; Ladson-Billings, 1998; Vaisey, 2010).

Culture: Shared values, norms, orientations, ways of being, ways of knowing, and traditions that bind a community together. Culture gives people a distinctive identity and causes resistance from outsiders (Ladson-Billings, 2009; Spindler, 1997).

Culturally relevant teaching: A pedagogy that builds on the thinking, experiences, and traditions of ethnically diverse students. This type of pedagogy stands in opposition to the traditional mode of teaching. A culturally relevant pedagogy is committed to the collective empowerment (Ladson-Billings \& Tate, 1995) of students by using their culture and cultural referents to transmit knowledge and skills, as well as to helping them create meaning and understand the world (Ladson-Billings, 2009).

Learning frame: learning how to better serve students and viewed team members as partners in addressing challenges associated with learning something new (Stosich, 2017). 
Professional Learning Communities (PLC): a group of people sharing and critically interrogating their practice in an ongoing, reflective, collaborative, inclusive, learningoriented, growth-promoting way (Stoll, et al., 2006)

Student of color: A person who is not white or of European parentage.

White: A socially constructed "racial" group that historically received the benefits of racism in the United States.

\section{Summary}

This introductory chapter presented an overview of the study that situated the similarities and differences between the CCSS and culturally relevant teaching. A brief explanation was also given for why the culturally relevant framework is not a common practice in reform movements and classrooms. Chapter 2 constructs the theoretical framework of the study through a review of literature related to the research questions. The review highlights the definitions of culturally relevant teaching and its three-pronged approach, with a particular focus on critical consciousness, which has received scant attention in the literature. Because this research is focused on the Reading CCSS, critical pedagogy will be explored, along with critical literacy, to investigate critical consciousness. The chapter defines the ways in which a teacher can possess a critical pedagogy while remaining a truly culturally relevant educator. Chapter 3 describes the research design employed when conducting the study, paying particular attention to the methodology and technique invoked for data collection and analysis. The study concludes by detailing the ways in which culturally relevant teachers navigate the Reading CCSS. 


\section{CHAPTER 2: LITERATURE REVIEW}

This literature review aims to explore the key issues encountered by teachers who use the culturally relevant teaching framework while implementing the CCSS. The literature was reviewed using the theory of culturally relevant teaching as defined by Ladson-Billings (2009). To understand how an increasingly diverse student population can achieve success against the backdrop of academic reform movements, we must first identify how culturally relevant teachers understand and implement said movements. To this end, four major bodies of literature were reviewed: (1) culturally relevant pedagogical models, (2) critical consciousness and critical literature, (3) the changing demographics of the United States, and (4) educational reform movements, with a particular focus on the CCSS. The theory of culturally relevant teaching (See Figure 1) will be used to illustrate the relevance to the diverse setting of $\mathrm{K}-12$ education while implementing a reform movement. 


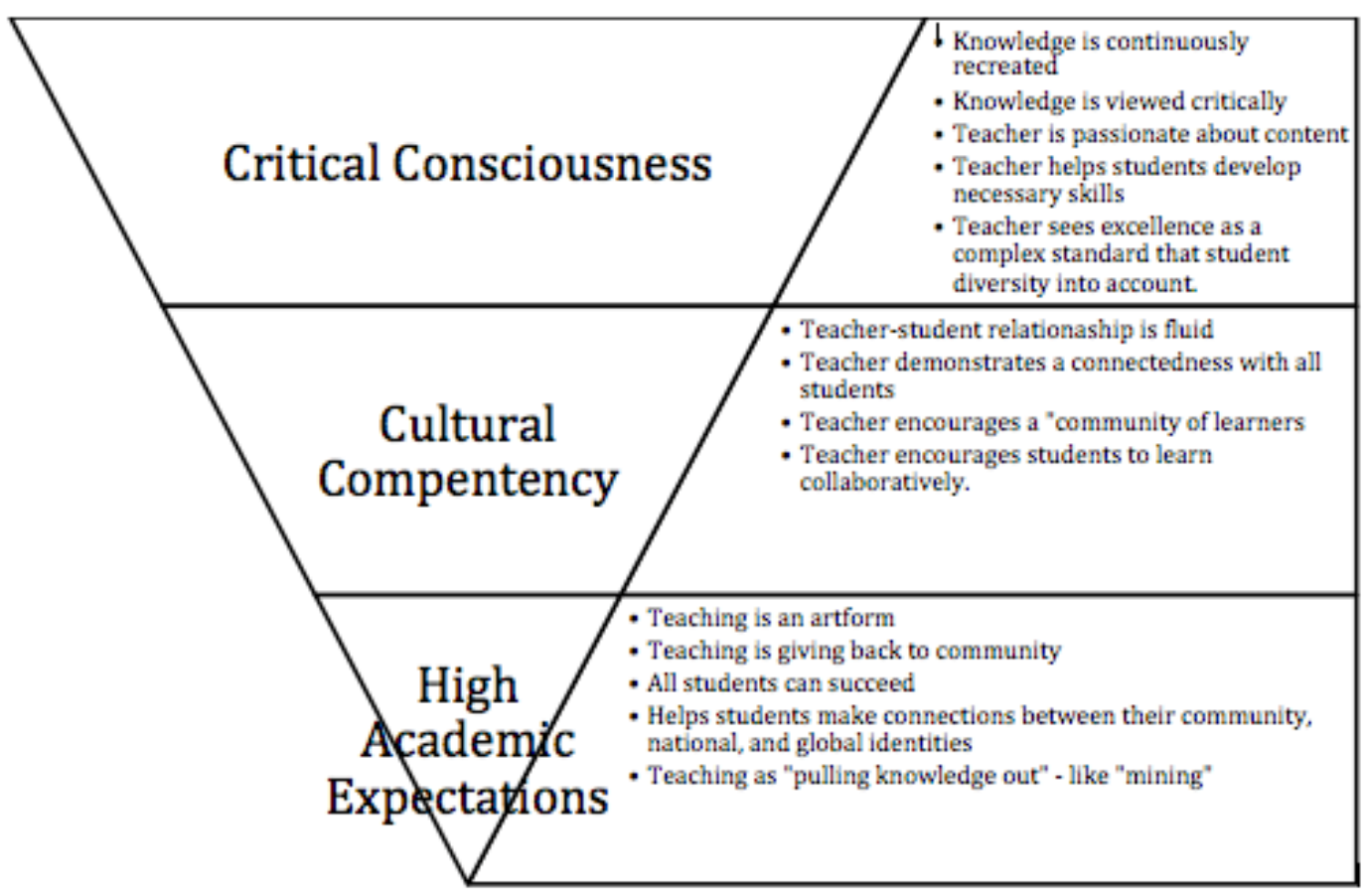

Figure 1. The three components of a culturally relevant teacher according to LadsonBillings (2009): philosophy, pedagogy, and personal commitment.

\section{Culturally Relevant Teaching: Extracting Knowledge}

Since the 1980 s, researchers have attempted to uncover the reasons why children of color experience difficulties in schools (Au \& Jordan, 1981; Cazden \& Leggett, 1981; Mohatt \& Erickson, 1981; Vogt, Jordan, \& Tharp, 1987). According to Pewewardy and Willower, (1993), the teaching and learning of American Indian children is strongly influenced by their heritage, as well as their experiences, environment, language, and culture. Within the literature can be found a plethora of frameworks and terms that address the need to connect the school environment to students' cultural backgrounds. Examples include culturally appropriate (Au \& Jordan, 1998), culturally congruent (Au \& Kawakami, 1994; Mohatt \& Erickson, 1981), culturally compatible (Irvine, 1990; Vogt et al., 1987), culturally synchronized (Gay, 2000), culturally responsible (Irvine \& 
Armento, 2001), and culturally relevant (Ladson-Billings, 1992, 1995, 2009)—all of which imply that educators must be mindful of students' cultural diversity in the classroom. Educational researchers have provided a range of conceptions and definitions relating to culturally responsive pedagogy (Ladson-Billings, 1992, 1994; Smith-Maddox, 1998; Villegas, 1991). The following is an example from Ladson-Billings (1992): Culturally relevant pedagogy prepares students to effect change in society, not merely fit into it. These teachers support this attitude of change by capitalizing on their students' home and community culture. These teachers ... empower students intellectually, socially, emotionally, and politically by using cultural referents to impart knowledge, skills, and attitudes. (pp. 382-383)

In The Dreamkeepers (2009), Ladson-Billings evaluated culturally relevant and assimilationist teaching styles to conclude that teachers who subscribe to the former believe that all students can succeed, while advocates of the latter maintain that failure is inevitable for some. Moreover, assimilationists encourage competitiveness, while culturally relevant learning environments promote community and collaboration. Culturally relevant teachers have a critical view of knowledge, in contrast to assimilationists, who believe it to be flawless.

Culturally relevant teachers posit that students contribute preexisting knowledge to the school environment, meaning that it is incumbent on teachers to explore, use, and build on this knowledge as a means of ensuring academic success (Ladson-Billings, 2009). Teachers who respect their students' experiences understand that learning is reciprocal between the two sides; in other words, teachers learn from their students and 
are capable of extracting the latter's cultural capital and combining that knowledge with statewide academic standards to achieve excellent scholastic outcomes.

Culturally relevant teaching is about more than getting to know the students and building on their strengths; it is a theoretical framework for education that embraces learners from culturally diverse backgrounds (Gay, 2000; Ladson-Billings, 2005). It is underpinned by three principles: “(a) Students must experience academic success; (b) students must develop and/or maintain cultural competence; and (c) students must develop a critical consciousness through which they challenge the status quo of the current social order" (Ladson-Billings, 2005, p. 160). Thus, culturally relevant teachers encourage students to view the curriculum and policies through the lens of their cultural capital. Such skills foster crucial adult citizenship practices, leading to the creation of citizens who contribute and add to their communities (Ladson-Billings, 1998). In addition, culturally relevant teachers are critical when evaluating the curriculum, instruction, and assessments because historically, these components have been used to justify students of color's receiving a substandard educational experience (LadsonBillings, 1998). Culturally relevant pedagogy promotes a connection between culture and learning and recognizes the link between students' cultural capital and academic success; culturally relevant instruction uses "the cultural knowledge, prior experiences, frames of reference, and performance styles of ethnically diverse students to make learning encounters more relevant to and effective for them. It is culturally validating and affirming" (Gay, 2000, p. 29). It is comprehensive, multidimensional, empowering, transformative, and emancipatory — a style of teaching that both plays to and takes advantage of the strengths of diverse students. 
Culturally relevant teachers both acknowledge and combat racism as a practice that prevents students of color from reaching their full potential. They know that racism exists as an ordinary, accepted, and natural way of classifying people according to physical, mental, or behavioral contexts (Delgado \& Stefancic, 2012). These teachers challenge racist norms by recognizing that they are hidden behind a colorblind conception of allowing all students the same educational curriculum and instructional methods (Delgado \& Stefancic, 2012; Ladson-Billings, 1998). In the dominant culture, which sets the colorblind standards, achievement tests and/or IQ testing are used as a means of classifying students and justifying different educational opportunities based on the test results (Delgado \& Stefancic, 2012). Culturally relevant teachers have no fear of breaking from colorblind programs, curriculums, and initiatives, because they do not take into account the contextual factors and cultural strengths of individual students of color (Ladson-Billings, 2009).

The concept of "equal opportunity," as expressed in Brown v. Board of Education (1954), has been used to justify a one-size-fits-all educational experience (Delpit, 2006; Ladson-Billings, 1998). According to Ladson-Billings (1998) "this notion of equal opportunity was associated with the idea that students of color should have access to the same school opportunities i.e. curriculum, instruction, [and] funding facilities as White students" (p. 17). This concept leaves no room for different points of view even as it legitimizes dominant, White, upper-class male voices as "standard" knowledge that students need to know (Ladson-Billings, 1998). To tackle racism in mainstream curriculum and instruction, culturally relevant teachers critically analyze the former. Textbook companies downplay the experiences of people of color and rewrite activists as 
folk heroes and slavery as immigration (Ladson-Billings, 1998). A recent example, reported in the New York Times on October 5, 2015, came in the form of McGraw-Hill Education's decision to talk about the United States as a country of immigration and African American slaves as "workers from Africa" who came to the United States to work in the agricultural plantations of the South (Fernandez \& Hauser, 2015). This reflects the dominant culture's belief in a homogenized and colorblind "we," a collective comprising people who are all the same and share the same experiences (Ladson-Billings, 1998). However, teachers who use the school's community encourage their students to recognize their cultural strengths and to use them to make a stand against injustice.

Ladson-Billings (2009) research differed from other studies in that it focused on teaching practice rather than on curriculum. She observed teachers whose practice and beliefs were contrary to traditional views of education. First, the teachers whom she assessed believed that all their students had the ability to learn and felt it their responsibility as educators to ensure that each individual attained success. The educators proudly rejected the idea of their role being that of a disseminator of knowledge in favor of allowing their students to discern a better way of enabling excellent outcomes for all. Second, the teachers immersed themselves in the students' community as a means of bringing it into the classroom, in the belief that this would unlock cultural capital and empower the students to be agents of change who could make a positive contribution to their home environment. Third, these teachers did not exclusively rely on the district's supported materials but rather used them as a platform for the raising of questions and critical analysis to determine whom the text benefited. Ladson-Billings concluded that "equal opportunity" is about more than textbooks and school buildings; instead, a high- 
quality education for students of color means teaching them to deploy a critical lens for the evaluation of the world around them, which allows their voices to be heard in the local, national, and global arenas.

\section{Criterion 1: Academic Success}

Currently, a prevailing view exists that educators alone improve the quality of instruction and learning environments within schools, which in turn enhances student outcomes (Heck, 2009). In their quantitative study, Love and Kruger (2005) found that a teacher's view of himself or herself as a disseminator of knowledge correlated positively with achievement in reading. According to the findings of this study, when teachers valued students' input and let them agree or disagree with another point of view, these students scored higher than those of their counterparts whose teachers taught their point of view on a topic as the only truth. Additionally, when teachers deliberately built a community of learners and held both themselves and their students to be mutually responsible for each other's learning, students attained higher scores on the Iowa Test of Basic Skills. In Song's (2006) quantitative study, the majority of participants believed that students needed basic skills and content knowledge to develop their powers of reasoning and gain thinking skills on a higher level. The teachers in this study developed a learning environment based on their personal belief of what a classroom should be and expected their students to accept and learn by teaching materials absent of culture.

Although these teachers also believed that students required individualized teaching approaches, they failed to depart from the master script of the provided curriculum. To be culturally relevant, a teacher must change the script to suit the varying needs of their diverse students (Ladson-Billings, 2009). 
Heck's (2009) study showed how teachers' effectiveness affected students' academic outcomes. It was found that teachers' beliefs regarding their students' ability colored the former's expectations of the latter, which directly affected achievement. Specifically, students performed worse academically when their teachers believed that they needed to master basic skill instruction before moving on to more advanced thinking activities and texts. Heck (2009) also found that the effectiveness levels of successful teachers were positively associated with student achievement in both reading and math. Thus, when teachers allowed students to think, reflect, and respond to their learning, they outscored those of their peers whose teachers were merely disseminators of information. The author also discerned that over time, students who were taught by more effective teachers outperformed those of their counterparts who did not benefit from the same input. In addition, teachers and leadership with stronger beliefs that students can reach higher expectations on achievement assessments can positively affect student outcomes (Heck, 2009).

A culturally relevant teacher believes that he or she can learn just as much from their students as the students can learn from him or her. These teachers understand that student engagement is the key to academic achievement (Ladson-Billings, 2009). Culturally relevant teachers ensure that their students are aware of the academic and behavioral expectations so their learners will be successful in all environments, as well as being accountable to themselves by setting goals. Culturally relevant teachers also require that students hold each other accountable for their studies, and students learn this trait through the example set by the teacher. Such teachers do not accept academic failure; they teach, reteach, and teach differently to ensure that all their students attain academic 
success. Teachers had students describe how they were going to be their best and explain what that meant, thus having them take accountability for achieving their best daily. The teachers gave students the credit for their success, complimenting them by saying that the students' knowledge had made them a better teacher (Ladson-Billings, 2009).

\section{Criterion 2: Cultural Competency}

Educators expect students to share in their cultural experiences and norms (Watson, 2012). Even if cultural differences exist, assimilationist teachers assume that learners will adapt to the dominant culture to help them succeed in the classroom (Love \& Kruger, 2005; Watson, 2012). To become a culturally relevant teacher and recognize and respect their students' unique cultural identity, teachers should align their classroom instruction to the cultural orientations of ethnically diverse learners (Gay, 2000). This requires teachers to become principled while developing a cultural competency with relation to their students (Ladson-Billings, 2006b). Cultural competency is defined as the ability to develop respect for and an understanding of the origin of students' culture, which in turn obviates the effects of colorblind school-based education on ethnically diverse students (Ladson-Billings, 2006b). When teachers use their students' cultural knowledge and experiences, they create cultural democracy in classroom learning by understanding the cultural traits and contributions of their ethnically diverse charges (Gay, 2000, 2002; Howard, 2003). An understanding of the "explicit knowledge" of ethnically diverse students is a necessity for culturally relevant teachers and requires an understanding of the multiple perspectives of ethnic diversity (Delpit, 2006; Gay, 2002). Specifically, an understanding of students of color's “cultural values, traditions, communication, learning styles, contributions, and relational patterns" (Gay, 2002, p. 
168 ) is a part of the teachers' decision-making process. Teachers draw their decisions from their experiences based on facts and repeated exercises that build knowledge about students, pattern recognition, and their beliefs of how to educate their students (Vanlommel, Van Gasse, Vanhoof, \& Petegem, 2017).

Culturally relevant teachers embrace their students' cultural experiences and perspectives and use those elements as tools for the publication of a curriculum that should reflect the various cultures present in the classroom. Delpit (2006) highlighted that teachers must understand cultural differences when teaching (e.g., teaching styles, approach to curriculum, language acquisition, and misrepresentation in curriculum in regards to Latino, African American, American Indian, and Native Alaskan students). Such an awareness of cultural differences legitimizes Delpit's (2006) reference to the "culture of power." Teachers who truly embrace and understand their students' culture can connect the curriculum to the individual, which leads the student to having the skills to question what is being taught using their culture capital. When teachers use culture as the core of their teaching, they are not only creating self-esteem but also empowering all the students, regardless of culture (Ladson-Billings, 2009). The creation of cultural competence validates students, because it allows the teacher to break down cultural hegemony by deploying the cultural knowledge and experiences of their students to increase learning's relevance and effectiveness (Gay, 2000). This is a focus of culturally relevant teachers as they develop cultural competence in their students of color, because textbooks, curriculum, and state reform programs support the culture of power; specifically, students of color are told to read, write, speak, dress, and communicate like White students (Delpit, 2006). In response to the cultural hegemony, the development of 
cultural competence validates students of color by creating relevant learning environments that are not in conflict with the students' cultural background; the school mimics the home thanks to culturally sensitive teachers' structuring their classrooms to mirror the values of the students' families and communities (Howard, 2003). Students are being taught to connect lessons to their own lives, school, community, state, nation, and global issues, using metaphors and experiences from their own worlds (Delpit, 2012; Ladson-Billings, 2009; Sleeter \& Stillman, 2005). Simultaneous validation of the various cultures in a classroom can be achieved by the teacher's implementing a range of instructional strategies and providing multicultural materials and by students' learning to appreciate each other's cultural backgrounds (Gay, 2000).

Teachers make pedagogical decisions that either assist or hamper learning (Delpit, 2012). Good teaching is about more than just imparting content; it must instill in students the desire to learn more (Ladson-Billings, 2009). Educators who lack cultural competency tend to look past the natural resources brought by students to the school setting. According to Ladson-Billings (2009), culturally competent teachers allow students to be themselves and provide them with the resources and skills with which to extract the knowledge that will lead to success. Teachers must possess cultural competence to adequately connect lessons to their students' home experiences. One method of validating students' cultural capital is for teachers to have a critical consciousness, allowing them to align lessons taught in classrooms to students' communities and global experiences.

\section{Criterion 3: Critical Consciousness}


As the student population of the $\mathrm{K}-12$ educational setting in the United States becomes increasingly racially and ethnically diverse - even as the teaching workforce remains consistently and overwhelming White-educators must strive to make the educational environment relevant to the student population (Goldenberg, 2014; Villegas \& Lucas, 2002). References to culture, both intentional and unintentional, naturally occur in the classroom as teachers and students interact with each other and with literacy texts (Garrett \& Segall, 2013). If the adults in the classroom avoid considering the role played by race and culture in the educational experience, then tensions between teachers, students, and the wider community will persist regardless of the curriculum used. Teachers must acknowledge students' frustrations, questions, and defenses and take advantage of them to create teachable moments (Garrett \& Segall, 2013).

Culturally relevant teaching involves "dealing directly with controversy, studying a wide range of ethnic individuals and groups; contextualizing issues with race, class, ethnicity, and gender, and teaching multiple kinds of knowledge and perspectives" (Gay, 2002, p. 108). One reading teacher in Ladson-Billings' (1992) study required students to come to an alternative decision on the Vietnam War. The teacher used the book Charlie Pippin (Boyd, 2011), the story of an 11-year-old African American girl who has a troubled relationship with her father. Students, working in groups, wrote letters to the characters based on the issues in the text, used webs, metacognitive journals, and debates, and then connected the Vietnam War to the then-current conflict in the Persian Gulf. At the end of the unit, students wrote open and honest letters to the government expressing their opinions and fears. This teacher capitalized on the teachable moment by connecting the text to a real-life political occurrence that students were experiencing first-hand. 
Students require strong social and political skills to be successful contributors to a democratic society (Delpit, 2006; Duncan-Andrade \& Morrell, 2008; Lynn, Johnson, \& Hassan, 1999). Teachers who experience success with students of color from poor backgrounds make the connections between education, and they access both political and economic issues that are relevant to students' lives (Duncan-Andrade \& Morrell, 2008; Ladson-Billings, 2009). When culturally relevant teachers approach literary and historical texts, they acknowledge multiple viewpoints rather than taking a unified view of an issue. The teacher in Lynn et al.'s (1999) study wanted to teach students to rethink their assumptions about what they considered beautiful. At the beginning of the lesson, students had to identify what it means to be beautiful and were shown an example of an African American woman. This teacher sought to help his students analyze their uncritical notions of race and prejudice over skin color, with the goal of having them think "more deeply about their own racially constructed subconscious thought and behaviors" (Lynn et al., 1999, p. 50). A critical analysis of a text benefits all students, who should be encouraged to become critical observers who analyze texts and question the visuals, the wording, and the voice (Ladson-Billings, 2009). Ladson-Billings (1992) found that teachers whose students obtain a high level of achievement in reading tend to understand literacy as being "less about what is on the lines and pages than what is between the lines and pages" (p. 318). Furthermore, critical teachers' acknowledgement of the prescribed curriculum often fails to include multicultural perspectives; accordingly, these teachers must identify ways to connect with the cultures of their students.

Through classroom observations and teacher interviews, Ladson-Billings (2009) identified culturally relevant practices that encouraged social change, collaboration, and 
the empowerment of African American students. According to her earlier study (1994), a culturally relevant understanding helps teachers acquire certain perspectives regarding themselves and others. First, teachers view themselves as part of the community, second, they see the social relationships they develop with students as being "humanely equitable" (p. 60), and third, they see knowledge as a "social construct" that creates a "community of learners" in which teachers and students are equal in terms of the knowledge that they bring to the classroom (p. 89). But that's just good teaching is a phrase that Ladson-Billings $(1995,2009)$ heard from her audience when she first shared her theory of culturally relevant teaching. However, for teachers to be culturally relevant, they must ground their instructional content in a sociopolitical consciousness that allows students to critique and analyze society (Ladson-Billings, 1995, 1998). Teachers need to use the inequalities inside the school and in the larger community as material that is ripe for critical analysis by their students. The CCSS lend themselves, even for elementary students, to opportunities to analyze, interpret, discuss, and explain texts through written and spoken words. Students are called on to read between the lines to discern an author's purpose and to evaluate, through text-based evidence, what drives a character's decision making. These are critical skills that can be extended to real-world application. Even with young children, the use of multicultural texts allows students, regardless of cultural background, to challenge preconceived notions.

\section{Critiquing Societal Norms}

Freire (2011) described the phrase banking education as a means of depicting and critiquing the traditional education system. The banking system paints students as empty containers into which educators place the knowledge that they consider students must 
know and understand. This type of education is devoid of critical thinking; the teacher's narrative is detached from the students' reality. This form of education sees students as manageable beings that are to be molded into adults who then accept a passive role in their home community (Freire, 2011). In short, the students become adults who adapt to the world as it is. This is a profitable situation for the oppressors because the learners are deprived of powers of critical analysis or higher-order thinking ability that might allow them to raise questions. Thus, when educators try to liberate the oppressed mind of students, the oppressors react against any reform movements that encourage children to question the world in which they live.

Teachers are the epistemological authority in this system (Freire, 2011); they accept and trust the curriculum handed down to them by legislators or publishers. Teachers learn what is expected of them before passing this prescribed knowledge on to their students. However, students of color sometimes push against this rigid system (Lynn, 2006). As students realize that their daily struggles with racial and class oppression are out of step with the knowledge that the teacher is trying to pass on to them, they reject that knowledge. The teachers in Watson's (2012) study considered this rejection as urban education; the author found that these participants used symbolic identifiers as a means of distinguishing students. The primary identifier used was skin color, as it signaled certain beliefs about race that influenced how the teachers saw themselves and their students. This marker also shaped how the teachers interacted with their students. The more amenable students were to the teacher's instruction, the more positively they were viewed. However, when students questioned or rejected the content, they were seen as being more "urban." The teachers concluded that students' being 
"racially isolated" or having a "cultural disadvantage" caused them not to "bank" the content they were disseminating (Freire, 2011; Watson, 2012).

References to culture occur frequently in the classroom as peers interact with one another, with school personnel, and with instructional materials. As topics of race or ethnicity arise in classrooms, educators embrace a common pedagogy to avoid issues they deem irrelevant in a school setting (Delpit, 2006; Ladson-Billings, 2009; Love \& Kruger, 2005). Culturally responsive teaching involves "dealing directly with controversy; studying a wide range of ethnic individuals and groups, contextualizing issues within race, class, ethnicity, and gender, and including multiple kinds of knowledge and perspectives" (Gay, 2002, p. 108). The teachers in Lynn's (2006) study understood that their teaching was integrally tied to an understanding of their students' lives; they invited the children to use their own cultural communities as a bridge with which to successfully navigate cultures of power. Teachers who displayed a strong critical consciousness did not create barriers between themselves and their students, instead demonstrating how students could retain their own language while learning the dominant tongue (Lynn, 2006). According to this source, teachers must take full advantage of the teachable moments that students formally or informally bring to the classroom.

The teachers in Ladson-Billings' (2009) study demonstrated a critical consciousness in the way they used the prescribed school curriculum, disputed the "rightanswer" approach to assessments, and taught students to embrace intellectual challenges. Although the teachers used curriculum materials, they also engaged students in a wide range of critical analyses. Educators would tell their students about the materials they 
were expected to use, along with the supplemental materials supplied by the teachers. Students used comprehension strategies that encouraged critical analysis of text: compare/contrast, problem/solution, point-of-view, and purpose of the materials. Teachers would openly express why they incorporated text that share a different perspective than those found in publisher provided teaching materials. As well as, these teachers expected their students to find text in the community that supported or opposed materials used in the classroom. The participants used a variety of assessment strategies; although students expected simple-answer assessments, the teachers would expect them to interrogate the questions being asked. Teachers also expected students to challenge the answers the teacher gave. This questioning format supported students in "role-switching" between an intellectual challenge and a questioning of authority (Ladson-Billings, 1992). Other teachers supported children in deciding what evidence would be used to evaluate their learning. As regards the district's standardized test, one particular teacher and her class expressed assessments as a necessary irritation in which the latter scored better than their age-grade peers at the school. The students in this study viewed standardized assessments as an extremely limited means of evaluating their learning and took a greater degree of pride in how they used their critical analysis to demonstrate what they had absorbed.

Ladson-Billings (2009) found that the students she studied engaged in social learning by partaking in conversations with each other and their teacher. Boyd and Markarian (2011) defined what it means to be a dialogic teacher, as characterized by Freire (Shor \& Freire. 1987) including the aspects of dialogic talk he summarized in an interview with Ira Shor. Freire opposed the "banking" of education, advocating that 
students question their learning environment. For example, a teacher who wants students to become critical thinkers "delays a response when students request the teacher's opinion, instead defer[ring] to other student opinions" and "signals the importance of student statements" (p. 518). The dialogic approach is more effective, because it enhances students' critical thinking and retention. Boyd and Markarian (2011) noted that:

Teachers adopting a dialogic stance encourage students to articulate what they know and position them to have interpretive authority. There is purposeful negotiation of the discourse of "everyday" knowledge that students bring with them to school, and then when students are readied, there is connection to the discourse of formal education, "school" knowledge. (p. 519)

Teachers who espouse the critical consciousness are attentive listeners who heed, follow, and support students' ideas, goals, and lines of reasoning (Boyd \& Markarian, 2011; Delpit, 2006). For example, a teacher in Boyd and Markarian's (2011) study incorporated discussion moments in the lesson to respond to, question, and comment on students' statements. According to these authors, the attention paid by the teacher to the students' conversations let them know that he was listening to them, that their ideas were important, and that learning was serious while also being fun and playful. The researchers discerned that all of the teacher's students in this study were engaged in the learning process by observing their conversations, questions, and body language. The authors' watched the students and teacher work together through collaborative conversations to understand the information being taught. The students learned the academic standard and the teacher learned how the students made sense of what they read. 
Students of color are entitled to quality instruction that enhances their cultural identity, self-efficacy and overall reading proficiency. Instruction that incorporates critical consciousness provides the underpinnings needed to support reading proficiency in culturally and linguistically diverse learners. Likewise, students of diverse backgrounds exposed to literate learning communities are stimulated to become skillful readers and writers (Bean \& Moni, 2003). Research surrounding multicultural education, culturally relevant pedagogy is thought to be particularly successful in the area of literacy (Au \& Jordan, 1981; Gay, 2000; Ladson-Billings, 2009). Subsequently, the theoretical and research implications are reviewed to explain the relationship between culturally relevant teaching and critical literacy as practiced in the classroom.

\section{Critical Literacy: Empowerment through Literature}

Critical literacy theory in the United States was founded on the discussions between Freire and Macedo (2005) recorded in Literacy: Reading the Word and the World. According to Freire and Macedo, learning to read is not just about mechanically memorizing vowel sounds but rather has more to do with the student's relationship with the material they read. They added that because word meaning is connected to "people's existential experience not the teacher's experience" (p. 35), only the student can make meaning of the language. For example, they described what emancipatory education for African Americans might look like in the United States:

The successful usage of the students' cultural universe requires respect and legitimation of students' discourses, which is their own linguistic codes, which are different but never inferior .... In the case of black Americans, for example, educators must respect Black English. It is possible to codify and decodify with 
the same ease as standard American English. The difference is that black Americans will find it infinitely easier to codify and decodify the dialect of their own authorship. The legitimation of Black English as an educational tool does not, however, preclude the need to acquire proficiency in the linguistic code of the dominant group. (p. 127)

To achieve emancipation, students must learn not only about their own languages, backgrounds, and cultures but also about the dominant codes of literacy, so that they might have the tools to change their world and personal situation for the better (Freire \& Macedo, 2005). A true critical pedagogy connects to students' history while including dialogue and questions to which the answers are unknown; thus the role of the teacher is as a guide, inquirer, and participant. Moreover, the same authors encouraged educators to nurture students' creativity both individually and within their social context, as well as to question knowledge that is presented as factual. In their view, the exposure of biases allows student to question the myths perpetuated by mainstream culture such as the idea that racism ended after the victories of the civil rights movement.

Since Freire and Macedo's (2005) development of critical literacy theory, researchers have applied these Freirean tenets and practices in classrooms. Critical literacy empowers the oppressed through education and activities that question common knowledge in an equation that reveals the oppressor's superiority while inspiring them to action. In a review of the literature, McDaniel (2004) found that critical literacy fostered skills that led to the development of a sense of agency, self-sufficiency, and confident decision-making. Critical literacy teachers challenge readers to think about the relationship between language and power; students are taught how to incorporate critical 
thinking and questioning as a means of transforming their world. According to the tenets of critical literacy, "text" is anything that can be read, which leads to infinite possibilities. A critical literacy-inspired reader can "rewrite" almost any aspect of his or her world (McDaniel, 2004).

After a review of previous studies, Bean and Moni (2003) argued that taking a critical stance in the classroom empowers students to consider the author's choices and ideology when they wrote the text and, consequently, to construct a reading that may actively resist and challenge the prescribed reading of a text. Bean and Moni (2003) stated, "Critical literacy teaching begins by problematizing the culture and knowledge in the text—putting them up for grabs, critical debate, for weighing, judging, critiquing" ( $p$. 638). Through discussion of such choices, students may also better understand how they are being constructed as adolescents in the texts and how such constructions compare with their own attempts to form their identities. The authors suggested that teachers use the following discussion points to engage students in critical analysis:

- Subject and reader positioning: Acknowledge, first, that novels are adult constructions portraying a particular view of adolescent identity that may have reference points in gender, ethnicity, urban or rural, and other contexts and, second, that the author has constructed an ideal reader for the novel and that readers may choose to accept or reject this positioning.

- Gaps and silences: Address voices and positions not included in the novel that may alter identity construction.

- Classroom transformations: Ask students to go beyond the novel to create alternative expressions of identity construction. 
Critical literacy shifts the boundaries of discussion between teacher and students, changes relationships, and generates substantive conversations about texts. The texts themselves become changeable, transparent constructions that can be accepted or rejected and in which multiple meanings are explored (Bean \& Moni, 2003).

Hasty and Fain (2014) undertook a qualitative study that followed two fourthgrade classrooms in urban settings. The teachers participated in an intense monthly professional development plan in which each classroom was provided with book bins filled with texts on global and informational matters. At the beginning of the study, the teachers lacked clarity on how to teach close reading and critical literacy; however, by the end of the project, they were encouraging their students to read and reread closely and carefully. The teachers were asking students questions that demanded critical thought and often required revision of their initial understanding of a text. The educators saw their students as having "funds of knowledge" in which they drew on the skills and talents of their families and communities (McLaughlin \& DeVoogd, 2004). These teachers found that Freire's "banking education" was not needed for their students. Just as in LadsonBillings' (2009) study, students came to school with a wealth of cultural capital that could be used to engage and empower their academic achievement.

According to Rozansky-Lloyd (2005), Ladson-Billings (2009), Gay (2000), and Nieto (2010), all children come to school with prior knowledge. The problems start when their knowledge differs from what is expected by educators. "In other words, students' very cultural and ethnic identity, among other characteristics, places them at risk without even taking into account the individual abilities or talents they may have" (Nieto, 2010, 
p. 122). In Rozansky-Lloyd's (2005) qualitative study, an elementary participant remarked,

I'm thinking that people need to realize that when you are dealing with lower income, these kids don't come to school knowing their alphabet .... [A] lot of them don't come from homes where even skills that you teach at school like the reason to learn to read or just reading for enjoyment with your family is enforced in the home. (p. 599)

To deny students of color opportunities to learn because of their race or socioeconomic status is to deny them an equal education. Nieto (2010) noted that students of color are especially at risk of receiving outdated teaching and irrelevant curricula, which in turn negatively and disproportionately affects them in terms of pedagogy and curriculum.

\section{Theory to Practice for Culturally Relevant Teachers}

Ladson-Billings (2014) shared that she had grown dissatisfied by the misinterpretations of her culturally relevant teaching framework. She saw practitioners fixated on superficial notions of culturally relevant pedagogy (Ladson-Billings, 2014). Moreover, although she saw good intentions in the classrooms she visited, the teachers "rarely pushed students to consider critical perspectives on policies and practices that may have a direct impact on their lives and communities" (p. 78). These teachers showed a strong belief in the academic efficacy of their students and tried to bring in students' culture as they taught prescribed curricula, but culturally relevant teaching is a pedagogy of opposition (Ladson-Billings, 2009). Accordingly, by definition, for a teacher to be culturally relevant, he or she must demand academic excellence, embody cultural competence, and maintain a critical stance on students' learning environment (Ladson- 
Billings, 2009). A teacher lacking any of the three foundational aspects of culturally relevant pedagogy is not a culturally relevant teacher.

Walker (2011) replicated Ladson-Billings' (2009) research study with some modifications in sample selection. Ladson-Billings (2009) used recommendations from principals, teachers, parents, and students regarding teachers who were successful at teaching African American students. Walker adjusted his sampling procedure solely relying on the recommendations made by principals. His final sample consisted of 10 teachers. Walker found that the relationship between teacher and student was instrumental in the learning process for students. These teachers spoke of the differences between their culture and their students. Some participants spoke of how they took the time to listen to their students so that they could incorporate what was important to students into classroom instruction. The teachers, because they also believed that all their students could succeed — and expected them to do so—went beyond the prescribed school curriculum to ensure that all their students were successful. Walker found that the principals selected teachers based on academic outcomes of their African American students. Even though the principals did not use cultural competence or critical consciousness in their selection, all 10 participants believed that students' cultural backgrounds were important to include so that relationships could be built. However, when speaking of "culture," the participants avoided conversations about race and focused on religion, food, music, language, family makeup, and values. All teachers spoke in an assimilationist tone when describing the affects that poverty had on students' achievement. Only a few of the participants discussed how they used students' prior experiences as an instructional strategy. At the end of the study, Walker (2011) called 
these teachers culturally relevant teachers — but based on Ladson-Billings' (2009) framework, these teachers were not. Walker did not address how these teachers practiced and taught critical consciousness to their students, instead merely accepting their superficial understanding of cultural competence.

Bennett (2012) studied the effects that a diversity class had on preservice teachers' ability to use a culturally relevant pedagogy. Bennett followed eight preservice teachers who tutored eight elementary-age students from different racial, socioeconomic, linguistic, and cultural backgrounds than their own. All participants were White, Englishspeaking, and middle-class and were aged 19-24. By using a reflective journal, scenario responses, and group and one-on-one interviews, Bennett (2012) found that the teachers demonstrated a generic understanding of culturally relevant teaching. Echoing the findings of other research, they acknowledged the need to incorporate culture by using multicultural literature or creative arts (Atwater, 2008; Ford \& Kea, 2009; Goldenberg, 2014; Lawrence, 2005). One group of four students immersed themselves with students, built relationships with students, and started to critically reflect on their biases based on their dominant culture views. The second group stood and "huddled with each other rather than placing themselves near the elementary students" (Bennett, 2012, p. 398). She concluded that all teachers showed growth in their understanding of culturally relevant teaching, but the group whose members immersed themselves understood much more intimately how their personal beliefs might affect the educational environment of their students of color (Bennett, 2012).

Sleeter (2012) researched a professional development school connected to an urban teacher education program, seeking to observe how teachers were instructed in 
what it means to encompass a culturally relevant pedagogy. When Sleeter asked about the connection the school had built with the community it served, the educators said that the community was hard to reach, that they served more than one community, or that a community network had ceased to exist. In the program, participants used adopted textbooks for instructional purposes and did not challenge or critically reflect on the publishers' lesson objectives or design. In one lesson in which school-age students participated, they talked about their personal lives outside school, but the teacher discounted students' experiences and focused instead on standardized learning. Only one teacher used cooperative learning. At the end of the observation, Sleeter found that the educators viewed culturally relevant teaching as a series of steps needed to incorporate a superficial understanding of students' culture.

This section shows that even when research projects, professional developments, or teacher fieldwork intend to develop culturally relevant teachers, they fall short in ensuring that participants understand all the components of culturally relevant teaching. Walker's (2011) study was void of any analytical conversations or evidence of teachers' using critical consciousness in their decision-making. Bennett's participants had spent a whole semester in a diversity class taught using their theoretical framework of culturally relevant teaching. Bennett (2012) focused on teachers' personal development towards understanding students of color and acknowledged participants' cultural competency growth. However, such a compromise diminishes the theory of culturally relevant teaching (Ladson-Billings, 2014). Sleeter (2012) saw this same practice in a professional development school in which teachers were not corrected when they did not use dialogic 
talk and when they required students to "bank information" (Boyd \& Markarian, 2011; Freire, 2011).

\section{The Path to Becoming a Culturally Relevant Teacher}

When teachers believe in culturally relevant teaching and see it as part of their instructional decision-making, marginalized students have shown growth (Love \& Kruger, 2005). Accordingly, culturally immersed instruction is important to focus on, as the percentage of students of color (Hispanic, Asian, and Pacific Islander) has increased in recent years (National Center for Education Statistics, 2016). Teachers who understand diverse children living in poverty, living with a learning disability, or having a minority ethnic background make a difference in those children's educational experiences (Ladson-Billings, 2009; Sleeter, 2011).

Young's (2010) qualitative research approach used the combined methods of action research and critical case study to investigate what was needed to help develop inservice teachers' culturally relevant pedagogy. She found deep structural issues related to teachers' cultural bias, the nature of racism in school settings, and the lack of support for adequate implementation of theories into practice. However, she added that as teachers became more open to the possibility of a culturally relevant pedagogy, teachers and administrators saw the "possibility of going beyond celebrating holidays and highlighting minority students' social and racial inequalities" (p. 259). As teachers' culturally relevant teaching beliefs increase, so does their confidence in incorporating race, culture, and ethnicity into instructional practices (Love \& Kruger, 2005; Siwatu, 2011).

A participant in Sleeter's (2011) study remarked that even though she had participated in the same professional development twice, her views on culture and race 
had led her to hear culturally relevant teaching as a means of cultural celebration. She had filtered out everything else. By the end of the professional development, she started to understand and reflect on the fact that cultural relevant pedagogy is not separate from academics but rather is more of a path of relationships and mutual respect between teacher and students.

Participants in Garrett and Segall's (2013) qualitative study mirrored the results of Sleeter's (2011) study in that studied participants' reactions to Spike Lee's film When the Levees Broke, which depicts the devastation in New Orleans after Hurricane Katrina. They found at the beginning of the study that the participants, five White teachers, lacked knowledge about issues of differences and thus were resistant to engage in them. The themes that arose concerning why White teachers felt they were excluded from speaking, or not qualified to speak, about race were as follows: (1) White teachers are ignorant about issues of race, (2) teachers are saviors sent to rescue students from their environments, and (3) these issues can be fixed by giving White teachers information about racism. In this study, teachers talked about race after viewing a documentary film about Hurricane Katrina and its aftermath in New Orleans. The researchers used three kinds of analytic tools: narrative analysis, discourse analysis, and psychoanalytically informed notions of ignorance and resistance. They found that when teachers were in a professional development opportunity that allowed them to deconstruct those narrative frames of the documentary and relate it to their work with their diverse students, the teachers better understood how they were positioned to help their students read and write about their world. 


\section{Critical Reflection}

All the teachers in Young's, Sleeter's, and Garrett and Segall's studies reflected on their instructional practices, taking part in a reasoning process that allowed them to move past the master script and that had them think critically about the experiences of their students' community. As a result, the teachers speculated about their future practices and designed a plan for how to act in future interactions with their diverse student bodies.

When teachers critically reflect on their pedagogy, they address the moral, political, and ethical contexts of the learning environment (Howard, 2003). Critical reflection is part of the decision mindset of a teacher who has a culturally relevant pedagogy (Howard, 2003). Freire (2011) stated that true reflection comes from evaluating the consequences of actions. The teachers who participated in Watson's (2012) study did not use critical reflection when they made decisions about their instructional practices. Instead, they spoke openly about the cultural deficits of students of color and about how these deficits hampered the learning environment. For example, "Janet" said,

I think that . . . a traditional curriculum . . . doesn't necessarily bring in the lives of . . . all . . . kids, but somehow urban kids' lives are . . . further from the school culture .... And whereas ... suburban or kids from, I mean I have kids at the school that aren't, um, that aren't struggling as much .... So they get the school thing .... The urban kids don't. (pg. 993)

Janet acknowledged that the school's curriculum environment did not match the interests or backgrounds of the majority of the students it served. However, Janet decided that students of color, or "urban students," did not get the school thing instead of her reflecting on and understanding how the curriculum she taught intensified students' lack 
of engagement. Ladson-Billings (2001) found that excellent teachers perceive students' lack of achievement differently. She stated, "Excellent teachers who are faced with student failure are quick to ask themselves, 'What am I doing that contributes to this failure?"” (pp. 267-268).

Hence the most critical tenet of culturally relevant teaching is the rejection of deficit-based belief thinking about students of color (Howard, 2003). For teachers to engage in effective critical reflection, they first must acknowledge how deficit-based notions of students of color are present in traditional school practices (Howard, 2003). Second, teachers have to connect students' cultural capital to the instruction they delivery to their students (Howard, 2003). Third, they must recognize traditional teaching practices and acknowledge how these practices reflect middle-class, European American cultural values (Howard, 2003). These types of conversations require teachers to have deeper levels of self-knowledge and acknowledge their own worldview (Howard, 2003). A teacher who participated in Ladson-Billings' (2001) study reflected on why a student of hers became agitated every time she gave him one-on-one attention. The teacher decided that hovering over his every decision was hurting the way he saw her as his teacher. She decided to change the way she delivered instruction and gave her student more time to develop his "personhood." She gave him the expectation of what she wanted and allowed him to drive the conversations about his learning and needs. The more she allowed him to be himself, the more he trusted her as his teacher.

Critical reflection does not come easily to teachers. Howard (2003) stated, "The nature of critical reflection can be an arduous task because it forces the individual to ask challenging questions that pertain to one's construction of individuals from diverse racial, 
ethnic, and cultural backgrounds" (p. 198). These conversations can bring to light the racist and prejudiced notions about racially diverse groups that have been passed from generation to generation (Howard, 2003). Freire (2011) believed that words or actions alone do not cause effective change. Critical reflection about what is oppressing the condition is the only way to drive out the oppressor and eject the exploitation (Freire, 2011). Until all teachers critically reflect, they cannot exit the "contrary conviction" and will continue to use pedagogy contradictive to the needs of students of color. Selfreflection provides an essential foundation for the development of culturally relevant teaching. An effective system for self-reflection is professional development opportunities (Garrett \& Segall, 2013; Jaquith, Mindich, Chung Wei, \& DarlingHammond, 2010; Sleeter, 2011; Young, 2010). Schools use professional development to provide training to teachers regarding programs, teaching strategies, or review of quantitative student testing data. However, schools rarely gather teacher perception data, which would allow the teaching staff to reflect on their beliefs about the students they teach.

\section{Empowering Environments}

For a teacher to have a successful classroom, they first must believe in their abilities to promote student learning (Hoy \& Spero, 2005). This belief is seen in their pedagogy, in how they approach curriculum and assessment, and in how they and students interact to encourage learning (Ladson-Billings, 2009). One aspect of their instruction and assessments is their use of higher-order thinking activities and assessments. Culturally relevant teachers know that basic skill level instruction does not connect students' cultural capital to their instructional needs (Duncan-Andrade \& 
Morrell, 2008; Ladson-Billings, 2009; Love \& Kruger, 2005). Regardless of a student's level of achievement, students are exposed to higher-order activities that are connected to real-life experiences. To support higher-order thinking activities, students work collaboratively and take personal responsibility for each other's learning (LadsonBillings, 2009; Love \& Kruger, 2005). Students and teachers understand that when one student fails, everyone has failed (Ladson-Billings, 2009; Love \& Kruger, 2005). Critical reflection is part of a culturally relevant teacher efficacy belief process. They reflect on their biases, students' community experiences, and students' achievement (Howard, 2003).

Milner (2010) showed that building a relationship between teachers and students is essential for a teacher to have cultural relevant pedagogy. Milner followed a White male science teacher who believed that he needed to be prepared to do much more before he could actually teach science. The setting of the research was a middle school in which $60 \%$ of students were African Americans, 30\% White Americans, 6\% Hispanic Americans, and 4\% Asian Americans or American Indians. This third-year teacher realized that he had to talk about the role that race plays in his students' lives, because their community was subjected to matters of racial injustice. The teacher participant had been considered weak by his peers because he did not send children to the office for administrative discipline. The participant believed in giving second chances and used students' missteps as teachable moments. However, foremost, he did not allow students to opt out of class or assignments. He demanded excellence, and his students produced excellence, because they knew that their teacher wanted what was best for them. He used the Discovery Channel as a bridge to build relationships with his students, first speaking 
of how much he himself enjoyed watching and learned from the channel, then introducing his students to the Discovery Channel. He then used this commonality to engage students in science lessons. Once his students trusted him, he was able to engage them in conversations about race and topics that interested them. He connected their reality to the science in the classroom. Ultimately, he empowered his classroom by not allowing students to opt out of their learning opportunities, openly talked about race and how it affected his students' lives, and found ways to build a bridge between interest and curriculum.

\section{Pedagogical Practices}

Ladson-Billings $(1992,2009)$ focused on teachers whose African American students performed at or above grade level. These teachers validated and incorporated "African-American culture by making it a frame of reference for all texts" (LadsonBillings, 1992, p. 316). The teachers did not shy away from issues of race and culture but rather used race as a catalyst for building community pride and as a means to support the surrounding community.

The teachers' classroom structure varied in Ladson-Billings' (2009) study. Some teachers adopted an open concept classrooms, whereas others used a schedule. Some instructors used school materials; others created their own. Teachers' central beliefs surrounded the success of all students regardless of race, socioeconomic level, neighborhood, or previous learning success. These teachers believed that instruction and learning go beyond the surface level of teaching "strategies," instead emerging from students' culture. A culturally relevant teacher implementing the CCSS will take this approach. The standards welcome critical interpretation from students as they draw 
inferences, respond to characters and speakers, distinguish literal and figurative language used by authors, or determine a speaker's point of view. Such a teacher will also supplement his or her use of the standards with literature, media, or text to make the written or spoken word more relevant to students' cultures.

Ladson-Billings proposed that culturally relevant pedagogy extends the use of culture in the classroom to integrate students' cultural capital into the school culture as a means of offsetting the negative effects of the dominant values and beliefs. The cultural mismatch between the dominant culture and students of color among schools' structure, curricula, teaching patterns, and student learning styles may account for the poor academic performance and post school socioeconomic status and/or quality of life attainment of students hailing from diverse cultural groups. Beliefs of culturally relevant pedagogy offer a theoretical framework within which to improve the African American educational experience. Gay and Kirkland (2003) argued that most multicultural education propositions posit a common set of assumptions, a core set of issues to be addressed, a framework of objectives, and a desire to advance cultural pluralism and ethnic diversity as integral parts of the educational process. When multicultural education is part of a school's curriculum, it is viewed as a supplement to the curriculum rather than as a core component of the educational program (Gay \&Kirkland, 2003). However, a culturally relevant teacher implementing the CCSS understands that multicultural education is not a sequential process but rather a well-prepared lesson that welcomes student conversations and the contribution they make to building on student cultural capital (Delpit, 2006; Lynn et al., 1999). 
Ladson-Billings $(1995,2009)$ examined high-poverty, high-minority schools that were home to high-achieving African American students, finding that teachers' beliefs influenced their pedagogy and instructional practices (Ladson-Billings, 2009). Since the publication of her study (1995), researchers have continued to investigate the disconnection between teachers' beliefs and the students they serve (Lawrence, 2005; Love \& Kruger, 2005; Natesan \& Kieftenbeld, 2013; Nelson \& Guerra, 2014; Siwatu, 2011; Song, 2006).

Ladson-Billings (2009) coined the term culturally relevant teaching to describe these teachers' beliefs, including the theory that they themselves were part of their students' community. Furthermore, they saw teaching the community's children as a way of giving something back to the community. As part of an established community of learners, students became active members of the learning process and contributed to their own academic success. Culturally aware teachers believe that students maintain high standards without compromising their cultural identity. Accordingly, culturally relevant teachers took part in community functions and extended the sense of community into their classrooms (Ladson-Billings, 1995; Love \& Kruger, 2005).

Culturally relevant teachers believe that a success or failure for one student is a success or failure for the whole class. Love and Kruger (2005) found a positive relationship between teachers whose students took responsibility for one another and higher standardized reading scores. Also, students whose teachers incorporated community members in the classroom environment achieved higher test scores (LadsonBillings, 2009). Culturally relevant teachers view their work as artistry involving creativity, flexibility, and attentiveness to students' responses (Ladson-Billings, 1995; 
Love \& Kruger, 2005). Viewing teaching as an art allows an individual focus on students, which causes all students to succeed. Creativity ensures fluid and equitable relationships between teachers and students (Ladson-Billings, 2009; Love \& Kruger, 2005). These practices of artistry reduce competition among students and help strengthen the teacher's bond with each student (Ladson-Billings, 2009). Ladson-Billings (2009) observed students teaching the class and the teacher functioning as the learner, which enabled them to establish a system of trust that allowed for continuous re-creation, recycling, and sharing of knowledge. Students felt that teachers cared about their success. Accordingly, when teachers invested in students' success by using creative instructional strategies, African American achievement improved (Lawrence, 2005; Love \& Kruger, 2005). Culturally relevant teachers believe critical thinking to be essential (LadsonBillings, 1995, 2009; Lawrence, 2005; Love \& Kruger, 2005). Teachers do not depend on the state curriculum to educate their students (Ladson-Billings, 1995, 2009; Lawrence, 2005; Love \& Kruger, 2005). Rather, they use the curriculum to critically examine the conventional thoughts of society. Also, teachers expose students to alternative thoughts with an eye to encouraging problem-solving and critical analysis (Ladson-Billings, 1995, 2009; Lawrence, 2005; Love \& Kruger, 2005). Culturally relevant teachers use the lenses of race, socioeconomic status, and community to make connections (Lawrence, 2005; Love \& Kruger, 2005). In short, they connect their teaching to students' real-world events and personal lives. Culturally relevant teachers believe that all students achieve through critical thinking instruction (Lawrence, 2005). For students to be critical thinkers, they need instructional opportunities in higher-order thinking activities. 
Higher-order thinking for students means making predictions, deciding what to believe, creating new ideas, and solving nonrountine problems, as noted by Lewis and Smith (1993), who observed that higher-order thinking activities allow children to bridge gaps through the interpolation, extrapolation, and reinterpretation of information. When students are using higher-order skills, they take new information and information stored in memory and rearranges this knowledge to find a possible answer as it relates to their reality. Accordingly, higher-order thinking is an evaluation process. Students decide whether the information being presented to them is valid and reliable.

The CCSS were written with the intent of having students build knowledge through different lenses via texts so that they could learn self-sufficiently. For example, CCSS ELA-Literacy.RI.5.9 states that students should "integrate information from several texts on the same topic in order to write or speak about the subject knowledgeably" (Common Core State Standards Initiative, 2010). The tasks that students must accomplish to demonstrate mastery include making evaluative judgments, synthesizing information within and across texts, developing a spoken or written presentation, and using metacognitive strategies to manage the entire enterprise (Common Core State Standards Initiative, 2010). In short, reading instruction is more than cognitive ability: It includes student motivation and self-efficacy as part of the learning environment (Afflerbach, Cho, \& Kim, 2015).

In addition to using traditional assessments in the traditional classroom, teachers assess students' learning through basic measurements (e.g., multiple-choice pencil-andpaper methods). However, the CCSS are assessed best when using task assessments: For example, readers critique text perspectives, create informative resources, and share 
constructed meanings to address relevant problems and issues (Afflerbach et al., 2015). Taylor, Pearson, Peterson, and Rodriguez (2003) found that when teachers use higherorder thinking activities as formative assessments, students show greater levels of achievement than in classrooms in which teachers use traditional teaching and assessment methods.

Taylor et al. (2003) used the cognitive engagement framework to guide their study, in which they followed classrooms that used higher-order questioning and assessed the techniques used in comparison with those seen in classrooms that used lower-level questioning and basic skills instruction. The most consistent finding in their study was that higher-level questioning is related to student literacy growth. They also found that teachers who use higher-order questioning techniques know that when students can challenge what they read, they truly understand what they read. Lewis and Smith (1993) concurred with this finding by showing that when a student decides to believe or disbelieve an argument, he or she must have examined the information (i.e., the grounds for the claim), compared the claim with his or her experiences, and finally made a judgment about the claim. Teachers who welcome and value students' opinions create a classroom environment in which students feel as if they matter. Teachers who allow students to be the teacher and allow themselves to become the student empower students, which leads to a positive classroom environment. In such an environment, student achievement improves. As research shows, teachers do not easily give up power and control over their classrooms, because they have a set and preconceived notion of how the class is to operate (Watson, 2012). Accordingly, for a teacher to enhance his or her effectiveness with diverse students, that teacher must look internally. Love and Kruger 
(2005) urge teachers to reflect on their own beliefs about the community in which they teach. Teachers must examine their expectations of students with a critical lens so that they can push back against deficit or racist beliefs (Atwater, 2008; Howard, 2003; Nelson \& Guerra, 2014; Walker, 2011).

\section{Changing Demographics within the United States}

Culturally relevant teaching is a framework that works for all students regardless of their race, primary language, or socioeconomic status (Ladson-Billings, 2009). However, over the years, it has become apparent that certain cultural groups find success in accountability assessments even as other cultural groups do not (NAEP, 2015.). Milner (2010) argues that "focusing on an achievement gap inherently forces us to compare

culturally diverse students with White students without always understanding reasons that undergird disparities and differences that exist" (p. 8). The students of the teachers in Ladson-Billings' (2009) study viewed assessments as something that must be done but that were not used to label students. In turn, all students found academic success in class work and district assessments as well as in state assessments. More cultural groups are participating in public education than ever before. If schools continue to work as they have, then students of color will continually lag behind their White peers (NAEP, 2015).

The United States has never been a homogenous culture, for its people represent multiple ethnicities, economic statuses, and cultural beliefs and practices (Howard, 2010). This diverse population is represented in the public school system's student population. Even though the United States is diverse, home to many races and beliefs, each childregardless of race, ethnicity, culture, and economic status - is expected to learn and merge into mainstream, middle-class society (Howard, 2010; Ladson-Billings, 1998). 
Ladson-Billings (2009) says that this ““conventional wisdom'-leads to an intellectual death" for students of color (p. 17). This death is seen from the result of continual academic lag of African American and Hispanic students behind their White counterparts on standard measures of achievement (NAEP, 2015).

As diversity grows and achievement attainment is not realized by all students, more American citizens are at risk for dire social conditions. The public school enrollment has undergone noticeable racial transitions since the late 1960s. Between fall 2002 and fall 2012, the percentage of White public school students dropped from 28.6 million to 25.4 million, a decrease from $59 \%$ to $51 \%$ of total number of enrolled public school children (National Center for Education Statistics, 2017). Between fall 2013 and fall 2024, the number of White students enrolled in public school is projected to decrease from 25.2 million to 24.2 million, a decline to $46 \%$ (National Center for Education Statistics, 2017). By 2024 Hispanic public school students' enrollment is projected to constitute $29 \%$ of total enrollment (National Center for Education Statistics, 2017). Similarly, Asian/Pacific Islander students are projected to increase to 6\%. African American students' projected enrollment fluctuates between $15 \%$ and $16 \%$ of public school enrollment (National Center for Education Statistics, 2017). As racial diversity grows, so will the number of multiracial schools (schools having at least three racial groups comprising $10 \%$ or more of the total enrollment (Frankenberg, 2009). However in larger urban areas, students of color make up the majority of enrollment of racially segregated schools (Frankenberg, 2009).

Even though the public school student population racial makeup is changing and is predicted to undergo further racial adjustments, the teacher population racial makeup 
difference is minimal. According the National Center for Educational Statistics, White teachers constituted $86.9 \%$ of the teacher workforce in 1988 . Twenty years later, in 2008, the White teacher population had dropped only slightly, to $83.1 \%$. African Americans, who had constituted $8.2 \%$ of the teacher workforce in 1988 , constituted only $7.0 \%$ in 2008. Hispanic teachers, by contrast, had increased from 3\% in 1988 to $7.1 \%$ in 2008 . Thus a gap persists between the racial makeup of schools' teachers and students. In urban schools, the percentage of teachers who are White remains higher than the percentage of White students (Frankenberg, 2009).

This change in ethnic diversity is problematic for teachers who have little personal experience of diversity and limited understanding of inequality (Gay, 2000; King, 1991; Milner, 2007). structural issues More specifically, teachers whose students of color do not find success have claimed that these students came from a "culture of poverty, lacked motivation for high achievement, did not value education, possessed a poor command of Standard English, were intellectually deficient, or were lacking in their language development, so that their overall academic proficiency lagged" (Howard, 2010, p. 57). In Nelson and Guerra's (2014) qualitative study, 111 educators provided written responses to scenarios depicting culture clashes that commonly occur in classroom or schools. The results showed that $53 \%$ of participants blamed parents and students for their lack of academic success. Specifically, "They frequently indicated students or parents lacked the 'proper' knowledge and skills or had attitudinal problems" (Nelson \& Guerra, 2014, p. 85). Such beliefs are troubling, as the teacher population demographics are consistent even as the student population is becoming more culturally diverse. 
Ladson-Billings (2009) found that not all African American children in low socioeconomic communities shared the fate represented in national standardized testing. These pockets of achievement were found in particular classrooms with particular teachers. So she focused her research on the teaching practices, not the curriculum, because "it is the way we teach that profoundly affects the way that students perceive the content of that curriculum" (p. 15). In particular, she wanted to understand why this very particular pedagogy helped students be more successful academically—as well as how it supported and encouraged students' use of their prior knowledge to make sense of the world and to work to improve it.

\section{Education Reform Initiatives to Improve Student Achievement}

Traditionally, school reform movements have focused on instructional leadership, professional development, learning climate, family, and quality of instruction to improve student achievement (Payne, 2013). These reforms have tried to fix the achievement problems through surface-level efforts (Elmore, 2002; Hochschild \& Scovronick, 2003; Payne, 2013), so when discussing the lack of progress made by students of color, instead of looking at the curriculum or instructional style, educators look at students' reality as deficits instead of as cultural capital (Lareau \& Horvat, 1999). Reforms have also neglected a major phenomenon of the educational process, which is the interaction between teachers and students (Goldenberg, 2014). In addition, they have also failed to understand the complexity that diverse student populations bring to schools and how teachers' self-efficacy enables them to handle daily classroom occurrences (Elmore, 2002; Hochschild \& Scovronick, 2003; Kozol, 1991). Reforms have not addressed teacher's beliefs and how they affect student learning (Milner, 2010); moreover, they 
come and go, leaving minimal lasting change in a teacher's instructional decisions regarding students of color (Elmore, 2002; Hochschild \& Scovronick, 2003; Kozol, 1991).

After the release of A Nation at Risk (1983), school reform movements attempted to improve education for children of color through textbooks, programs, and use of technical strategies (Hochschild \& Scovronick, 2003; Ladson-Billings, 1995, 1998; Payne, 2013). The aim, then, is for teachers to focus on the program and not on their beliefs when African American students underperform (Gay, 2010; Ladson-Billings, 1998; Sleeter, 2011). However, teachers tend to blame underperformance on students' societal factors instead of on the lack of culturally appropriate education (Goldenberg, 2014). Using students' race in conversations makes teachers uncomfortable, because doing so runs counter to the colorblind views of equitable education (Goldenberg, 2014). When school organizations do not emphasize students' culture as a means of academic improvement or fail to recognize students' culture at all, the environment is not conducive to learning (Goldenberg, 2014; Ladson-Billings, 1998).

As pointed out by A Nation at Risk (1983), educators have focused on curriculum and instruction instead of student achievement. Teachers have had the authority to teach all educational content and material as they have seen fit. Pre A Nation at Risk (1983), a period of complete teacher autonomy, a lack of continuity and an inability to have a reliable measure left students of color with educational opportunities that did not meet their individual needs (Hochschild \& Scovronick, 2003; Ladson-Billings, 2009). However, after the standards-based reform ignited by A Nation at Risk (1983), officials took some power away from the individual classroom, shifting to a top-down reform 
model designed to increase student outcomes and reinforce uniformity across school districts and states (Hochschild \& Scovronick, 2003). These top-down reform initiatives show inconsistencies at the school level (Desimone, 2002; Hochschild \& Scovronick, 2003; Payne, 2013).

The standards-based reform movement aimed to clarify what to teach, when to teach, and how to define what achievement looked like at different levels (Glidden, 1998). The standards defined what students should know at each grade level, thereby creating consistency among public educators by providing a minimal baseline for what students should know at certain points in their education process (Glidden, 1998). During this era of standards-based reform, the gap between the standards and the curriculum taught by individual teachers became evident (Hochschild \& Scovronick, 2003; Kendall, 2011). Schools and school districts started to align the curriculum to address the gaps between how teachers taught their state standards and what they themselves taught (Hochschild \& Scovronick, 2003; Kendall, 2011).

As school systems within state boundaries adjusted their educational decisionmaking to state standards, it became clear that not all states were educating equally (Glidden, 1998). There was a discrepancy between standards incorporation and curriculum development between states, which caused vast inequalities among public school systems (Glidden, 1998). The discrepancy was made evident both by National Assessment of Educational Progress (NAEP) results and when comparing individual state assessments (National Center for Education Statistics, 2017). Accordingly, a new focus on state accountability through testing became embedded in the standards movement of the 1990s (Glidden, 1998). 
Standardized tests measure standards-based instruction (Ogawa, Sandholtz, Martinez-Flores, \& Scribner, 2003). Ogawa et al. (2003), however, found that the consistency of teachers' shared, clear, and comprehensive instructional philosophy has influenced the effectiveness of the standards, which in turn has affected students' level of achievement in state assessments. Advocates of the standards movement have seen assessment as a means for teachers and administrators to receive feedback on student performance and thus on their instructional effectiveness (Ogawa et al., 2003). However, critics of standardized testing and standards-based reform have viewed the system as a further loss of autonomy and have increased centralized control at the cost of built relationships with students (Crocco \& Costigan, 2007). Although state-driven standards have promoted uniformity and equitable educational opportunities for students, teachers have often struggled to change their ways of teaching, which they have used for years (Payne, 2013). Deviation and change do not come easy for educators, and the failure of educational reform movements is indicative of this phenomenon (Hochschild \& Scovronick, 2003). The inequality between states and the lack of overall achievement prompted the federal government to take action in 2002 with NCLB, a reform movement that sought to minimize disparities among schools while also facilitating effective instruction (Hochschild \& Scovronick, 2003).

Even though NCLB emphasized the core academic subjects, sought to improve achievement among low-performing children, and targeted measurable outcomes that spurred far-reaching changes in elementary children education experience, students of color did not find the same academic achievement as their White counterparts (Hochschild \& Scovronick, 2003; Payne, 2013). The inequalities of achievement among 
different racial groups persisted even though states had standards and the federal government held states accountable for the achievement of all students. Dee et al. (2010) looked at the trends of the NAEP and found that White, Hispanic, and African Americans progressed academically, but the racial gap persisted - White students progressed to the same degree. Dee et al. (2010) also looked at the Trends in International Mathematics and Science Study in the years 1995, 2003, and 2007, finding that fourth-grade math achievement had comparatively improved in the United States in 2007. However, the Progress in International Reading Literacy Study looked at some countries in both 2001 and 2006 and found that although the United States outperformed other countries, no growth had occurred since enactment of NCLB. Hursh (2007) looked at NCLB data for New York and Texas, comparing each state's assessment system. Even though both states had boasted academic success since the enactment of NCLB, questionable testing practices and reporting of results were identified. Accordingly, Hursh's (2007) research showed that NCLB led schools to offer less rigorous curricula and experience more dropping out during high school while also showing a consistent achievement gap. Hursh (2007) stated, "Moreover, not only has NCLB not resulted in improved learning, but its neoliberal premises also have the potential to radically transform democratic decision making" (p. 512). NCLB set minimal standards that failed to signify a belief in rigorous, high expectations or in individualized educational experience for all students. Payne (2013) asserts that educators and policymakers must remember, "that we are talking about a systemic problem that cannot be reduced to individual explanations" (p. 91). Thus the failure of NCLB became evident when schools focused solely on test scores and basic educational expectations that they did not require students of color to exceed. 
Students of color need educational environments that acknowledge the multiple strengths that each child brings into the classroom and that thereby value each child, making more children engaged with learning in school (Ladson-Billings, 2009; Nelson \& Guerra, 2014; Walker, 2011).

\section{From NCLB to CCSS Reform: Continued Efforts to Improve Student Learning}

The CCSS were developed to ensure that all states held their students to the same level of expectation. These skills would prepare them for success in postsecondary education and the workplace, allowing them to compete in the global arena (Kendall, 2011). The Council of Chief State School Officers and the National Governors Association committed to this work, with representation from 48 states, 2 territories, and the District of Columbia (Kendall, 2011). An advisory group of experts from Achieve, American College Test (ACT), the College Board, the National Association of State Boards of Education, and the State Higher Education Executive Officers also participated (Kendall, 2011). Subject-area organizations provided feedback before the release of the standards for public comment (Kendall, 2011). Then, during the public comment period, teachers, parents, business leaders, and the general public gave feedback.

Up to this point, the federal government had not played a part in the development of the CCSS. However, in March 2010 the Obama administration recommended revisions to the Elementary and Secondary Education Act and NCLB. Entitled "A Blueprint for Reform," these revisions suggested that states adopt and implement college and career readiness standards (U.S. Department of Education, Office of Planning, Evaluation and Policy Development, 2010). Besides common standards in English language, arts, and math, the blueprint addressed improving educators' effectiveness for all schools, 
empowering parents to improve students' learning, and ensuring intensive support and effective interventions for America's lowest-performing schools (U.S. Department of Education, Office of Planning, Evaluation and Policy Development, 2010).

According to Conley (2007), an implied goal of the standards was to increase expectations of student performance as well as to develop common national assessments. Specifically, the standards provided a roadmap that included clear and concise expectations for all students and that held all teachers and students accountable to the same accountability system (Conley, 2007). Another important goal was for American students to remain competitive with their global peers (Kendall, 2011). The CCSS were designed to be a rigorous, sequential, and increasingly complex set of benchmarks for student learning. Teachers who depend on the common standards alone will not adequately prepare students for college or careers. The release of the standards prompted development of resources for educators to use to adapt their current practice with the intended practices and assessments to measure student progress (Doorey, 2012). In response, the U.S. Department of Education developed the Race to the Top Assessment Program assigning \$362 million to support and encourage the development of new assessment systems and support systems (Doorey, 2012).

The CCSS differed in several significant respects from state-level standards. First, the standards were aimed at college and career readiness (Kendall, 2011): Their design mapped out the knowledge and skills students need to be prepared to enter first-year courses in colleges or to join workplace training programs for careers offering competitive salaries. Second, the standards are internationally benchmarked (Kendall, 2011). Third, they aim to send clear signals to students, parents, and educators about what 
is most important to learn at each grade level (Kendall, 2011). Fourth, they should be common across states (Kendall, 2011).

The U.S. government announced its Race to the Top grants in the hope of encouraging states to adopt these standards. Notably, a $\$ 4.35$ billion grant program was established as part of the American Recovery and Reinvestment Act of 2009. (The stimulus package sought to help jump-start the economy after the Great Recession.) The U.S. Department of Education required candidate states to make four "assurances": that they would strengthen standards and assessments, would improve data systems, would enhance teacher and school leader quality, and would turn around low-performing schools. According to the official CCSS webpage (Common Core State Standards, 2010) 42 states, the District of Columbia, 4 territories, and the Department of Defense Education Activity have adopted the CCSS.

The CCSS initiative differs from previous school reform efforts for multiple reasons (Kendall, 2011). The CCSS framework allows educators to fit the standards into instructional time (Kendall, 2011). Also, the CCSS are designed to be concise and direct, giving teachers focus and allowing them to place attention on key concepts for students (Common Core State Standards Initiative, 2010. Schmidt and Houang (2012) argue that teaching fewer topics at a more meaningful and in-depth level can support student learning. Because the CCSS are not a scripted program, teachers have the opportunity to be autonomous in their instruction and to cultivate higher-level thinking skills through a coherent and organized curriculum.

The CCSS are not a national curriculum but were instead designed "to identify essential skills and knowledge students need — not how students acquire them. The 
initiative is state-led [and an] oversight of curricular matters will continue to be the prerogative of the individual states" (Doorey, 2012 p. 28). Accordingly, schools—and, more important, teachers - have the autonomy to design how to teach the standards. A teacher who possesses cultural competence and critical consciousness and who maintains high expectations of all students can create a curriculum specifically designed for his or her ethnically diverse class. Delpit (2006) states that a curriculum can start as small as an individual classroom. Ladson-Billings (2006b) suggests that being a culturally relevant teacher is a way of "being." She also explained that she would not tell a group of young teachers, when asked, how to become culturally relevant teachers: "The reason I would not tell [them] what to do is that [they] probably do it!” (p. 39). As the conversation progressed, the young teachers in question realized that their part in a child's education is to prepare the child to become a participating citizen in a democracy—and that nobody could tell them how to prepare their students. Accordingly, they needed "to commit to democracy as a central principle of their pedagogy" (pp. 39-40). Thus culturally relevant and diverse curricula can use the standards to decide the end goal, but the teacher must use the needs of the students to decide how to teach.

\section{Conclusion}

As student diversity continues to grow in school systems, culturally relevant teaching become essential to minimize the academic impact of the current cultural and social gap between teacher and student (Ladson-Billings, 2009). As demographics in the United States continue to change, so should the way a teacher decides how to teach. The teaching force has and continues to consist mostly of White female teachers, but the student population is growing in the percentage of students of color. When White 
teachers have little experience with diverse student populations or the effects of inequality in society, they do not understand how their pedagogic choices hamper student learning and engagement as well as the relationships they hold with their students of color (Gay, 2000; King, 1991; Milner, 2007). Researchers found that teachers who were biased towards students of color and the reaction those students of color had to instruction caused further damage to students' achievement (Howard, 2010; Watson, 2012). Teachers who hold students to high academic standards, acknowledge and learn about their students' culture and values, encourage students to critically engage with the materials, help develop a learning environment in which students of color are empowered to take the lead in their learning. Culture is an instructional strength and resources a teacher can use regardless of grade level, content area, or ethnic groups. This pedagogical practice enables teachers to differentiate, and modify instruction to meet the learning needs of every student better. In particular, using students' culture in instructional decision making encourages relationship building and a way of developing trust amongst all stakeholders in a classroom (Gay, 2010; Ladson-Billings, 2009; Nieto, 2010).

Culturally relevant teachers see their teaching as fluid. They adjust their instruction to the needs of the students. They do this by seeing the value in the community in which their students live, and they incorporate what is relevant to students' lives in their community into the classroom. The teachers are passionate about their instruction. More so, when it comes to teaching state standards, these teachers only accept mastery. They do not blame their students for lack of achievement but reflect on their practice and make adjustments. These teachers do not believe they are the sole 
holder of the information. They know they can learn much from students just as it is their responsibility to prepare students for their communities. Culturally relevant teachers use collaborative learning as a strategy for students to take responsibilities for each other, and for the teacher to get an inner view of how students make sense of what they learn. Most importantly, culturally relevant teachers regard knowledge critically. They understand the expectations put on their students but use higher order learning activities for students to demonstrate the knowledge of the state standards. Since cultural relevant teachers see knowledge as constantly changing and different for individuals, they teach students how to analyze information.

Critical literacy is an instructional approach used by culturally relevant teachers. They use various texts and media for students to analyze and find the author's purpose, blatant or hidden. Teachers use reading strategies to teach their students how to evaluate an author's point of view, and the reliability of information since authors' personal beliefs influence their perspective. More so, culturally relevant teachers help their students examine author's messages for bias or false messages that go against a marginalized group. Critical literacy goes beyond being able to read words on a page and being able to answer basic questions. Culturally relevant teachers engage their students in cooperative tasks, critical conversations of what they see on television, movies, words posted in their communities, music, movies, and videos, or anyway, a person shares their views. The most important thing is for students to analyze, discuss, and share the different meanings a text might have.

Common Core State Standards (CCSS) language is similar to critical literacy in they way they both encourage and expect students to question and even challenge they 
author's message with facts from other texts on the same topic. CCSS expects all students to have access to an increased level of text complexity. The standards are written in a progressive development of reading comprehension so students can have a more personal experience from what they read. Delpit (2006) and Ladson-Billings (2006b) suggest the teacher is the one who decides the success of the curriculum. CCSS are concise, fewer, and are meant for students to have an in-depth experience as they move from grade to grade. Researchers agree that when teachers use students' culture as context or a springboard, then the standards bring meaning, purpose, and authenticity to the learning experience in the classroom environment. The students then can use the standards in real life context to make a difference in their community. CCSS does not encourage teachers to use students' cultural capital to determine what materials to use. The suggested texts represent the dominant culture's experiences and point of view. It will be up the teacher to use these texts to engage students in critical conversations. But-just as other reform movements have shown - most teachers do not teach their students to be critically think and engage with academic materials. When teachers only focus on academic achievement, student achievement improved for all students. Unfortunately, the existing gap in student achievement between racial groups, and in particular, students of color continue. However, if teachers follow all three criteria of culturally relevant teaching, then academic performance by students of color, will improve and it would be possible to close the achievement gap with their White counterparts. 


\section{CHAPTER 3: METHODOLOGY}

A qualitative case study research design was used in this investigation to analyze elementary teachers who use Reading CCSS to teach their students critical consciousness. Three teachers were selected based on their choice to attend profession developments emphasizing the need for culturally relevant instruction to engage students of color. Moreover, these teachers used cultural awareness in their explanation of a clash between teachers and not only their students but also their students' families (Nelson \& Guerra, 2014).

This chapter first outlines the methodology that this study will employ, including the (1) research rationale, (2) data collection procedure, (3) sample description, (4) interview procedure, (5) approach to data analysis, (6) trustworthiness criteria, (7) possible limitations, and (8) positionality, and then concludes briefly.

\section{Research Rationale}

Diversity in the public classroom is broader and more complex than ever before. Students are likely to be multiracial or multiethnic but also to be diverse along lines of linguistic, religious, ability, and socioeconomic status (Eng, 2013). Ladson-Billings (2009) found that as classrooms' diversity expands, educators place students into categories, one of which - easily given to students who do not conform - is "at risk" of failing. Instead of setting the expectation of success, educators settle for blaming the lack of achievement on a student's context: 
To whatever extent children don't have the confidence in their ability to affect the future, it is all the more important that they be connected to adults who can envision futures the young people cannot and keep them moving towards those futures. (Payne, 2013, p. 116)

Students fare better in the public school setting when they are exposed to cultural competent teachers who believe in all children's academic successes and who use critical consciousness to engage students in their learning (Gay, 2000; Ladson-Billings, 2009; Payne, 2013). Accordingly, the earlier that students of color are exposed to culturally relevant teachers, the better chance those students have of academic achievement. Debnam et al. (2015) and Ford and Kea (2009) found that students of color found academic success when taught by teachers who incorporated students' lives with the curriculum, identified which aspects of lessons matter to students, and used students' cultural capital in instructional decisions. Teachers who embrace culturally relevant teaching serve as a stimulus for improved reading achievement among students who are culturally and linguistically diverse — so much so that Debnam et al. (2015) and Ford and Kea (2009) call for research into what drives a teacher to use a strengths-based approach and into the role that professional development plays in teachers' use of students' cultural capital. Accordingly, this study examines how teachers integrate culturally relevant pedagogy in implementing CCSS so that students can move toward a future in which they are contributing citizens in a democratic society.

\section{Research Questions}

1. What practices do culturally relevant elementary teachers use to ensure academic success, develop their cultural competency, and teach critical consciousness? 
2. How do teachers develop a critical consciousness to better serve the needs of diverse students?

3. How do teachers develop a critical consciousness to address the lack of diversity in the CCSS?

\section{Research Approach}

In this study, a qualitative case study (Marshall \& Rossman, 2011; Merriam, 1988; Miles, Huberman, \& Saldana, 2014; Yin, 2014) research design was used to explore the research questions. This design was selected as a way of studying the indepth beliefs and literacy practices of teachers who adopt a culturally responsive approach to teaching elementary Reading CCSS. As a methodology, case study "takes the reader into the setting with a vividness and detail not typically present in more analytic reporting formats" (Marshall \& Rossman, 2011, p. 267). The purpose of this research is not to generalize findings but rather to match findings to an underlying theory of culturally relevant teaching (Miles et al., 2014). The research explored the interaction of teachers' beliefs with students' culture and community while teaching the CCSS.

The qualitative research design sought to produce a holistic account of the complex factors that are at play when teachers use a culturally relevant pedagogy while implementing the CCSS (Creswell, 2013). The research design used multiple sources of teacher data for purposes of triangulation to determine "converging lines of inquiry" (Yin, 2014, p. 120). The specific teacher data that were collected consisted of interviews, observations, and student work samples.

A qualitative research design allowed the researcher to explore perceptions. "The qualitative paradigm assumes that reality is socially constructed and it is what 
participants perceive it to be" (Creswell \& Miller, 2000, p. 125) —or "otherwise [how participants] manage their day-to-day situations" (Miles et al., 2014). These culturally relevant teachers were empowered to share their stories in their own voice (Creswell, 2013). Moreover, teachers shared their personal beliefs and practices about how they understand their context of teaching the Reading CCSS to their racial diverse classrooms (Creswell, 2013).

\section{Identifying Participants}

This research is “theory-driven”: Teachers' use of culturally relevant pedagogy was used to select participants (Miles et al., 2014). The research did not start with a set number of participants. "'Enough' is an interactive reflection of every stop of the interview process and different for each study and each researcher" (Seidman, 2013, p. 75). Accordingly, considering the focus on exploring how these culturally relevant teachers implemented CCSS, the teachers selected for the study avoided “colorblind/culture blind" approaches and philosophies. A purposeful sampling approach was used to determine the participants. As a way of locating teachers who understood and used a culturally relevant pedagogy, participants were selected who had participated in three or more professional development opportunities offered by the diversity department of the district. This professional development, which focused on using literature to engage African American males, using hip-hop music in the literacy setting, using culturally relevant materials to engage students of color in reading and writing, understanding cultures from around the world, and the like, sought to educate teachers in culturally responsive activities as well as to expand teachers' cultural awareness and thereby prevent student misconceptions based on cultural differences that might result in 
lower levels of student achievement. Debnam et al. (2015) found that teachers could still lack an understanding of culturally responsive teaching even after attending professional development that focused on teachers' evaluating their personal beliefs on teaching students from diverse backgrounds, so to screen professional development attendees with a view to finding ones who shared the three beliefs of Ladson-Billings' framework of culturally relevant teaching, a scenario from Nelson and Guerra's (2014) qualitative scenario study was used. The scenario addressed school reform, saying that "data from a needs assessment administered to teachers in a low-performing school identifies students and parents as the greatest challenges to improving achievement and staff and programs as assets" (p. 75). The teachers selected for this study were additive in their responses, which were coded as ranging from pluralist awareness to deep awareness (Nelson \& Guerra, 2014).

The procedure for determining the sample was multi-staged. First, the diversity department provided 2014-2016 attendance rosters for all cultural pedagogy professional developments offered to teachers. Each roster was combined in one Excel document. Participants were sorted and then filtered by those having attended three or more professional developments over the three-year period. The first round of participants consisted of 35 teachers. As the second step, an invitation email was sent to all 35 teachers. The invitation email also served as their consent to participate in the study. After seven days, no responses to the email had been received, so in the third step, three principals were contacted and were asked to speak to the seven teachers on behalf of the researcher. The three principals asked for the email to be sent to them, offering to forward it to the specified teachers in their building. After seven days, two responses to 
the email had been received. However, both were coded as exhibiting little cultural awareness based on their subtractive and deficit belief responses. The fourth step, then, focused on the five teachers who had not responded to the email and involved contacting them by phone instead. Messages were left with two teachers, but those teachers did not return the call or respond to the multiple emails. Three teachers were contacted over the phone. During these phone conversations, the participants were emailed the consent email and asked to read it. Should they agree to participate in the study, they would respond with an email agreeing to participate in the small prompt and possible interview and observation, providing student work. All three participants asked whether they could answer the interview questions over the phone to save time. In the fifth step, the participants responded to the email, agreeing to the parameters for being a research participant. The phone app Call Recorder was used to record their responses. Coding of their phone responses revealed these three teachers to be culturally aware (Nelson \& Guerra, 2014). Finally, the participants were contacted via phone to move to phase 2 of the research.

\section{Description of the Sample}

In qualitative research, sampling drives the research by limiting who and what will be studied (Miles et al., 2014). Looking at teachers who believed in and used a culturally relevant pedagogy allowed for better understanding and specified how and where - and, if possible, why — these teachers carried on as they did (Miles et al., 2014). The sample is purposive: The teachers believe in and incorporate students' culture as an essential element in instructional decision-making (Miles et al., 2014). 
When Ladson-Billings (1995) began combining her research findings, she looked for common threads that she could use to pull the studied teachers' practice together, allowing her to relate her findings to others'. Initially she looked for teaching strategies that the participants shared in common (Ladson-Billings, 1995). But when she realized that she had to "go beyond the surface features" of the teachers' practice to look at the philosophical underpinnings and ideological foundations of their practice, she found that overall, the teachers shared common ways of thinking about themselves as teachers, of thinking about the community in which they taught, of building social relationships within and outside the classroom, and of perceiving knowledge; these revealed their similarities (Ladson-Billings, 1995).

\section{Data Sources}

To generate data relevant to the research questions and gain knowledge from teacher participants about their use of culturally relevant strategies, this research study used the following data sources: (1) in-depth interview, (2) reading lesson observation, (3) pictures of the participants' classroom, (4) field notes, and (5) student work document review (Yin, 2014). The collection of multiple data sources from each teacher allowed for data triangulation to generate an in-depth understanding of the research questions (Creswell, 2013). Moreover, the use of different sources of data to document a code or theme gives validity to findings (Creswell, 2013; Creswell \& Miller, 2000).

Interviews. Merriam (1988) has written that the qualitative case study research approach strives to understand something from the participant's point of view while also uncovering the meaning of his or her experiences. Merriam (1988) also stated that interviews allow researchers to find out from participants what is in participants' minds. 
A researcher cannot observe how participants make sense of and organizes the world, so the researcher must ask participants questions to understand their perspective (Merriam, 1988). This research used a semi structured research protocol: The interview was guided by a list of questions, but the wording and order of questions varied among participants. Interviews were arranged to accommodate participants' schedules. Two of the interviews took place in the teachers' classroom and the other at a local coffee shop. Interviews ranged from 45 minutes to 68 minutes. Each interview was recorded with participants' consent and was transcribed by a third-party transcription company. The interview protocol (Appendix A) addressed Reading CCSS, assessments, teacher beliefs about culturally relevant teaching, and a focus on critical consciousness. Because the researcher had spoken to the participants over the phone during the first phase of the interview, a rapport had been established. Even though it was unintentional, this established rapport caused the participants to speak honestly about their feelings. In particular, one question during the face-to-face interview protocol asked participants to describe "a normal student." All three participants openly expressed their displeasure at the question, and one opted not to answer the question at all. Each participant participated in a follow-up phone call in which to clarify answers given using the interview protocol.

This study focused on the individual teachers' experiences of being culturally relevant teachers while implementing CCSS. "A study focusing on individual lived experiences typically relies on an in-depth interview strategy" (Marshall \& Rossman, 2011, p. 93). Interviewing allows research to "capture the deep meaning of experience in the participants' own words" (Marshall \& Rossman, 2011, p. 93). To allow for flexibility within the interviews, a semi-structured interview protocol was used to allow the 
researcher the ability to ask follow-up questions and to explore unexpected topics (Marshall \& Rossman, 2011).

Interviewing was an appropriate research tool for this study. Culturally relevant teaching is a belief system that does not align with mainstream educational environments (Ladson-Billings, 1998; Nelson \& Guerra, 2014). Accordingly, the researcher must be what Yin (2014) called a good "listener" to find out what is going on in someone else's mind (Merriam, 1988). To listen during an interview means to receive information through multiple modalities of observations while making sense of what is happening during the interview (Yin, 2014). The important role of a case study researcher is that of hearing the exact words used by the participant, capturing the mood and affective components, understanding the context of the participant's world, and inferring the meaning intended by the participant and not the researcher (Yin, 2014).

Classroom observations. Yin (2014) writes that observation allows the researcher to gain an in-depth examination in its real-world context. Also, Merriam (1998) adds that observational data provide a firsthand experience with the phenomenon of study instead of the secondhand account of information gained from an interview. Observations note the phenomenon in the field setting through the five senses of the observer, using an instrument, and recording observations (Creswell, 2013).

All three observations took place during each teacher's reading block. Each participant chose the date and time of the observation, along with the topic that was covered. An observation protocol was used to document the lesson topic, purpose of lesson, assessments used, collaboration among students, materials used, and mode of instruction (Creswell, 2013). Field notes were documented in a journal (Creswell, 2013). 
The role of nonparticipant/observer as participant was used during the observation as documented in the IRB (Creswell, 2013). Each teacher had a set place for the observation to take place in the classroom. Based on all the locations in each classroom, the observer was able to hear multiple student conversations, watch students complete work collaboratively and independently, observe reading and classroom materials used, and teacher collaboration with other adults in the room. The data collected from the observation came from the three elements described by Ladson-Billings (2009): (1) students' experiencing academic success, (2) students' maintaining and developing cultural competence, and (3) students' developing a critical consciousness.

Documents. To assist with triangulation, documents were collected and reviewed. The researcher reviewed each participant's school website and school academic data to determine whether the school was reaching its annual measurable objective (AMO). Culturally relevant teachers understand that students bring knowledge with them into their classrooms (Ladson-Billings, 2009):

A hallmark of the culturally relevant notion of knowledge is that it is something that each student brings to the classroom. Students are not seen as empty vessels to be filled by all-knowing teachers. What they know is acknowledged, valued, and incorporated into the classroom. (Ladson-Billings, 2009, p. 95)

However, Ladson-Billings (1992) acknowledged that not all teachers have complete autonomy regarding the materials they use to teach. So in her research, Ladson-Billings (1992) observed teachers who had the autonomy to use any reading materials they saw fit to move their students of color. However, Ladson-Billings (1992) also observed teachers who were required to teach from a basal series. One of the schools in which one of the 
teachers taught is meeting its AMO and is considered to be progressing. The other school has not met its AMO in two years and is labeled a focus school. The teacher from the progressing school used multiple reading materials to teach the standard. The other two teachers from the focus school were required to use reading materials focused on CCSS. As noted by Yin (2014), “documents can provide other specific details to corroborate information from other sources. If the documentation evidence is contradictory rather than corroboratory, [the researcher needs] to pursue the problem by inquiring further into the topic" (p. 106). The general knowledge about each teacher's school's background helped guide the semi-structured interviews in the questions regarding autonomy, assessments, and materials used.

Field notes were used during the interviews and observations. These captured the descriptive details of the context as well as of the researcher's reaction. Participant observation is a major means of collecting data in case study research (Merriam, 1988). Observation "gives a firsthand account of the situation under study and, when combined with interviewing and document analysis, allows for a holistic interpretation of the phenomenon being investigated" (Merriam, 1988, p. 102).

\section{Data Collection}

The first stage of data collection involved the emailing of a writing prompt to determine participants' level of cultural awareness about a school reform agenda. An IRB consent email (Appendix G) was part of the email asking teachers to participate in the study. After teachers were selected to move to the next phase of the research, they were engaged in a face-to-face interview. These interviews allowed the participants to share their beliefs, practices, and knowledge about culturally relevant teaching. Each of the 
three teachers was observed one time after the interview. Prior to the observation, each participant was given the parental consent letter to send home with the students that would be in the room at the time of the observation (Appendix H). These observations took place during the second semester of school, during each teacher's reading block. Literacy instruction lasted for over an hour. An observation protocol was used as a method for recording the structure of the lesson. A field journal was used to document conversations, the physical environment, interactions between students and teachers, interactions between students, and the researcher's interactions and reactions to the observation and environment.

Data gathered from the previously described techniques were subsequently interpreted through the analysis techniques/procedures of simultaneous coding and crosscase comparisons (Miles et al., 2014). Simultaneous coding was appropriate, for a teacher's single action can have multiple culturally responsive meanings and thus receive more than one code (Saldana, 2013). Dedoose was the CAQDAS program used during the simultaneous coding process. Dedoose allowed application of multiple codes to the same passage of text or picture. After each participant's interview, observation, and student work was coded, a cross-case comparison was used. This technique treats each individual case study as a separate study, allowing the researcher to probe whether “different cases appear to share similar profiles and deserves to be considered instances of the same 'type' of general case" (Yin, 2014, p. 166). This technique fits the research question by allowing the researcher to see whether culturally relevant teachers shared common themes when implementing CCSS. 
A third-party service transcribed all the interviews into a Word document, with each interview transcript saved as a separate file. Creswell (2013) identifies "coding" as the organizational process for separating large quantities of data into smaller categories across databases. Saldana (2013) defines a code, in qualitative research, as a word or short phrase that "symbolically assigns a summative, salient, essence-capturing, and or evocative attribute for a portion of language-based or visual data" (Saldana, 2013, p. 3).

\section{Data Analysis}

Yin (2014) has stated that a case study involves the study of the case within a real-life setting. The analysis of this case study consisted of a detailed description of the case and setting. Interviews, observations, and document analysis were used as data sources. To accomplish this task, a cross-case analysis was used in an effort to "not only pin down the specific conditions under which a finding will occur but also help ... form the more general categories of how those conditions may be related" (Miles et al., 2014).

For the first cycle of coding, the researcher read and coded the interviews multiple times, with reference to the research questions, for the specific themes of culturally relevant teaching: high academic standards, cultural competency, and critical consciousness (Ladson-Billings, 2009). Creswell (2013) used the term theme to refer to "broad units of information" (p. 186). Miles et al. (2014) suggest that researchers lean on conceptual frameworks and on the research questions when approaching data analysis. Yin (2014) has noted that a researcher should do at least four things to ensure a highquality analysis:

- The analysis should show that the researcher attended to all the evidence.

- The analysis should address, if possible, all plausible rival interpretations. 
- The analysis should address the most significant aspect of the case study.

- The researcher should use prior; expert knowledge in the case study. (p. 168) Saldana (2013) noted that it is acceptable to have one's choice of provisional list of codes "beforehand (deductive) to harmonize with the study's conceptual framework, paradigm, or research goals" (p. 65). So the initial three reads allowed the researcher to categorize findings into the major themes that correspond to Ladson-Billings' framework for culturally relevant pedagogy (Ladson-Billings, 1995; Ladson-Billings \& Tate, 1995). The researcher used simultaneous coding for the first cycle of coding. In Ladson-Billings' 2009 book The Dreamkeepers: Successful Teachers of African American Students, she defined each of the three foundational beliefs: high academic expectations, cultural competency, and critical consciousness.

The second cycle took a cross-case analysis approach to seeing the pattern codes, which are explanatory or inferential codes—ones that identify an emergent theme, configuration, or explanation. "These codes pull together much material from the first cycle of coding into more meaningful and parsimonious units of analysis" (Miles et al., 2014, p. 86). Saldana (2013) adds, "the primary goal during Second Cycle coding is to develop a sense of categorical, thematic, conceptual, and/or theoretical organization from your array of First Cycle codes" (p. 207). Because the participants shared a belief in the importance of using a culturally relevant pedagogy while implementing CCSS, pattern coding led to the examination of patterns that showed how teachers are culturally relevant teachers when participating in the CCSS reform movement.

Beginning the more intensive phase of data analysis, all the data collected were brought together-interview transcripts, field notes, school data, reflective prompt, 
pictures, and reflective memos. All these materials were organized in Dedoose in a way that was easily retrievable; Yin (2014) called this organization method a case study database.

The first stage of data analysis began with an examination of the interviews. Each interview was placed in Dedoose. Coding took place one teacher at a time. Whole sentences were highlighted and coded as HAS (high academic standards), CC (cultural competency), and/or CritCon (critical consciousness). Each code was then exported to excel, with each code given an individual cell. Each teacher's interview was reread several times and an analysis conducted based on Ladson-Billings' (2009) theory of culturally relevant teaching. Then a clean copy of each teacher's excerpts was placed back into Dedoose. Pattern codes were used to identify an emergent theme, configuration, or explanation that allowed grouping of material into more meaningful units of analysis. According to Merriam (1988), the researcher needs to keep track of thoughts, musings, speculations, and hunches while engaging in analyses. So the next step was coding the observation field notes and any data collected during observation of teachers' literacy instruction. Each observed action was given a memo that detailed the thoughts behind how the teacher's actions were related to the theory of culturally relevant teaching.

Member checking was conducted after each written case narrative. Participants were first given their interview transcripts to review and were then encouraged to clarify or add to the thought they shared during the interview. None of the participants added to his or her interview. After the first round of thematic coding, participants were given a form that had their excerpts sorted into Ladson-Billings' culturally relevant teaching themes of high academic expectations, cultural competency, and critical consciousness. 
Creswell (2014) explains that the use of member checking helps determine the accuracy of the qualitative finding by taking the descriptions back to the participants to determine if they were accurate. Once again, the participants did not add or change any of the analysis.

\section{Reliability/Validity/Triangulation}

Establishing the validity and reliability of a study has to do with examining the component parts of the research (Merriam, 1988). Qualitative validity means that the researcher checks for the accuracy of the findings by implementing certain actions, whereas qualitative reliability shows that the researcher's approach is consistent across different researchers and different projects (Creswell, 2014). Creswell (2014) and Yin (2014) have both suggested that qualitative researchers should document the procedures of their case studies and have advised that they document as many steps as possible; moreover, the researcher should set up a detailed case study protocol and database. This research used member checks to verify or extend interpretations and conclusions (Miles et al., 2014). Also, it allowed respondents to spot information that would identify them and that might cause negative consequences for their well being (Miles et al., 2014). The researcher took "data and interpretations back to the participants in the study so they [could] confirm the creditability of the information and narrative account" (Creswell \& Miller, 2000). Throughout that process, the researcher asked participants whether the themes made sense and whether the overall account was realistic and accurate (Creswell \& Miller, 2000). The participants chose to let the results stand when given the opportunity to react, adding credibility to the study (Creswell \& Miller, 2000). 
Triangulation supports a finding by showing that at least three independent measures of it agree with or at least do not contradict the finding (Miles et al., 2014). Triangulation is a systematic process for proving corroborating evidence through multiple methods (Creswell \& Miller, 2000; Miles et al., 2014). Accordingly, if research is inconsistent by teachers' actions deemed as culturally relevant or if conflicting findings arise when triangulating the data, the integrity of the data collection method is examined. The research will consider "undetected variability of something that we need to consider or unanticipated anomalies and outliers of the phenomena" (Merriam, 1988, p. 299).

A peer review is a "review of the data and research process by someone who is familiar with the research or the phenomenon being explored" (Creswell \& Miller, 2000, p. 129). In this case, the peer played the devil's advocate, who keeps the researcher "honest; asks hard questions about methods, meanings, and interpretations; and provides the researcher with the opportunity for catharsis by sympathetically listening to the researcher's feelings" (Creswell, 2013, p. 251). This peer, a doctoral classmate, has shared observations, research topics, and conversations about the educational experiences of students of color, kept interpretations valid through scheduled debriefing sessions. The researcher and her peer used the memo aspect of Dedoose. After each coding session, the peer would review the codes and left a memo. Then the peer reviewer checked for validity of code in regards to the theory of culturally relevant teaching. Moreover, the peer reviewer added their personal reflections and thoughts about participants' interview responses and lesson observation. Creswell (2014) writes that the goal of reliability is to minimize the errors and biases in a research study; in this study, protocols were used for the interviews and observations to minimize documentation errors and create consistency 
in the collection of data. These protocols were followed for all three participants in the study.

\section{Limitations}

Even though data were triangulated, the design of the study presents limitations. Multiple cases were studied, but all teachers were selected from the same school district - and two of the teachers, moreover, were from the same school. Selection from one single district limits the generalizability beyond the district. Considering the sensitive topics of personal beliefs about teaching students of color, participants might have disclosed what they perceived to be appropriate and might have withheld ideas that they felt might not be received favorably. Even though participants were asked to share student work samples and allow a classroom observation, the possibility remains of a disconnect between what they articulated and their actual practice, for they were not observed at length. Studying the practices of such a small number of teachers in a single school district impeded the generalizability of the findings, but studying the practices of these teachers did reveal an assortment of practices and experiences that could lead to further research into culturally relevant teaching during a time of high-stakes testing and varying education reform movements.

\section{Positionality}

The researcher is an African American female who gained her teaching certificate through an alternative certification process designed to increase the number of African American teachers in the district. The researcher has been a classroom teacher for 19 years in the district in which this study will take place. She has taught children aged 5-11 in various self-contained classrooms while also being an itinerate computer and arts and 
humanities teacher. The researcher has taught in three schools during her career. She started off in a Title I school, then transferred to a school that did not receive Title I funding because of its middle-class and racially homogeneous student population. She then later transferred to a Title I school having a high percentage of African American students.

During the researcher's time as a teacher, she has witnessed national reform movements (Goals 2000, NCLB, CCSS) and local reform movements (Four Blocks of Literacy Model by Allington and Cunningham, Reading Workshop, and Close Reading) designed to address the disparity of results achieved by students of color when taking tests compared to those achieved by their White peers. The researcher has approached each reform movement with fidelity and a positive attitude. However, she has seen her teacher peers lock themselves in their rooms, as it were, while they wait out the reform movement storm. Also during these reform movements, she has seen teachers complain that "nothing will help these low-performing kids." Blame is easily placed on students' lack of motivation, parental involvement, parental attitudes, but the researcher has never opted out and accepted less than successful results—and has also required students to hold themselves to high standards.

The researcher has been vocal about issues of social justice as regards the school climate and teachers' instructional decision-making. Before earning this degree, the researcher would have called herself not a culturally relevant teacher but rather an advocate for or voice to the students and parents - yet one whose voice could be muted if challenged. The researcher did not speak out against curriculum, field trips, or materials that were culturally inappropriate or were culturally biased. Also, the researcher did not 
speak against educators who held deficit thoughts or practices that harmed children of color. The researcher was not afraid to discuss with her students matters of race, even when parents, students, and fellow teachers push back. Since having researched culturally relevant teaching, the researcher has become even more intentional in questioning choices made by fellow teachers and administrators. Before conducting this research, she heard teachers explain that race does not influence their expectations, choices, and beliefs; now she will challenge those who make decisions that are harmful to students of color. The researcher has determined that she has an ethical responsibility to advance educational understanding of how reform movements do not address the ways in which students' race and culture influence teachers' beliefs and decisions. Accordingly, this research will present examples of teachers who believe in students' cultural capital while implementing an educational reform movement. To address this enlightenment and to preserve the validity of the study, the researcher will use a peer to continually question analysis and address any biases.

\section{Conclusion}

This chapter focused on the methodology for this study, which sought to understand the beliefs and practices of culturally relevant teachers implementing CCSS. This study described teacher perceptions of how they might maintain a culturally relevant pedagogy while implementing Reading CCSS. Multiple sources of evidence were used to ensure the quality of data, including interviews of teachers, observation of literacy lessons, and examination of related documents. Participants in this study included two fifth-grade teachers and one-fourth-grade teacher. One of the fifth-grade teachers and the fourth-grade teacher teach in the same school. In Chapter Four, the researcher describes 
her qualitative research case study results as well as how she used triangulation to validate her research into how culturally relevant teachers implement CCSS. This research will add to the theory of culturally relevant pedagogy and intensify its empowering effects on teachers and students alike. Furthermore, this research adds to the body of research into how to best train teachers for their diverse classrooms. 


\section{CHAPTER 4: RESULTS}

This research study examines the beliefs and literacy practices of teachers who use students' culture as a catalyst for instruction in accordance with the Reading CCSS. The findings in this chapter are the results of interviews, classroom observation, and artifact analysis with an eye to answering the following research questions:

1. What culturally relevant practices do elementary teachers use to ensure academic success, develop their cultural competency, and teach critical consciousness?

2. How do teachers working in an urban school district develop and use critical consciousness to better serve the needs of their diverse students?

3. How do teachers develop a critical consciousness to address the lack of diversity in the CCSS?

This chapter reviews the data collected from three elementary classroom teachers selected for their beliefs and practices and their use of culturally relevant pedagogy during literacy instruction. Data collection began in January of the 2016-2017 school year. The three participants came from two elementary schools in the same urban district. The participants of the study consisted of one fourth-grade teacher and two fifth-grade teachers. The results presented hereafter involve a within-case analysis of the three teachers and are presented in no specific order. 


\section{Stephanie: Fourth-Grade Teacher}

Stephanie (a pseudonym) is a married African American female in her third year of teaching who received her bachelor's degree in business administration from a local public university. Stephanie received her certification through an alternative certification program designed to increase the number of African American teachers in the district that served as the context for this study. She received her master's degree in elementary school counseling from the same local public university that awarded her a bachelor's degree. At the time of this study, Stephanie had taught in the same elementary school for the entirety of her three-year career. In this environment, she had the opportunity to collaborate with a special education teacher and with a resource teacher of English as a second language.

Stephanie explained that she had entered the educational field as a second career choice, having first sold pharmaceuticals to doctors' offices. Stephanie was unhappy in this role, which prevented her from spending as much time with her children as she would have liked. She came from a family of educators, and her father was a principal of a local elementary school. A friend, knowing her to be unhappy in her work, suggested that she apply for the alternative certification program; she did and is now a teacher. Stephanie added that her schedule and hours allowed her more time than she had had for many years when working a year-round job. Along with more family time, the teaching profession gave her the opportunity to help children, just as so many of her family members and friends had also done. Because Stephanie felt a personal responsibility to be an encourager, motivator, and supporter of young people, teaching students of color aligned with her desire to be a responsible person. 


\section{Stephanie's Classroom Design}

Student desks were placed in small groups, all facing a dry-erase board. Stephanie put her desk in the corner of the room, her laptop computer and document camera atop it. On both sides of the large dry-erase board were green chalkboards. On both sides of the chalkboards were bulletin boards. On the left chalkboard, she posted students" "I Can" statements, based on the CCSS that they were learning for the day. The following were the "I Can" statements for the day of the observation:

1. I can determine unfamiliar words by using context clues.

2. I can write a rough draft for my literary analysis.

3. I can review my MPA 3 [math proficiency analysis].

4. I can identify and explain how to use Kentucky’s resources.

5. I can explain weathering and erosion.

On the small section of the whiteboard not lit by the ceiling-mounted projector, she listed the week's vocabulary words. She selected the words from the class's chapter book, read aloud. Stephanie viewed vocabulary as an essential part of her lesson planning. In her class, more than half her students spoke another language at home. When her students read books or collaborated with their peers on their math instruction, vocabulary limitations could hamper their learning. Stephanie stated:

I realize that things like vocabulary separate my kids. So I'll have a student-just because they come from a different background or different language, different words mean different things to different kids. I have to make sure, when we're going through our reading lessons and math lessons, that they might be able to answer the question, but what they feel about a certain word or what they think a 
word means is different than the next kid. An example is once I had a small reading group. We were reading a text where one of the characters was cutting the grass with a riding lawn mower. Some of my kids will say riding mower. Some kids will say lawn mower. Some kids don't even know what [it] is, 'cause they didn't have yards where they came from, and now they live in apartments. We have to be careful when we make up tests or even have conversations about what we read. We have to make sure texts are culturally appropriate when it comes to comprehension - that everybody has an equal level playing ground to answer those questions that assess their knowledge.

The teachers in Ladson-Billings' 1992 study encouraged students to incorporate their experiences and language into the instruction, appreciating that their students' languages had meaning and brought depth to the lesson. Stephanie encouraged students to use their language during their small group work time. She added, "When students speak in their home language, at times, it can engage students in the lesson. Next thing I know I have students speaking Spanish words when they are telling me what they read."

Above the whiteboard was a bulletin board to which Stephanie had affixed separate posters listing various organizational text structures of informational reading and writing. Two posters listed the school's behavioral expectations and procedures for meeting those expectations. Next to those was a poster labeled S (situation) P (purpose) A (audience) T (task), which reminded students of how to attack a writing assignment. Students referred to this poster during the observed reading lesson, working in small groups to determine what writing format to use when proving that they understood the vocabulary used by the author of an informational text, as well as that author's purpose in 
writing it. Stephanie displayed student work and instructional materials on a large bulletin board that took up most of the wall space in the back of the room.

On arriving in Stephanie's room for the interview, which took place during her planning period, the students were completing a small math review sheet. Stephanie shared that she used this type of student work to keep previously covered topics fresh in her students' minds. Anchor charts offered students information to help them with their writing, math skills, and individualized Bloom's taxonomy verbs. The school district had provided the Bloom posters years before Stephanie started teaching; seeing value in them, she had asked the principal to have a set reprinted for her students. She stated:

We have graphic organizers up so we can refer to them when I have my kids think about their reading. Sometimes we'll do a reading passage; I'm like "Okay, let's look back there, at our verbs. We are going to look at two characters today, or we are going to look at two different articles on the same topic. Which verb should we use to help us understand what we are reading? So we are talking about different breed of dogs, and we have to decide which one we need for our families. Which verb can we use to help us organize the information we are reading?" So I'm always pointing up there when I am teaching, so they get used to the verbs and know which to use to help them think about their reading. Stephanie's room was small, but she used every bit of space not taken up by the desks. On three of the four walls of her room were four-foot, three-tiered bookshelves filled with bins containing single-setting books. On a separate bookshelf, title and author organized chapter books alphabetically. Stephanie's room had a class set of dictionaries and thesauruses. On a five-foot, five-tiered bookcase, she kept a class reading basal set 
purchased by the school, along with teacher resource materials that accompanied it. Students' class sets of writing and math books were atop the student lockers in the classroom. Next to the teacher desk was a kidney table used for guided reading and writing blocks. Behind the kidney table were additional sets of multiple copies of single setting reading texts used for guided reading. The books included short stories, poetry, dramas, and informational texts. Her classroom contained four computer workstations that she used for research projects. Next to the workstations was a Chromebook cart holding 30 Chromebooks; Stephanie shared these with her fourth-grade team for use in interventions and enrichment technology programs.

Stephanie was aware of the important connection between positive studentteacher relationships and increased academic achievement. One of her personal goals was to create an environment of trust starting from the first day of school. She called the first six weeks of school the most important part of the year, a time when students learn rules and expectations. Also, she made it a point for students to feel important, as if their presence added to the community. During the 75 -minute observation, students were observed five times talking about their learning and supporting each other through the learning process. During this time, Stephanie released students to work cooperatively. She did not have to manage behavior; instead, she gave students additional support and recorded student learning. Stephanie's collaborative setting and willingness to listen and adjust her instructional plans based on her students of color environmental needs, proved Stephanie had the beliefs of a culturally relevant teacher. 


\section{Stephanie's Culturally Relevant Pedagogy Analysis}

Academic success. When asked how she ensures student learning, Stephanie replied:

We use diagnostic assessments. Diagnostic assessments are comprehensive pretests provided by the district to help teachers know what their students need in regards to instruction for the quarter. These evaluations are a voluntary resource, which is usually left up to the school to use.

We [the school as a whole] don't do them anymore, but we [Stephanie and her students' resource teachers] use them. There are 18 questions on a test; we'll take one, or two, or three of those, cut them up, and use that as a basis to figure out where the kids are. Instead of feeling like they're taking redundant assessments, it's just like a little exit slip at the end of the day or lesson. So we use the formative assessments to guide us to figure out what groups we need to put our kids in.

Stephanie demonstrated that her students' presence in her classroom is essential so that students learn from one another and hold each accountable to their learning. This was evidenced by how Stephanie planned and directed students to talk about their learning together, write about their learning together, and redirect each other if someone got off task. Assessments serve as a means for her to know the effectiveness of her teaching and how she had students collaboratively learn. She does not use assessments as a way to label or classify students. She also described how she personally reflected on her students' assessments to determine her next step. Part of her reflection process takes into 
account students' home lives, cultural backgrounds, and attendance, as well as the resources that they receive. She described the process she follows when students are absent from school, speaking as she did of one student who that very current school year had missed one day each week. The school's social worker had worked with the girl's mother, but little had changed. Stephanie, reflecting on this, built into her daily schedule an instructional time during which she works with students who have missed assignments. Also, during the observation, when a student came in after the lesson had started, Stephanie gave the students an open-ended question for the table groups to discuss while she got the student caught up.

The table groups had a process for answering the question-a process, moreover, that was observed every time students worked in small groups to enhance their learning through conversation. Each table had a facilitator who started the conversation; this student was first to answer the question. Without having to be told or called on to do so, each student agreed or disagreed with a detail of the first student's statement. Then the second student gave his or her answer, and each student, again, agreed or disagreed. This process continued until all four students had shared their response and received feedback from their peers. Then Stephanie brought the students back together, and each table leader summarized the table discussion. Part of the observation protocol involved checking student engagement. The observation corroborated Stephanie's assertions, in her interview, that she had built a community of trust in which students could work together to determine the meaning of words.

Stephanie discussed her beliefs on how student "buy-in" is critical for learning. Because she believes that students from different cultures see the same experience 
differently, as the lead teacher, she must be cognizant of what her students are thinking about their learning. Her students used the Chromebooks for intervention and enrichment and used a school-designed Google Doc to track their formative assessments. Stephanie explained, stating:

They each have a student goal sheet that they've sat down and they've filled out with a resource teacher or me. The resource teachers came in and helped us with that, and we keep them in the drive-Google Drive. So every test and every assessment they've taken are looked at then compared to their last assessment. From this data, they create a goal of how they're gonna do better on the next one. We show them what they didn't score well on, so they know what to practice on. So when we're pulling them in reading groups, they're in groups based on ability. So if I have these kids that are struggling with the main idea and key details, that's what they're getting. Because why would I study point of view with them if they've already mastered that? So they're actually in groups based on ability, and it's just rigorous. Also, during this one-on-one time, students can share why they feel they did well, average, or struggled. Because we have built relationships, the kids trust us to talk to them about their learning. They know we want them to do well. So then they know what they need to work on, their parents got a copy of a goal, they signed it, brought it back. It's a big family trying to help these kids move on. Yeah-understanding keeps everyone a little more accountable. Stephanie displayed a binder of resources that the students had collected over the school year. These different resources had come from Stephanie, the ESL teacher, and the special education teacher. Stephanie had started designing resource binders for individual 
student needs that would help her give individualized instruction and resources for students to use when an adult cannot assist immediately. She believes that when her students see her, and when her team teachers give students the materials that they need to be successful, her students trust that their teachers want them to be successful. As illustrated in her interview and observation, Stephanie believes that conversations between students and with her often reveal things about her students that she can use to better their educational experience. As demonstrated in Stephanie's observation, she listens for student frustrations and success so that she can find materials to place in the binder. Her students often shared about activities that they enjoyed or described how what they were learning helped them with other things at home. This, she said, is how she connects the content she teaches to students' interest. For example, during the observation, she read the chapter book Fourth-Grade Fuss. Each student had a copy and followed along as she read aloud a story in which characters discussed preparing for picture day. Stephanie allowed students to share their experiences about picture day, talking in small groups at their tables about having getting ready for their picture days. They talked about where they shopped and what they planned on wearing. The whole time, Stephanie walked around listening to their conversations, contributing at times: She understood that sometimes children are the teacher and the teacher the student.

Cultural competency. Stephanie used her knowledge of her students to achieve success in the learning process. The time spent interviewing Stephanie helped provide insight into her views about teaching a diverse class in a school that educates 19 different nationalities. She explained that many things she does in the classroom have become habits. 
Stephanie's students were affected by the November 2016 United States Presidential national election. Traditionally, her students have focused on learning, but some children were concerned about whether their parents would be safe while the children were themselves at school. At times, Stephanie shared during the interview, her students looked to her for reassurance that they would be safe at school; specifically, that no one would come in and take them away. Her students also shared their concerns for their siblings, some of whom had experienced negative interactions in other classrooms. After two weeks of students' not demonstrating proficiency on their formative assessments, Stephanie stopped teaching and asked them what she could do to help. Overwhelmingly, they wanted to know to whom they could talk as a way of changing what people thought of them. Accordingly, Stephanie changed her reading and writing materials to focus on persuasive letters, and her students wrote to their state senators (See Appendix B). During the interview, Stephanie eyes watered as she detailed the process of helping her students find their voice and giving them an outlet, allowing them to feel as if they were making a difference. At the end of the persuasive writing unit, her students asked whether they could make and hang posters throughout the school that read "I Syria!" The principal supported the idea, and other teachers' classrooms joined their campaign. In Stephanie's words, "the school became united."

Stephanie created a rapport with her students that made them comfortable enough to communicate with her about their personal as well as their academic problems. Instead of acting out, her students learned to use words and skills practiced at school to solve problems. During the observation, students worked cooperatively and embraced instruction as a way to help them make a difference. 
When I walk around and listen to them speak to each other, I give positive feedback on how they support each other, along with the use of the standard we are learning. If I make it all about the teaching, they will get bored and not listen to me or anyone. When I let them know "I hear you," it helps develop the respect between me and my students.

Only rarely did students come to Stephanie when she worked with individual students. Once during the observation, when a student did not know a word, he whispered to his neighbor. A fellow student then pointed to the lesson on the SMART board and walked him through the steps required. When the helper went back to her assignment, the boy she had helped kept working until Stephanie called the class back together.

Critical consciousness. Students, Stephanie holds, must always understand why they were learning material. She encourages them always to ask "Why?" if her basic explanation was not good enough. She was observed saying, "Guys, you are being too quiet - we always look, then talk between the lines." Everything she teaches, she believes, must be relevant to her students so that they can apply what they learn. At the end of each lesson, Stephanie's students try to write about the topic or engage in a reflective writing activity so that they can think about how to use the information:

We just did a science lesson: "Okay, write and tell me what you did in your lesson and how you knew that motor actually ran. Where'd you hook the wires up?" It's not just looking at pictures and circling a letter-“"Oh, this is the right series or parallel circuit" - but you can actually tell me how to put one together. So we do a lot of writing (See Appendix C). 
Stephanie also believes that writing about what students learn is a way for students to take new information learned and retain it for future use. When students get to share their writing, she believes, they can see multiple ways of applying new information. Indeed, some students gain a different perspective on the lesson, one previously unavailable to them:

So now they have to apply [CCSS]. It can be as simple as challenging wives' tales about why things are the way they are. I remember when we read about snake charmers. Many of the students had seen movies or cartoons that showed someone playing a flute and the snake immediately obeys, so I asked, "Okay, so did you really understand why cobras [respond to the flute], and so you understand how snake charmers actually can trick the cobra? It's not just the sound of the flute, it's the vibrations that the snake feels." So they have to actually put this in their own words. Everything that we do, it's step by step by step. And I think this is challenging, having them write down what they did to make sure that they understand [the new reading information] and apply the standard while they write.

Stephanie's classroom had four different cultural groups, and her students spoke three different home languages. However, during the observation, no differences could be seen among the students. Her students read eagerly and willingly, openly sharing their thoughts and beliefs about what they were reading. Stephanie taught them how to communicate respectfully but purposefully. During the observation, when two students were speaking during silent reading time, a table peer touched one of the talking students on the shoulder, whereupon both talking students looked at the third student and then 
went back to work. It was evident that Stephanie had spent time talking to her students about choices and about communicating their feelings when confronted with an issue. Stephanie herself shared that she had spent the first six weeks of school teaching students how to communicate frustrations, fears, anger, success, happiness, and gratitude. She thought it important that teachers welcome their students' differences and incorporate their cultures and beliefs into the classroom climate. Other teachers, she said, did not see the same value in student differences that she did: At the beginning of the year, she could tell which teachers her students had in the previous year. Students who have not been a classroom of trust take longer to build confidence, which must be developed between teacher and student as well as, and all the more so, between student and student.

Stephanie highlighted the importance of her students feeling safe about everything they talk about in the classroom, and must know that their differences are positive: When we wrote our immigrant letters, they [the students] were talking about, "You know, it is so neat to sit next to someone that speaks another language, 'cause now I'm learning." They're actually teaching each other. There is no majority, because actually, you're learning from more of the minority differences. We're actually learning. When you keep doing things the same way, you're not growing ... we have a Post-It note board where they can put Post-It notes up there about things that you do in class. One of the things that one of my kids wrote [was] "Ms. Stephanie always has great pep talks." We talk about everything in this class. It's just reality.

The Post-It board is a place for students to reflect on their learning, compliment or challenge a friend, ask a question, voice a concern, make a request, or leave an emoji. 
Stephanie pushed her students to know that their views, beliefs, and feelings matter. She taught them how to express their message and encouraged them to do so. In small groups, she taught them to listen to different perspectives. Also in small groups, she taught them how to use available resources to agree and disagree.

\section{Summary}

Stephanie ran her class in a more traditional format; relying heavily on the basal series to decide which materials she would use to teach the Reading CCSS. As a culturally relevant teacher, she extended the basal series, having her students talk and write about what they read more than her professional learning community (PLC) or basal series suggested. She always required them to think about what they read, then ask whether their thinking had changed because they had read the text. She encouraged them to then use what they had learned from their community experiences to accept the text, add to the text, or reject the text.

Moreover, Stephanie was in tune with the needs of her students. She understood that when her students' emotional needs were threatened, their lack of engagement was not disrespect but rather signified a teachable moment during which she could teach them how to use in their community what they had learned in school. Stephanie also expected

all her students to achieve. She used formative and summative assessments to help herself reflect on her own teaching, taking responsibility for low scores when they occurred and adjusting her teaching against her PLC plan to make sure her students were successful.

\section{Claire: Fifth-Grade Teacher}

Claire (a pseudonym) is an engaged White female fifth-grade teacher who was at the time of this study, in her seventh year of teaching. Her educational background had 
begun with the awarding of her bachelor's degree in elementary education from a public university in Mississippi. She was currently working on her master's degree in literacy and reading from a local private university and had been teaching in an elementary school setting for seven years; she had worked at her current school for two years. She had taught fourth- and fifth-grade levels. Claire, who is the mother of one girl, lost her mother when she was in fifth grade, and this influences how she sees her students: Her teachers at the time helped her through the loss of her mother. Claire attended a local private school for grades $\mathrm{K}-12$. In this intimate and bounded school setting, all her teachers knew of her experience. Her teachers individualized her learning experience to make her feel safe when her "world changed out of nowhere."

\section{Claire's Classroom Design}

Claire's classroom was added to the original school building eight years ago. At the time of this study, she was responsible for 29 fifth-grade students. Claire arranged her students' desks in groups of four to five. At the front of the room, an area rug atop the tile floor was big enough for her to meet with small groups of children. She had a SMART board, a document camera, and a mounted projector all connected to her laptop computer. In the front left corner of the room she had a four-computer workstation designated for research. She had a reading table in the center of the left side of the room. Claire's classroom consisted of a window that went halfway up the wall to the ceiling, letting in much natural light. In front of the window were two dish chairs atop a small area rug. A five-tiered bookshelf held fictional and informational chapter books, magazines, comic books, graphic novels, and higher-level picture books. A door led directly outside. In the back of the room were upper-level flat-faced cabinets and lower-level cubbies for 
students to hang up coats and backpacks. On the right side of her room was a dry-erase board on which she had written a daily schedule, in-school activities, differentiated homework assignments, a classroom management list for resource teachers, and a writing workshop schedule that consisted of independent writing, meetings with the teacher, typing, and peer editing. In front of the dry-erase board was a kidney-shaped table. When asked where in the room she held reading workshop, she said, "The floor," then elaborated: When the building had been renovated, each room had been assigned furniture that was required to stay in that room. Groups of students worked there, or a resource teacher used the table to support students. Claire's desk was next to the whiteboard, along with additional storage.

Many anchor charts were placed around the classroom, covering many different skills. She stated that she used anchor charts "as a reminder of what we have learned" (See Appendix D). Plus they help connect the various content areas." Claire used crosscurricular activity during the observation when a small reading group was reading Sarah Plain and Tall. She had the students review the cover of the book to determine the period of its setting. Claire's students used strategies to answer the question. When she asked them, "What types of conversations might Sarah's family have had while eating dinner?" the students did not answer. One student turned around and referred to a social studies anchor chart to talk about the end of the Civil War and westward expansion. They continued to speak of the perspectives each character would have toward the Civil War and westward expansion, with students using the text to support their answer.

Claire did not have posted rules: She felt that the word rules caused discomfort for some of her students. Instead, she had a classroom pledge: 
We the kids of Ms. 's class, in order to form a more perfect class, promise to be responsible for our actions, make others feel safe, treat everyone with respect, and have each other's backs, do ordain and establish this constitution for Ms. -'s class.

For the first six weeks of school, her class breaks the pledge down into small sections, modeling, writing about, reading about, and reflecting on each of its components; this process, she said, helps build trust between her and her class and helps build relationships among her new students. As Claire stated,

I guide them to take responsibility for each other's learning. Even when one person steps out of our circle, I know another student will remind them what we are about. I can leave the room and come back. I can't tell I was even gone. That is students holding each other accountable, and it makes my job easy and fun all at the same time.

Claire intentionality towards building a climate and culture of trust was seen during the observation. Claire sat at the front of the room, on the floor, legs crossed, and worked with small groups of children. Her position in the classroom left a lot of blind spots but she did not look around. Her room was almost silent as children worked on the computers, iPads, reading books individually, reading books with partners, or responded to one of many paper assignments.

Claire found that her students worked harder when they could get up and move. Instead of having big blocks of reading and math, she had whole-class instruction and small-group instruction. The whole class spent between 20 and 30 minutes per subject per day. On her SMART board, she posted the small group reading schedule, listing each 
student's name in the group as well as the standard that he or she would be covering. As evidenced during her small-group instruction time, Claire differentiated her learning. Each student was assigned a CCSS group and a reading fluency group based on his or her reading level. In the latter group, children read books at the same reading levelsometimes even the same book, depending on the plan for the group. Her small-group instruction involved from one to six students at a time.

On the storage cabinets located on the back wall, Claire posted math performance tasks with the corresponding math book page. When students were finished or needed to take a break, they could get a math performance task from a folder, complete it, and then take it to the back of the room and check their answers. She posted student Reflex Math (a computer-based program that allows students to practice their math facts) certificates next to the math performance tasks. Claire explained:

It is important for my kids to see me acknowledge their hard work. Sometimes they don't want to work. They are tired and do not see why I am asking them to do "boring things," so they have to see me get excited about what they do.

Also on the back cabinets were students' artworks depicting each of the amendments in the Bill of Rights (See Appendix D). Claire stated:

I try to make everything I do relevant. It is hard for Brown students — or even any young student, but in particular, Brown students in this political climate- to believe that the documents that govern our nation matter and do make things better. So when students make choices, we refer to those posters to remind us the rights of human beings. But like I said, [my students] challenge me when they are 
scared. I just try to tell them that they matter and they can change anything they feel is unfair in their country.

At the beginning of the school year, Claire had students design a paper quilt that when put together showed what they had in common as well as their differences. To the unknowing eye, it looks like larger individualized squares with smaller hexagons of different colors. However, each hexagon is a question, and each color represents the answer. Once the quilt was posted, students were able to see their commonalities.

Throughout the interview and when she described the elements of her room, Claire openly shared, seemingly welcoming questions about her practice. Claire cried many times throughout the interview. Interview questions designed to explore her instructional motivations caused the most emotional reaction. She reiterated 25 documented times that she "cares" about her students" future. Also, when she gave specific examples of why she did what she did to motivate her students, she cried as she reflected over their responses. So with her demonstrating the need to include culture into her instruction and her sincere feelings towards her students, it became clear that Claire was a culturally relevant teacher.

\section{Claire's Culturally Relevant Pedagogy Analysis}

Academic success. Claire believed all students could succeed if they understood what was expected from them. This is evidenced by her interview when she stated that she starts each day by reviewing the plan for that day. During this process, she tells her students what she expects from them by the end of the day. She describes her teaching environment as being "loose," having found out during her first year that "the more you try to control like a tyrant the more likely you will lose your students." She sees it as her 
responsibility to make the students the best they can be. She added that just "saying the words" is not good enough for her students of color: She believes that this comes from past experiences of teachers' having told students that they care but not having given their all to help those students learn. Part of her morning routine involves talking about what can prevent learning from happening and what they can do to make sure that learning continues even when it might be easier not to work. She has a morning meeting in which she and her students cover the goals for the day. She also reminds them of past problems and of what they can do to address them before academic or emotional frustrations get out of control:

I share with them my expectations for learning and behavior .... I then tell them that 'I'm gonna be the first to have your back, but I'm gonna be the first one to get on to you when you're not meeting my expectations" ... . I say to them, "Let's talk about the good choices you can make, let's talk about the best self you can be." I really emphasize that everything is a choice. It's not "I have to do it [a way of learning] this way," because it's "I'm choosing to do it this way, and this is why I'm doing it this way." And so in this classroom, it's very laid back. I don't have a lot of discipline, because I don't need to, when I set those expectations in August and we spent six weeks explicitly building community and three months getting to know each other at this point of the year, so everyone knows I am about learning. And they know I expect them to be about learning.

Claire uses a teacher Facebook page that is private, shared only with her class's families. She uses this page as a way to communicate with her families and to stay abreast of the need of her students' community: 
I use the page to post homework, upcoming school events, ways that parents or family members can support us, or just anything they need to know. The fun stuff is when I take pictures of us and post them. I let my kids put the description of what we are doing. I get great comments from my families.

Claire shared that she learned how important family connections are when she studenttaught in Mississippi: Her students' parents did not trust her, because she was White, but she let them know that she cared by keeping them informed about their student's academic progress:

There are two ways to tell a parent about their child. One, your child is getting this grade. Or you can write or call them and tell them that their child is amazing because of how they showed they learned this material.

She shared that at first, the parents thank her and then hang up, but she said that she thought it important to have her students' parents support if her students were to learn. She did acknowledge that these African American parents saw her as a "young White blonde girl trying to tell them about their kids." She did not take offense at parents' views of her, however, but rather saw them as signifying the process through which she must go to build relationships between herself and her parents:

Then they got to know me, and it was, "Okay, we know you, we love you, we appreciate you, we appreciate what you do." And there's not a racist bone in my body, and I think they saw that, and they saw how much I loved their kids and wanted them to be their best .... A teacher wanted the best for me when I was lost, so it was important for me to give them same that was given me. 
During the interview, Claire cried openly when speaking about how important it was to her that her students learn and that her students' parents know that she believes in their children.

Claire knows her responsibility as a teacher is to "pull knowledge out" but she has to know what her students already know and what they need to learn (Ladson-Billings, 2009). This evidenced by how she uses student work and assessments to decide the best instructional path to engage students in their learning process. To ensure that her students are prepared for testing of their CCSS knowledge, Claire uses three data points. The first, Measures of Academic Progress (MAP), is a universal screener employed by her building. "MAP testing is a good place to start, but I have found taking a test on the computer can sometimes give misleading results, so I do not let that be the only way I decide to group my children." Her second data point came from her fifth-grade team use the district's summative assessments as a way to grade their teaching:

We have a strong PLC, and we make common formative assessments weekly. But the district assessments let us know if we are on track or not when we design questions that are similar to the state assessment. It causes us to talk about our teaching and how our students are progressing.

However, Claire got her best data point from making anecdotal notes on her students: This is my bible. I keep this clipboard with me all day long. I should empty it out and clean it up more, but I don't. It's full of notes, checks, stars, anything that goes on that day. This is my formative assessment, and it's "Are they getting it?"- as simple as are they getting it, and if they're not, then let's go over it again tomorrow. 
Claire confirms student mastery when a student independently uses a standard three times in a row. She knows then that the student is ready for the district assessment and the state assessment.

Cultural competency. Claire describes her family as well-to-do. She went to a private school from kindergarten through 12th grade. Her father sent her to a public university in Mississippi, for which he paid out-of-state tuition and all other expenses as she earned her degree:

I grew up privileged, and I never wanted for anything. I was very fortunate to have a father who didn't give me everything — and that was wonderful, because I was surrounded by kids that got everything. You know, I was pulling my bright red GMC hand-me-down pickup truck next to a dark green Jaguar when I was 16 years old. So I did have a privileged upbringing, and I've been a public education teacher since I started my career. I started teaching in Mississippi—in rural Mississippi, actually — and that was eye-opening for me.

I never heard anyone use the "N" word in my life—nobody besides rappers [chuckle] —and I go down to Mississippi and I hear this little White girl with pearls on and lipstick and hair fixed, and looking just adorable, seems like the nicest girl you could meet, said it in a racist way. And I turned ... 'cause growin' up in , my black friends looked and acted and talked like me ... and I turned and looked at her, and I laughed, and I was like, "You're kidding, right?" And she wasn't. And they looked at me like I was weird. And I was like, "We're in 2003. I've never even heard my grandmother say that. Who are you? Who are these people?" That really—it kinda lit a fire under me, and 
when I walked into my first big lecture hall, it was segregated, by choice. All the black kids sat together. All the White kids sat together. And so me being me ... [laughter] I went and sat right in the middle of all these black girls, and they looked at me like I was crazy, and I just sat there and got to know them. And my dad laughs at me. He tells me that I'm his peacekeeperthat I'm gonna go save the world one day, but I cannot stand people being unkind for those reasons. And being privileged and teaching in public education, I think is the best thing for me .... A lot of these babies, they need me and I need them. I'm just gonna cry through this whole interview.

Asked to elaborate on the word need, Claire responded:

I come from the world that holds influence. It's not that I am trying to tell them that my way is the right way, but they need to know what they are going to have to deal with ... . I feel that I have been given a lot. I want all my kids to make it. Claire uses published texts as read-aloud texts that relate to social studies content. For example, she used Patricia Polacco's book January's Sparrow to teach character point of view. When she read the book, all her students were on the side of the runaway slaves, the Crosswhites. However, after having her students read about and research the causes of the Civil War, she had them take on the persona of Patty Rollers and write a letter to a friend about the troubles they were having with their slaves. Her students struggled with the assignment: They were upset, and some even disengaged. However, Claire had built a classroom community based on equity, established community of learners, and incorporated students' community interest and concerns that students complied with the assignment. This was proven in her interview when she shared her 
personal experiences with racism and how she needs to prepare her students to maneuver racism in their community.

[Through] a lot of conferencing and tapping into our established trust, I had to convince them this would help them in the future when they come across a person who thinks differently than they do .... When they saw that, and they could actually get into the minds of someone that they didn't like and that they didn't wanna be a part of, that was meeting the standard for me. Because that was them really pushing themselves and making it a little uncomfortable. And so as I walk around, with my clipboard, it's, “All right, they really got into that character. They really understood what I was asking them to do, they've met that standard. When asked what student cultural means to her when teaching reading, she said, "It is being aware of where your kids are from and what they are dealing with." The African American students where she teaches now, she said, are different from the African American students whom she taught in Mississippi. Even the African Americans in the two different schools in the district are different. When she taught at a predominantly African American school, most of the children were from the neighborhood; some did not leave the community. Accordingly, the school was purposeful about building relationships with community organizations to give the students what they need.

Claire has high hopes for and expectations of all her students, as evidenced by the posted student created community building activities, posted learning expectations, differentiated instructional plans to meet individual needs, and a personal connection that encourages students to be their best. Claire shared in her interview that she sees her part 
as being able to give her students the tools they need to become community leaders and to let them know that they are destined for success despite any situation they encounter. During the observation, Claire provided her students with rigorous and challenging learning opportunities by asking them to synthesize social studies standards with reading standards. Claire used flexible instructional grouping during the small group literacy block. Claire saw these groups as being temporary, serving only to meet the immediate CCSS literacy standard. She explained that when grouping is done around an academic standard, students know that it is not about who is in the high, middle, or low group. Because she had built a community of learners and did not use assessments as a way to punish, she said, her students worked hard to show her what they knew.

\section{Critical Consciousness.}

Claire's critical consciousness came from her experiences as a child when her mother passed. She remembers her teachers and friends not understanding her grieving process. She reflected on teachers and her friends telling her she was using her mother's death as an excuse to not work. She shared when she student taught in Mississippi, teachers would make excuses on why their students did not learn. She felt like she was a little girl again with a teacher telling her she should be ashamed of herself for using her mother's death that way. Her father worked hard to give her a good education. When the teachers in Mississippi said the exact thing about their students, it made her realize that "a teacher does not know what their students' lives are like outside of school." So Claire sees her responsibility as her students' teacher to include,

We have an obligation to teach the next generation kindness, and compassion, and inclusion. There is no need for segregation. There's no need for assimilation. It's, 
let's get together and enjoy these different cultures, and learn from one another.

There are so many things we can learn!

Claire's critical consciousness allowed her to see the value in different perspectives and she uses diverse viewpoints to teach Reading CCSS.

Claire demonstrated she understood that knowledge is continuously recreated, recycled, and shared by teachers and students with how she helped students make since of the events occurring in her community. For example, Claire shared that after the November 2016 national Presidential election, her students were scared and hurt by the results. Many students did not understand how people elected a person who did not support immigration. Claire used this opportunity to teach different points of view. She had already taught the Revolutionary War. During those lessons regarding the causes of the war, students had to understand King George III's point of view, along with the colonists' point of view. After the election, Claire went through the same process of helping students to understand why the new president elect felt and acted as he did. Students researched the president-elects experiences and connected those experiences to his platforms. Claire shared the students did not come up with a unifying answer, but all her students could understand the president elects actions from his point of view. "They learned what it meant by the phrase We'll have to agree to disagree. Which is just as an important lesson as any Common Core standard."

Claire understands that knowledge needs to be viewed critically; this was illustrated and observed when she had her students write about why they read. "I try to have them question what is being said without using the obvious words. I find the standard that talks about theme is the best standard to get students thinking." During the 
observation, Claire was observed telling students to look at the words that were used. These words were their vocabulary words for the week. After their vocabulary quiz, students were directed to pick five of the vocabulary words and design a character map (Appendix E). Students first worked independently then shared how they sorted the words. Then she asked the students the question, "If the character you have in your hand right now was told that the way they made money was now illegal and would have to stop, how would they react?" Students explained how the vocabulary words allowed them to know the thoughts of the character. Claire was showing her students how to look past the surface level of an author's text to determine the true meaning. She left them the goal, "The next time we meet I want you to bring me a paragraph of something you are reading and tell me the message behind the message.” This task was written on a small piece of paper that students glued to a sheet of paper at their desk.

Claire helped her students build necessary skills to operate in a media rich society. Claire shared how she believes in using different media to comprehend. "I like to use historical pictures for the students to digest." She gave the specific example of the The Watson's Go to Birmingham:

I saw my students going through the motions of understanding the texts but they were ignoring the pictures. So I would start each lesson off dissecting the picture and then reading the text. Students had to prove to me that they understood why the author used the picture to bring more meaning to what they were reading. She also uses video to teach her students that they have to analyze what they read or see on visual media. 
We watched America: The Story of Us. [I] love that documentary, but it leaves out so much. So I really try to go back and look at the facts, the real facts, the true facts, not just what our history books and what the higher-ups have set in front of us. We talked about why Lewis Latimer wasn't in that show, we talked about why he wasn't in the 'Social Studies Alive' book that we read from, but he was in our other textbook. So we actually compared the textbooks and looked at the dates. One was newer, one was older and that was the biggest difference there. We've talked about Nazi Germany, we've talked about people in power wanting you to hear and read and see certain things in order to manipulate the way you think. I encourage my kids to question that constantly. I have some very powerful voices in this room that will call me out in a heartbeat and I encourage it. And I tell them, As long as you're disagreeing with me in a respectful way, let's disagree all day. We can pull it out in a debate. But especially with African-American history since so much of it has been distorted or just left out.

Claire shared she has to research any science or social studies lesson before she delivers the instruction. She said she does this to find relevancy to her students' lives. She shared that when she worked in Mississippi when the only thing she talked about were how White people discovered everything and they were the only ones to write books, her students lost interest. However, when she showed them inventors, writers, activist, or community members that did the same thing that the textbook discussed, her students were more engaged. So now inclusion of different culture contributions or different point of views based on cultural interest is part of her lesson design. 


\section{Summary}

Claire ran her room using a fluid cooperative model. Even though Claire's PLC met weekly to discuss student progress, she used the materials that she felt would reach her students. She did not depend on the social studies textbook to teach the social studies standards but rather used picture books and chapter books to put content into context.

Claire is a culturally relevant teacher who uses various assessments to measure student growth: She finds her anecdotal notes more useful than multiple-choice tests. She also realizes that as a White teacher, she must earn her students' respect. She did this by acknowledging her students' experiences and giving them opportunity to use CCSS as a means to make a difference in their community. Last, she acknowledges the societal systems that that work against her students' cultural upbringing, showing her students those systems and teaching them how to use the standards to gain a voice against those systems.

\section{Charles: Fifth-Grade Teacher}

Charles (a pseudonym), a married African American male fifth-grade teacher, was in his sixth year of teaching at the time of this study. Charles was part of an alternative certification program designed to increase the number of African American teachers in the district. He received his certification in $\mathrm{K}-5$ elementary education and has a master's degree in supervision and leadership. Education is a second career for Charles, who worked in business after graduating from a public university in Mississippi. In addition to being a classroom teacher, he was the sponsor of the father's volunteer club at his school, and he volunteered his time to tutor students during the week. When he thought back to why he became a teacher, he noted that his mother was a teacher; he attended the school 
in which she taught. He described how close the teachers had been with their students: Educators and students lived in the same community, attended the same churches, and shopped at the same stores. The community was close, and he had relationships with all his teachers until he graduated high school.

\section{Charles's Classroom Design}

In Charles's classroom, 29 desks were placed in groups of four or five, and a teacher's work area sat behind a half-wall. In this space were multiple sets of textbooks. A tabletop tiered shelf system held various articles, short stories, math sheets, science sheets, graphic organizers, maps, discussion cards, and assessments. Charles hardly goes behind "that wall," however: It keeps him away from his students. He called its very presence "bad planning."

Charles's room is small, so he used every space available. He had historical documents and banners on the front wall, which also held the SMART board; a ceilingmounted projector mirrored Charles's laptop on the screen. Next to the SMART board was a dry-erase whiteboard that had the day's "I can" statements based on the CCSS. The standards on the day he was observed were as follows:

Writing: I conduct a short research project that uses several sources to build knowledge about the topic.

Reading: I can use details from the text to determine the author's point of view about the subject in an information-reading piece.

Math: I can represent and interpret data.

Social studies: I can identify the causes and explain the events that caused the Civil War. 
Charles said that he tries to make the standards build on one another: "It is easier to teach social studies in reading. Sometimes [students] don't know that they are reading something in reading that will prepare them for social studies." Charles went on to explain that children in elementary school typically follow the truth presented by someone else. It is my job to make them think about the "bad guy" so they can understand why society says they are bad. Not everyone is bad that has been determined to be bad. At one time, black guys were regarded as bad guys, even though people don't say that out loud anymore—but police brutality proves that society still feels African Americans are not on the same level of humans as other racial groups.

Charles posted a daily schedule. He posted class expectations on the back wall, but because the students' desk ran perpendicular to the large walls, all students could see the front and back walls without any obstructions. The room contained two large bookshelves that held numerous picture books, novels, basal readers, magazines, reference books, and old newspapers. A three-tiered bookshelf held math manipulatives and a squirt water bottle that students used to clean their work areas and the whiteboards. The back wall also had an "effort meter" poster that detailed how students' actions determined their effort. On the back wall, a whiteboard held various questions that seemed to be cross curricular. Charles puts these questions up so that when the class is studying one subject in a different content area, students can see how one subject could help them answer another. Anchor charts and student work covered the walls. All student work displayed some sequencing activity, regardless of subject. Sentence strips covered different walls in different parts of the classroom. On one set of sentence strips, students 
detailed the sequence of events before the beginning of the Revolutionary War; another set depicted a sequence of events in a fiction chapter book. Also in the back of the room were four desktop computers. Next to the computers was a storage container that allowed each student to have his or her own "mailbox" in which to receive important papers or graded papers from the teacher. Atop the storage shelf was a box labeled "Homework."

Charles believes that the use of different materials is essential for assessing students' learning. For example, Charles had students research famous African Americans, then design a cereal box with the information they learned. On the front of the box, students put a large picture of an African American; on the back, they affixed or drew a picture showing why that person was famous. Under the picture, they wrote about the event or events that made that person famous. Moreover, on one side, students listed events from the famous person's life before he or she became famous (See Appendix F). On the other side of the classroom, students provided arguments for why that person deserved to be famous. Charles's class did a gallery walk of all the projects. He had given them questions designed to make them think about their peers' projects; they were then allowed to ask each other about their work product.

Before students proceed to talking about one another's work Charles has built relationships. He does this using the first social studies unit, which has students analyze different cultural backgrounds. Charles reflected on how many teachers just "gloss over this unit as if it isn't important." He stated:

I feel this is how I get to know my students and my students to get to know each other. I always tell my students my most important tradition for my family is to eat chitlins for Thanksgiving and Christmas. Now, most the White and Black kids 
know what I'm talking about. They like to tell the kids from other countries what I mean about chitlins; then it becomes them against me. But there is always one kid who takes my side, and the next thing you know, a family is born .... I do this every year, and every year the same thing happens.

Charles went on to explain how he tries to connect school expectations to the traditions that a family has: His school is a Positive Behavior Interventions and Supports school, so each classroom has the same set of expectations, which it calls a "creed." Charles breaks down the creed as if it were a respected family tradition: "For example, I take ownership of my responsibilities and actions. The word ownership is part of our ROARS [Responsible, Ownership, Appropriate, Respect, Self-Control] Creed. How I make that a tradition is that if we wrong someone, we say, 'My bad.'" Charles reiterated that it is important to connect everything he does in the classroom to the curriculum. So if they look at the creed as being social studies, then they are learning what it takes to make a tradition. He also shared how important it is for him to allow his students to know who he is - and that they have a lot in common:

I think I connect with them when I tell them about the things that I have experienced, the past teachers that I've had-you know, even the teachers I felt like I didn't get along with those teachers. I share how I was able to deal with those teachers, how I was able to be able to focus on my classwork, getting past thinking like this teacher because I have those teachers, too. I was thinking I don't think that teacher likes me, but I had to come to school and do my work. I tell them there are certain things they have to deal with—like a coworker: I have to 
work with them. I think they understand when I break it down to them. It's like I've been through the same things you all have, as the model student.

Charles's classroom was designed around collaboration and mutual respect among students. Charles has built his classroom strategy around what he knows about his students: Student collaboration is a must if his students are to learn. He encourages open communication by making himself vulnerable, allowing his students to know him as a person. He uses his background as a way to earn his students' respect. He also believes that peer learning, teacher as a student, and students having opportunities to critically think about what they read in reading and social studies helps motivate his students to dig deeper in topics of study.

\section{Charles's Culturally Relevant Pedagogy Analysis}

Academic success. Charles shared he did not rely on worksheets, tests, basal series materials, or publishing companies materials to determine his students' academic ability. He demonstrated during his interview and observation that he believed students need exposure to different types of materials to pull knowledge out (Ladson-Billings, 2009). Even then, when students produced work, it was more for self-refection than labeling students by their academic ability. As evidenced by the interview and observation, Charles believed in differentiated instruction to ensure student learning. He designed his assessments so that each child received the format that allowed them to exhibit what they had learned. The assessment formats that were observed and discussed was small exit slips, discussion prompts, reading and answer comprehension questions, and a reading response journal. Charles looks at his teaching as an inverted triangle where the top portion will master with his day to day instruction and the other percentage 
receiving additional help in purposeful small groups, one on one help, and assistance from the various resource teachers.:

If I did my job, then at least $85 \%$ to $90 \%$ of my students will have mastered the lesson's "I can" statement. Then I look at those students who need the additional support, and I make sure to give them the individual time they need.

During the observation, Charles used students' independent reading time to work with students one-on-one. Also, when students worked in small groups, Charles assisted those same students once more, helping them work through the group process.

Charles also knows that his students learn best when they get to talk about the topic. This, he believes, builds background knowledge, allowing students to apply what they know to what they are learning. During the first part of the year, Charles teaches his class how to discuss a topic:

At the beginning of the year, the only thing they are good at is arguing. I have them model how to disagree and even how to agree. You never know what is going to come out their mouth. We go over the different phrases a person that shows respectful disagreement and agreement use when defending their argument. When you teach different cultures, you have to be careful not to disrespect where the kid comes from.

Charles had his students participate in peer conversations for 43 minutes out of the 80minute reading block. This time did not include a 20-minute whole-class discussion during which students responded to his whole-class questions; this preceded the peer conversation time. 
Charles believes that the best way to ensure student achievement is to engage students:

I actually start thinking about what type of questions ... are going to get them thinking about the text: questions like instead of saying, "Just read the text," I say, "When you read, think about how this character would feel if they had to live forever in an igloo." Now, there isn't an igloo in the story, but it takes a certain type of person to live in the cold like that. So they have to learn about the character to be able to answer that question.

Charles went on to note that textbook materials do not go deep enough to make his students care about what they are reading.

When Charles reads student responses, he focuses on how they word their argument. Indeed, when they first enroll in his class, he must teach them how to write an argument:

They use to beg me for a worksheet. They would tell me how their last year's teacher would give them a worksheet. I think worksheets are the surface-level type of assessing. I want to know how they think and how they see things around them. So I give them these writing prompts, and I learn so much about them. I can see their grammar skills, their idea development, how they use text to support their answer: Can they tell fact from opinion? I really know who they are as a student ... . I give them examples of how their work should look when they are finished .... They keep those examples in the binder and pull them out if they need help writing. The main thing is I know what they know through their writing. 
Charles uses the district assessments to help him identify what his students know, but he does not make a big deal of these: "I see biases in the vocabulary they use." When he sees questions that are going to trip up his students, he jokes about how his kids need to teach the test makers how to make an appropriate test that lets kids really show what they know. He uses vocabulary "word clouds" to help his ESL students understand concepts. Charles stated:

A word cloud allows me to put synonyms, antonyms, Spanish words, or Vietnamese words. I try to hit them with the words they are going to see when you look at those proficiency and diagnostics. And you're not allowed to review the vocabulary. You don't have a chance to go over that vocabulary, you know, to explain what the test vocabulary means. You've got these vocabulary words, so especially on the reading test, it's not any particular content; it's just the skills you want. You've got content and vocabulary words that are dealing with something beyond their capacity. It sets them up for not being successful. Vocabulary does not mean my kids cannot comprehend; it means they do not understand that particular word that makes them feel bad about themselves. It sets them up for not being successful. I know all my kids are successful.

Charles tries to connect all content to some type of text that he can relate to social studies. For example, when he taught about the Revolutionary War, his main text was George versus George. Charles designed four different projects: a research paper, a flyer, a recruitment poster, and a PowerPoint presentation. Students got to choose their project, but he determined whether they would be pro-colonist or pro-king, then gave them a rubric outlining specific expectations for the project: 
So they got to choose what to read. I had help from the ESL teacher and the librarian. I believe learning is moving, talking, and a little arguing .... On that proficiency, I had $85 \%$ proficient or distinguished. The other $15 \%$ were apprentice. I was really proud of them and the work they put into their projects.

Charles shared it was important for student to have specific expectations for all assignments:

You have to let them know what you want. If you just tell them, I might as well have spoke it [the assignment] to no one - meaning they never hear me when I just tell them. If I tell them, "Good job filling out the whole graphic organizer," now they know what I want, and they feel good at the same time.

Charles went into each teaching moment knowing each cultural group could perceive his expectations differently. So he was intentional in giving specific directions and giving examples of what was expected from the students.

Cultural competency. Charles prides himself on taking the time to build relationships with his students and is proud of the relationships his students build among themselves. He has made it a priority to create a culture of respect among his students. $\mathrm{He}$ reiterated that respect should be given and received on a daily basis in every aspect of students' educational experience. Charles himself showed respect when a girl was speaking off-topic to a friend during the small group work time: Charles did not berate her but rather tried to redirect her to her work; in response, she talked back, telling him that she was working. He did not stop what he was doing but rather continued to work with the individual child. After a few moments, he walked over to the table and went over the classroom creed with the girl's group. He then gave the group the chance to talk about 
how they speak to one another. The girl apologized to Charles immediately and then apologized to the group for having stopped the learning. Charles and the group accepted her apology, and they got back to the discussion.

Charles has taught his students that no guest should enter the room and leave without feeling respected. He is proud of his students and wants other people to know how smart they are. He reminds his students that when they leave the room, they are his representatives: Their behavior outside the classroom is a testament to their personal character as well as the character of the class. This culture of respect allows his students to monitor their behavior during small group and independent work times.

During the observation, Charles's class participated in a fire drill. When the alarm went off, they knew exactly what to do. Charles led the group, never looking back to check their behavior. They walked quietly, stood where they were supposed to, and walked back into the building the same way. When they came back in, they went back to the group work in response to a simple direction: "Okay, guys— get back to work." He does not fear missing days, because his students are scholars; he tells them this regularly.

Charles feels fortunate to teach a diverse classroom with an array of beliefs, customs, expression, and personalities:

The kids are mixed together. I love to see the different types of kids together. I didn't have it like that. Like I said, when I was growing up, when I went to second grade, I was with White and Black kids. Then they closed the school down. Since I lived on the other side of the track, the black track, I went to the other school, which was Black. The White kids went to the other school. The White kids went mostly to private school. It was a Catholic school - it was a private school. So the 
kids would say, “Oh, you live on the wrong side of the tracks." I didn't feel that way, but I was little, so I didn't really know how to feel about it at first. I was in third grade when that happened. I'll never forget when that happened. So in my room, we don't have the right side or the wrong side; we have the learning side. At the beginning of the year, Charles tries to learn unique things about the different cultures in his room:

As you can see, I like to eat—and I tell my kids the same thing. Next thing I know, I'm getting authentic tamales every once in a while. My student tells me that she told her mom that I like to eat, so she gives me leftovers.

However, he knows that connecting to different cultures is about more than food. Some of his Hispanic students, for example, became frightened after the November 2016, national Presidential election. He became aware that it was relevant to his students because he heard them talking about what might happen to them. When he did, he allowed them to break from their assignments to write letters to their representatives. In doing so, they felt empowered; the process was therapeutic for them:

They felt like they were doing something. I think it is because I always have them write like they are part of a historical period. I always tell them that there is power in their words, so they made me practice what I teach them.

Charles feels that his strength as a teacher of students of color comes from thinking like the students. He said that he sits back and watches what they do. Because he is sensitive to how they lives are outside of school and pays attention, he believes, he gets a lot out of them: "When a teacher starts to chastise them, all you get is lip back. But when you listen and makes learning engaging and relevant, [the students] are on your 
side." He said that the way he connects everything to history makes it relevant to his students. Charles then encourages his students to make additional connections through research.

Charles shared throughout the interview that different student cultural groups could not be given a blanketed instructional plan. He believed that having them work in small groups allowed them to learn about each other and then support each other. Also, he used specific feedback to help define what he wanted. He had stated that Standard English vocabulary could be tricky for his students.

Critical consciousness. Charles feels that the best way to get his students thinking is to ask questions. During the observed lesson, students considered whether certain people deserved the title of legendary, including current personalities such as Lady Gaga, Little Kim, Stephan Curry, LeBron James, Little Wayne, Bruno Mares, and Miley Cyrus. Each table had to decide whether each person was legendary, then provide a collective argument supporting its answer. Charles never gave his point of view about their arguments but rather encouraged each group's response.

Then came historical figures: Martin Luther King Jr., Andrew Jackson, Squanto, Pocahontas, Sequoyah, and Sacagawea. On individual slides, Charles displayed a question mark behind the person's name, and students were encouraged to argue about whether the person deserved to be considered legendary. Students were engaged, and each table spokesperson was ready to defend the table's position. At one point, Charles started to move to another slide before everyone had shared, and the class reminded him that every student has the right to express his or her voice—so he continued to let each table share. 
When the time came for students to work independently, Charles used various sources to help his students research controversial people and propose arguments about why they deserved to be considered legends. Students took eagerly to the task. While students were reading silently, they used several different items to take notes: pencils, colored pencils, various colors of highlighters, and sticky notes. Students reading copied articles used pencils, but students reading books used sticky notes; after they had finished their books, they placed their sticky notes on lined paper and put them in their binders. If they wanted to use those notes later on, during writing, said Charles, they could —and, indeed, were encouraged to do so. Once Charles, seeing a student looking around and not working, said aloud, but without naming the student, "An idle mind—-" and the whole class finished "—is the devil's playground." Charles then said, "An idle hand-" and the students responded, “-is society's fall guy.” All students then went back to work.

Charles sees it as his responsibility to prepare students to be able to argue about injustice. He does this by always reminding them that school is a professional setting in which they can obtain the skills required to take on any person who tries to make them feel as if they are not entitled to a fulfilling life. He thinks it important not to judge students, whatever their situation, but rather to give them the skills to argue about, defend, and see the hidden meaning behind people's words and actions.

\section{Summary}

Charles's classroom can be described as a room of laughter that is used to engage students. Charles never discouraged any student's input. It was obvious that as long as they supported their thoughts with facts from the text, he would not dispute their thinking. However, in the community atmosphere he has built, students disagreed with 
their own facts from the texts; Charles called this "engagement." He smiled the whole time his students discussed whether a person deserved the title of legend.

Charles was a culturally relevant teacher, designing his lessons to have a critical lens. He taught his students to take different perspectives, addressing cultural differences among the students as he taught them how to speak to each other and taught them not to be disrespectful. What's more, academic achievement was nonnegotiable. Fully $85 \%$ to $90 \%$ of his students, he said, mastered the standards when taught—and he designates time for students to get follow-up instruction.

\section{Practices of Culturally Relevant Teachers}

These three teachers shared a common belief: All children can learn.

Accordingly, each teacher thought it his or her responsibility to plan and implement lessons that would help students experience academic success. All three teachers believed that assessments should be used in such ways as to reflect on their teaching and on the materials used. Moreover, each participant used the Reading CCSS to help students learn how to build effective arguments when something in their community needed to be addressed. These teachers also believed in doing whatever was necessary to make sure that their students learned.

Each teacher reported using the first weeks of school to develop a classroom culture that encouraged risk-taking, sharing of cultural beliefs, the setting of norms for classroom discussion, and the development of an integral understanding of the school's expectations for each student. These teachers built relationships with their students and set up systems that encouraged students to build relationships with one another. Every participant arranged his or her classroom environment so that students would talk about 
what they learned. These teachers believed that the more students heard the standards used and taught by their classmates, the more real and purposeful the standards became.

The participants' use of critical consciousness made them stand out from other teachers. All believed the participants believed that reading textbooks alone were not sufficient to teach their students of color. Even the teacher who followed the basal series used supplemental materials to help the students think critically about the basal text. The teachers intentionally related different reading standards through the different instructional contents. They believed that relating students' experiences to the reading material made learning rich and engaging. They also believed that for students to find relevance in what they learned, they must use it to make a difference in their community. Even though many of the activities in which students engaged were mock activities, practiced from week to week, when students felt a need to address something going on in their lives outside of school, the teachers used instructional time to help students convert their practice into purposeful community outreach.

\section{Developing Critical Consciousness and Addressing Lack of Diversity in the CCSS}

Ladson-Billings (2009) reflected on a time when she had served on a university interview panel. For years, candidates, when asked why they wanted to teach, overwhelmingly responded, "I just love kids" (p. 102). In response, she and her fellow committee members asked, "Yes, but why do you want to teach?" (p. 103). Candidates were then at a loss for how to respond. Ladson-Billings went on to state, "A search for important ideas and the construction of knowledge fuels the excitement and enthusiasm that exemplify culturally relevant teaching" (p. 103). The participants in this study stand out as educators who are more than adults who "love kids." They are teachers who have 
reflected on their past experiences and have built on those experiences to make their students' learning environment welcoming, purposeful, and engaging.

Each participant had an experience when he or she was young that he or she revisited multiple times throughout life. These experiences stayed with these teachers and affected who they had become as educators. Stephanie, on suffering verbal abuse from fellow students, asked her teacher for guidance as well as for an explanation of how a classmate could be so cruel. The teacher did try to help her understand, but now, as a teacher, Stephanie knows that the climate and culture of her teacher's room did not encourage that girl to become a part of the classroom community. Claire's experience came from her school—in particular, from an individual teacher's having gone beyond the school's program of study to allow Claire to enroll in two independent studies so that she could write through the grief of losing her mother. Charles's critical consciousness was born when his former White classmates told him that he did not belong—because he lived on the wrong side of the tracks: Out of that occurrence came positive, fulfilling, and loving friendships from the predominantly African American elementary school. In his close-knit community, teachers and students went to school, church, and parties together. What is more, Charles's teachers were African American and taught an African American-centered curriculum. These experiences caused Charles to find value in being African American and also caused him to wonder why his White classmates called his home "the wrong side of the tracks."

Ladson-Billings (2009) has reviewed the debate about the "conflicts between what has been regarded as the literary canon and what is historical fact. We now ask if the canon represents a culturally specific set of understands or objective truths" (p. 86). 
Furthermore, she notes that, as multicultural education programs have come into the classroom,

They have led to vitriolic debates and accusations from all sides about both our educational system and western civilization. At the universal level, conservatives have railed against the notion that African American writers like Alice Walker are taught more often than Shakespeare (a claim empirically disproved by Graff). (p.

There is a call, she says, "to return to a Western civilization tradition that would save 'us' from the 'barbarians at the gate.' For advocates of multiculturalism, the questions are 'Us' refers to whom? And 'barbarians' refers to whom?” (p. 86). The critically conscious teacher stands against what mainstream educational material says is appropriate to teach. Instead, culturally relevant teachers provide an educational experience that prepares students to thrive in a multicultural and multi-perspective community.

Each participant's path to critical consciousness differed, but their experiences showed them the importance of a teacher's decision making. This district requires 24 hours of professional development for teachers yearly, but the participants in this study participate in at least 36 hours of such development, all of them focused on developing and enhancing students' multicultural education experiences. What's more, these teachers had participated in two or more years of professional development focused on teaching students of color. Although this study showed the teachers reflecting on teaching students of color, they all expressed a need to continue to learn to serve their students better. The participants understood that a "teacher-proof" curriculum does not engage or provide the rigor needed by students of color (Ladson-Billings, 2009, p. 87). Accordingly, they 
engage in professional development to continue to learn the best way of educating their diverse student population.

The participants shared how they valued professional development as it helped them understand and educate their students in ways they had not considered before. For example, at the time of this study, Stephanie had signed up for a number of professional development opportunities that enlightened teachers on how to use dance, karate, drums, and hip hop to teach reading and math. She was excited about learning new techniques to engage students with CCSS. During the interview, she reflected on a particular summer institute she attended. A main theme of the institute was to teach teachers how to deescalate children of color. The focus of the professional development was not how to calm an angry child but how to keep the child from becoming angry in the learning environment. The presenter shared how hands-on activities that allow students to talk about their learning, keeps them too occupied to become frustrated. Secondly, the presenter shared that the media can be a positive source, as well as, a negative source of materials to make students learning relevant. Stephanie commented on how some teachers get themselves in trouble when they try to incorporate the current fad for students of color.

What I do is bring it in during conversation, not actually do the current dance in the middle of my classroom. I could, but I don't. First off, I do not know all the dances for all the students in my room so it would be disrespectful. But really, that isn't me and my students would know. These teachers lose control of their room when they put on the current fad dance. The kids think it is a joke and act as if it is a joke. 
The take away from the professional development was to listen to your students. Their stories and experiences allow a teacher to connect the standards to what matters most. Also, Stephanie stated, "Just because I like a story or have gotten super excited about a topic doesn't mean my students will. I have to use what interests them. I have to listen to them. When I listen to them, they tell me all the material I need to make the learning fun." So Stephanie is very intentional in participating in the Diversity department's professional development as the topics are more than African American students, they address all students in all their situations, so she can make CCSS relevant and engaging for all of her students. Stephanie's growth from her professional development opportunities was evidenced by the way she used the basal series selected by her school. She could have used it as a whole class experience where each child was responsible for their own learning. However, she allowed continued shared experiences between students as they read the text. While students were working collaboratively, she walked around and listened to their conversations. Sometimes she made comments but mostly she listened and took notes.

Claire shared her experiences with the Diversity department was about knowing what it meant to be a student of color in the classroom. Her main take way was building relationships with students. Second, she learned if she was unwavering in changing her curriculum choices, she was asking for behavior issues. "I found one of the best way to build relationships is to tell the kids, I'm changing this because you said that. They feel empowered." Claire expressed sharing her story with children, creating a family atmosphere, having a strong classroom management plan that provides for opportunities for learning, being aware of differences, being intentional, and reflect on her students 
academic outcomes has prepared her for CCSS. She was exposed to conversations about race and what it meant to be a White teacher responsible for learning particularly, for students of color. During the interview, Claire's discussion focused on building classroom community. She shared that trust was essential if any learning was going to take place. So her professional development taught her it did not matter what material was being utilized, it was the mutual respect that allowed for learning. What she liked about CCSS is that it did not tell her what materials to use for teaching. However, she shared the school expectations that she follow her PLC meeting expectations. As long as her students were learning and they performed as expected on the PLC common formative assessments, she was able to continue with her classroom design. Overall, the way Claire was observed addressing the lack of diversity in CCSS was to make whatever material they read relevant to her students' lives. Even if the text did not represent the cultural background of her students, she had her students critically evaluate the characters as to understand their point of view. She shared at times she had to convince her students to read about a character they found offensive or boring. She said she tells her students, "It is fun to get into someone's head. You don't have to like them you just have to understand them. That's how you beat them." So Claire demonstrated that she used the context of culture through lessons that could be applied to real life.

Charles shared that his lack of understanding other cultural groups motivated him to participate in professional development opportunities offered by the Diversity department. He complimented his school in providing professional development workshops that addressed the beliefs of students from different cultural groups they served. He stated, "I learned early on that in traditional Hispanic homes, females were not 
allowed to openly express themselves. This let me know that as a man they might not speak to me as they would a female teacher." His school's professional development courses did not suggest materials to use to engage students of color with CCSS. The materials he used for instruction was up to him but he would consult with the ESL teacher to make sure he was being sensitive to all the cultures in his classroom. "That's why when you come to my room, I use every type of resource to teach reading. I want to be respectful of my kids' home life." He went on to share a professional development experience where the speaker showed how to use hip-hop music, urban art, and classical art to teach social studies and reading. The first example he shared was the artwork Manifest Destination. He said he used this artwork in the past to give a visual of the different people involved in the expansion. He then laughed and said because of the professional development he took, he now incorporated Hip Hop to take it a step further. "I get lyrics from different rappers that talk about their community and how it has changed and why. I then have the kids pick one of the groups from the picture and what would they say back then. Some of my kids try to write raps but it gets them engaged to read about the Westward Expansion that would normally be boring." Charles used his professional development experiences to widen his teaching strategies to engage different cultures in CCSS. During the classroom observation, he used controversial historical characters and current day "bad guys" to engage students in defending their point of views with facts. In his interview, he shared how professional development exposed him to materials he could use to engage his students of color.

Ladson-Billings (2009) has stated that "culturally relevant teaching recognizes the need for students to experience excellence without deceiving them about their own 
academic achievement" (p. 108). An assimilationist, she has said, sees the assumption of excellence as being independent of student diversity or individual differences (2009) but she has noted that the dominant culture that developed curriculum also developed what is considered academic excellence (1998). Accordingly, a culturally relevant teacher critically thinks about the curriculum being taught and adjusts as needed so that students of color can experience excellence and academic achievement. Indeed, Ladson-Billings (2009) shared how one of the teachers in her study was "just trying to get the kids to see that we work for more than money. We work because our work means something to us" (p. 108). Students do not find value in work that is not relevant, and so they seek relevance in places that do not help them find a fulfilling place in society (LadsonBillings, 2009). It is up to teachers to have students see that there is more to their education than receiving an A grade.

The teachers in this study practiced critical consciousness more than any of the other elements of culturally relevant teaching. All participants gave students multiple ways to express what they have learned. Each student was given an individual plan on how to master the Reading CCSS. These teachers met with students in small-group instruction, and not every text they used had characters who looked like the students or who shared their personal experiences. These teachers believe that students need to understand perspective and motivation, as well as how to develop an argument of support or opposition. Holmes, Powell, Holmes, and Witt (2007) found that texts featuring similar character backgrounds did not motivate a student to read. Instead, when students can question the author's development of a character's or evaluate the choices of people 
from the past, regardless of their ethnic background, they think critically about what they read (Ladson-Billings, 2009). 


\section{CHAPTER 5: DISCUSSION, CONCLUSION, AND RECOMMENDATIONS}

This investigation used a qualitative case study research design to analyze elementary teachers who have used their culturally relevant belief and practices to teach the Reading CCSS. All three participated in teacher interviews and classroom observations, answered questions in a follow-up phone interview, and provided samples of student work for analysis. The purpose of this study was to explore on what cultural relevant teaching looks like in a classroom guided by the Reading CCSS. The following research questions guided this study:

1. What practices do elementary culturally relevant teachers use to ensure academic success, develop their cultural competency, and teach critical consciousness?

2. How do teachers working in an urban school district develop and use critical consciousness to better serve the needs of their diverse students?

3. How do teachers develop a critical consciousness to address the lack of diversity in the CCSS?

This chapter interprets, analyzes, and discusses the findings in light of these research questions, offering recommendations for teachers, school administrators, and professional development facilitators while also addressing future research needs. 


\section{Findings}

Five common themes emerged from this study. The following are the major themes gathered from data from three elementary teachers. Each teacher was interviewed using semi-structured interview questions. Each was also observed for a whole reading block, and each responded to a follow-up conference call to clarify answers given during the semi-structured interview.

Table 1. Findings in Practice
Finding 1
Classroom culture is built upon relationships and respect for each student's cultural background.
Finding 2 Assessments are used to inform instruction, not classify students.
Finding 3 Higher-order questioning and rigorous activities are used to engage students in learning environment.
Finding 4 Cross-curricular instruction is used to bring relevance to what is being taught.
Finding $5 \quad$ Reflection practices are used to question instruction effectiveness and individual student needs.

\section{Finding 1: Classroom culture is built upon relationships and respect for each}

\section{student's cultural background}

Weinstein, Curran, and Tomlinson-Clarke (2003) have called a culturally responsive teaching classroom management practice a "frame of mind" held by teachers who recognize biases and values (p. 275). Moreover, teachers who build community around the different cultural aspects of their classroom encourage the development of respectful relationships among all stakeholders (Delpit, 2006; Ladson-Billings, 2009; 
Weinstein et al., 2003). Thus, culturally relevant teachers welcome differences and make them a part of their classroom management plan. These teachers do not use their management plan as a means of control. Instead, it is a system of equitable opportunities for learning (Weinstein et al., 2003). The following are specific examples of how the teachers highlighted in this study have built a culturally relevant community of learning.

All three had a clear plan and process for developing their classroom management technique: Teach students how to listen, how to learn from each other, and how to speak respectfully. During the first 6 to 10 weeks of school, each participant has students learn about each other, write to each other, think about what life is like for their peers at home, and be open about what makes them happy and scared. While these teachers are allowing students to learn about each other, they are also intentionally teaching classroom procedures and processes. Climate and culture building were evident: None of the three participants' rooms posted rules for students to follow.

These teachers actively sought to add detail, context, and emotion to the emotional construct they built with students. The interviews revealed that their teaching decisions regarding their students of color, students of low socioeconomic status, and students who spoke English as a second language were organized and well-intended. It was important for them that students feel valued, trusted, and respected. Participants shared that some children are taught to be distrusting of people who do not share the same experience. However, building relationships through affirmation helps students come to value, trust, and respect the teacher.

These teachers manipulated events and interactions within the classroom to guarantee that all voices would be heard. They spent a great deal of time creating 
relationships of mutual respect between students, and everyone (including the teachers) worked hard to keep promises, display kindness, express courtesy, and apologize when mistaken. Time was used not only for clarifying expectations about student behavior but also for the teacher to critically reflect on his or her expectations for student behavior. Analysis of the interviews and observation data revealed that the teachers had undertaken an intentional process of learning about their students and their students' families. They considered this an important task for building a community of learners. These teachers wanted to have enough knowledge about individuals to judge when and how best to intercede in any conflicts that might occur. These teachers used this knowledge to reinforce students' ability to make a change in the world through education and by speaking out against injustice as seen through the students' eyes.

Teachers used the knowledge they gained from their students in various ways but did not consider that doing so made them experts. Instead, they used students' communities as a way to engage them in learning while making lessons relevant to their students' lives. Even when students pushed the boundaries of the classroom community, each teacher thought about why the behavior was occurring before intervening. These teachers did not retreat to a position of power, but rather had the backing of other students to help them maintain the climate and learning environment set up in the first weeks of school.

Each of these teachers had an earlier positive experience with a teacher. Charles grew up in the same community as his teachers, attending church with them, and going to birthday parties and cookouts with them. Stephanie grew up in the same house as a principal and had a teacher make a special effort to help her understand why some 
students are mean. Even though this teacher had the best of intentions, Stephanie always felt as if there were a better way of changing a person's behavior. Claire, for her part, lost her mother while she was in school. When this happened, her school family embraced her and adjusted her education program to meet her emotional needs. Each of these teachers understood what it meant to not comply with the dominant culture's beliefs and practices of how to educate students of color. These teachers also realized how biased thinking could influence their own interactions with their students. Each consider that not every student-initiated action could be judged as inappropriate just for running counter to some universal expectation or rule. What's more, Stephanie, Claire, and Charles all engaged in an informal process of reflection that caused them to question their beliefs and actions and that informed them about how their perspectives on culturally appropriate behavioral interventions influenced the climate of their classroom.

\section{Finding 2: Assessments are used to inform instruction, not classify students}

Ainsworth and Viegut (2006) explained that although assessments are often used to determine mastery, the primary purpose of evaluation should be for educators to learn how much progress students are making toward a particular learning objective. LadsonBillings (1998) said that a "dysfunctional curriculum coupled with a lack of instruction innovation (or persistence) adds up to poor performance on traditional assessment measures" (p. 20). The teachers in this study understood how their instruction affected student outcomes, so they used assessments as a way to determine whether their teaching was effective. All three teachers described their system of evaluating formative assessments for trends and needs for additional instruction: Charles and Claire described a system that divided students' results into categories. Charles called the categories 
"deeper understanding," "met the standard," "a few minor errors," and "reteach standard"; Claire called them "teacher," "nailed it," "talk it through," and "reteach." Charles and Claire both described the process of how these results led them to decide how instruction would take place the following week. Children who displayed a deeper understanding of the standard were allowed to work with students who struggled or were given more independent time in which to work on projects and other cross-curricular activities. Students who needed clarification would have a chance to work with the resource teachers or in small groups with the purpose of clarifying any misconception.

Because both teachers used open-ended formative assessments, it was easy, they explained, to see where students needed additional support. Stephanie was more confined than the others to her PLC schedule, but she had a close collaborative relationship with the school resource teacher and ESL teacher, which allowed her to collaborate with those teachers to make sure that students got the additional support they needed. Although this was the practice of her whole PLC, she noted that “my team doesn't always use resources the way I do. I feel guilty when my students are not masters, so I give them the support they need to get the standard." The teachers used formative assessments to determine student progress toward grade level standards and used assessment results to inform their instruction and adjust it to meet the needs of students who required additional support.

All three teachers were members of highly effective PLCs. Every two weeks, they would plan out the standards and would create common assessments to be given to every student in the grade. Stephanie's team used the district's diagnostic tests; the three teachers commented on how important it was to have questions' vocabulary not keep students from showing what they had learned. Each teacher talked about how the ESL 
resource teacher would use teachers' knowledge of students' ability to help the teachers design questions showing what the students knew. The participants believed that working collaboratively with team teachers encouraged problem-solving with a view to using the best possible instructional practices to teach their students the Reading CCSS. They used the data as a team to help facilitate conversations that sought to understand what the standard asked of students. These discussions allowed for conversations about NCLB categories (race, ECE, ESL) as at times certain groups of children produced lower results than the other students. The results of the assessments caused teachers to discuss texts used, vocabulary instruction, and whether the teaching was culturally appropriate. This collaborative work has enabled teachers to assess students for mastery of specific standards and to reteach students who need additional time and support for certain standards.

The teachers shared how it had taken time and patience to build students' capacity to take formative assessments at regular intervals. At first student felt the purpose of the assessments was to judge them and if they did not do well, it was a reflection of them. However, the participants worked hard at building trust so students understood formative assessments were used to help the teacher be their best. In previous classes, their students had described how tests made them feel bad if they were not successful. So during the first 6 to 10 weeks of school, the teachers used review assessments to help build confidence as well as to get an idea of how their students felt about formative assessments. Claire and Charles noted that open-ended questions hid the fact that the task was an evaluation. Moreover, when students received positive feedback on what they had done, their confidence grew. When these teachers talked to their students about the 
students' results, the teachers approached them from the point of view not of what had been left undone or done incorrectly but rather of how to build on what was known. This type of differentiated instruction, based on assessment results, allowed for small-group instruction within the classroom setting. This instruction sometimes came in the form of peer tutoring that benefited students who needed additional support as well as those who had mastered the standard: The latter sometimes developed new ways of teaching the standard that their peers understood. In this setting, students took responsibility for one another. Stephanie's classroom was not as free-flowing as were those of the other two teachers, but she made much use of student conversation, allowing students to talk one another through the learning process. Moreover, she had built into her day a time during which to give additional support to students who had not mastered the standard.

\section{Finding 3: Higher-order questioning and rigorous activities are used to engage students in learning environment.}

As Ladson-Billings has stated, "intelligence testing has been a movement to legitimize African American student deficiency under the guise of scientific rationalism" (p. 19). Indeed,

Current instructional strategies presume that African American students are deficient. As a consequence, classroom teachers are engaged in a never-ending quest for the "the right reading strategy or technique" to deal with (read : control) “at-risk" (read: African American) students. (p. 19)

The teachers in this study understood this and were reluctant to trust a predetermined curriculum to teach their students of color. Teachers must teach students the processes of problem solving, of finding information, and of analyzing information. Providing the 
proper amount of challenge requires that the teacher have high expectations of all students. Teachers show students respect by expecting more from them (Delpit, 2006; Ladson-Billings, 2009). The teachers in this study built their classrooms on mutual respect, and every component of their reading instruction showed students how texts could help them solve problems. These teachers did not use drill and practice, recognizing that many of their students disliked that type of assessment. Rather, these teachers exposed the students to all levels of thinking. As seen during the interviews and observations, critical thinking skills were seen as being important to use in all instruction. The teachers in this study found that higher-order thinking questions led students to reflect on how to show their understanding in different ways.

Accordingly, these teachers used Bloom's taxonomy as a way to design their assessments. These teachers used assessments so students could demonstrate their understanding of the standards in a real world context. Students could use self-expression while validating how the standards are preparing them to be an influence in their community. So when teachers used these performance-based assessments as an alternative format to summative assess their students, the teachers prepared their students to be active citizens. Performance-based assessments help students prove what they know (Stiggins, 2007). During the formative process of evaluation, teachers talk to students about their learning; as students share what is going on in their lives, the teacher guides them in how to do a project that demonstrates their learning. These performance-based assessments based on Bloom's taxonomy included letters to government officials, reports, writing short skits, composing raps, designing display boards for subject areas studied, using various media to prove their comprehension of a text, writing speeches as 
if they were a politician seeking to influence the communities' way of thinking, taking on the personas of various characters and writing as if they were the character, writing poems, or skits based on the text they read in the basal, short story, or chapter book.

\section{Finding 4: Cross-curricular instruction is used to bring relevance to what is being} taught.

All the participants in this study designed their programs with an eye to creating cross-curricular integration between their literacy program and other subject areas. Crosscurricular integration is a program planning approach in which a teacher teaches core concepts and skills by connecting multiple subject areas under a particular theme (Drake \& Burns, 2004). A common understanding among the participants was that certain areas of the curriculum naturally fit together as they related to program planning and implementation. As part of their interviews, participants were asked how they engaged students of color in the reading process, and all responded that students must see the relevance of why they are being required to learn the standards. So the standards are stated in "I can" statements so students know what they will be able to do at the end of the lesson. Next, the participants made the learning experience social so that students could learn and experience different perspectives of the standards. They described themselves as being very intentional in the texts they use, which allows them to conduct additional activities using the text. Charles gave the example of students reading the book George versus George, published by National Geographic Children's Books in 2007. The cross-curricular activity included designing and writing brochures for both sides of the Revolutionary War. Stephanie and Claire conducted Black History Month activities during which students picked a person who had contributed to American society, then 
researched whether these people were given direct credit for their accomplishments or were given it later. Claire had students research Lewis Howard Latimer, the inventor of the carbon filament, which allowed light bulbs to burn for hours instead of minutes. Claire then allowed students to construct a circuit with which to turn on a light bulb. Students then wrote an argument expressing whether they felt that Thomas Edison should have given Latimer more credit than he was initially given. Claire elaborated on the injustice that students felt at people not receiving credit for their work. She used this emotion to gain insight into what was important to them as well as how she could connect her instruction to the needs of her students' community.

All participants identified science and social studies as subjects that were firmly integrated into their literacy programs. Next, participants judged that building students' computer skills through having them conduct research and use presentation software prepared them for the skills they would need in higher grades and, eventually, the workforce. Charles, for his part, tries to use texts that have a provided location. He covers the distance between locations, time lapse of travel, and time lapse of a story's evolution and said when students are required to use math to help them understand a setting, they come to understand the feelings of the character or the effect that time had on a historical event.

The participants employed three levels of cross-curricular integration, and all three included some writing activity as accompaniment for a reading assignment. These writing assignments could be a graphic organizer, a reflection on how the text affected the reader, notes on what was read, a counterargument, a research report, or writing explaining the summative project. Stephanie's approach to cross-curricular integration 
came from her use of the grade-level basal series, which runs in six-week themes, each social studies- or science-based. Students kept their work from each theme in a binder in their desk, allowing a theme to be highlighted and then revisited to help make connections to future topics taught during designated science and social studies blocks. These themes were highlighted to help students make connections between their learning in various subject areas. In this way, a theme could be emphasized and built on to make connections to prior knowledge at any point while allowing other broad themes to emerge when they were more applicable to students' current community issues. For example, the concept of "making a difference" was one theme of the basal series, and one story, Harvesting Hope: The Story of Cesar Chavez, showed students the ways in which a person can make a difference in his or her community. Students, able to make connections between Dr. Martin Luther King and Cesar Chavez, reflected after the 2016 U.S. presidential election on how they could make a difference, its outcome having caused many different emotions. As the year progressed, students built countless layers of cross-curricular integration on their understanding of these various themes.

\section{Finding 5: Reflection practices are used to question instruction effectiveness and individual student needs.}

Findings from the cross-case analysis suggested that participants reflected on various issues in the classroom, including teaching practice, students' academic progress, social relationships, and issues of the community. All three teachers considered how teaching and learning in the 21st-century school required a shift in pedagogy to meet the needs of the growing culturally and linguistically diverse student populations in the schools of today. In the first phase, that of finding participants, all three participants used 
the phrase that's a cop-out when the prompt asked them to reflect on educators' blaming students and students' families for the school's lack of academic progress. FeimanNemser (2008) argued that for teachers to meet the needs of their students, their practice must involve reflective consideration of multiple roles_-"thinking," "feeling," "knowing," and "acting"-in a responsive teaching practice for children (p. 698). Because the participants reflected on students' emotional and academic needs, they understood the relevance of macro issues such as inequities, community disparities, and fear of social outcomes, and they were aware of the needs of teaching diverse students. This might have been especially so because one participant had grown up in a community of economic disadvantage, another participant had suffered a loss that caused her to feel different from her peers - and her father had made her work when her peers did not have to - and the last had grown up in a family of educators who had always taught in communities of people of color.

Furthermore, as these findings suggest, as these participants reflected on their own practices—outside their PLCs - they considered these personal influences in the classroom and beyond, allowing these things to affect their teaching as well as the learning of diverse students. However, it was the criticality of these reflections and ability to reflect in and across systems that revealed participants' understanding of culturally relevant pedagogy. For example, the analysis suggested that participants knew how biased vocabulary in standardized or district testing could affect student outcomes. The participants recognized how standardized assessments based on mainstream expectations could result in culturally and linguistically diverse children's being labeled as low achievers and not being provided with high-quality educational experiences. 
Accordingly, they afforded students other ways of showing understanding so that when students had to take tests, they welcomed them and used strategies to navigate the assessment. Accordingly, one significant finding of this study was that the critical nature of participants' reflections was an indicator of the degree to which they understood culturally relevant pedagogy, providing empirical support for the argument—made by Gay and Kirland (2003) — that engaging teachers in critically conscious reflective practices will help develop their understanding of how to teach culturally and linguistically diverse children.

\section{Recommendations}

The findings from this study hold important implications for individuals who develop curriculum, who develop professional development policies, and for educators who lead teachers and teachers who teach students of color. The suggestions are based on the findings voiced by the participants of this study.

\section{Recommendation for Policy Makers}

The Every Student Succeeds Act (ESSA) is the most recent reauthorization of Elementary and Secondary Education Act (ESEA), which replaced NCLB in December 2015. ESSA differs from NCLB in that the most recent reauthorization moved toward decentralizing educational power away from the federal government and state governments. The act prohibits the federal government from mandating the adoption of CCSS and gives states more freedom to decide how to evaluate teachers and to set their own high academic standards. However, ESSA remains a test-based accountability system that requires interventions to the lower scoring five percent of schools. The law requires the states to evaluate data by race and wealth (Every Student Succeed Act, n.d.). 
NCLB, the previous reauthorization of ESEA, forced many school districts to evaluate how best to meet the needs of students in high poverty, low performing schools (Heck, 2009). NCLB required states to develop standards and assessments that covered and tested basic skills, but each state had the freedom to create standards and assessments, as well as a teacher evaluation system that would ensure highly qualified teachers. During the NCLB era, all student subpopulations saw improved academic success, but socioeconomic and racial gaps persisted (Heck, 2009). Moreover, the skills expected by NCLB ended up being interpreted by schools as mastery of grade-level expectations (Heck, 2009). Accordingly, American schools showed lackluster advancement when seen from the international stage (National Center for Education Statistics, n.d.). After taking office, President Obama allowed waivers to NCLB if states either committed to CCSS or self-developed high academic standards, new assessments, and new teacher evaluation systems. So when ESSA passed both chambers of Congress with bipartisan support, communities around the nation responded to the federal government's desire to allow greater state autonomy in identifying and addressing their needs (Mathis \& Trujillo, 2016).

Now that states have more choice in what and how to educate their students, they must not fall into a trap of low expectations from the students they serve. Under CCSS, states have shown growth in the NAEP results (NAEP - 2015 Mathematics \& Reading Assessments, 2015). In this study, the teachers participated in high functioning PLC grade level groups that dissected the standards as a way to better instruct and prepare their students for high stakes accountability testing. Organized programs and initiatives better enable teachers to include some culturally relevant teaching practices. Participants, 
in this study, expressed several limitations within their school context, including limited discussions of students' cultural context being integrated into curriculum choices. If anything was learned from NCLB, it was that if the expectation of higher-level instruction is not explicitly stated, then some students will not be given the opportunity. Just as in CCSS, higher-level instruction was the expectation, but the standards lacked expectations of using students cultural as a strategy. As informed by the research participants, student culture was not a part of their planning PLCs. However, since the CCSS standards are of higher expectations, the standards caused teachers to have conversations and instructional practices that caused higher order activities in their classroom compared to the NCLB era. If states fall back to the standards and teaching methods during the time of NCLB, students of color are at risk of losing exposure to high academic expectations offered by CCSS and will continue to miss out on teachers using their cultural experiences as an asset.

\section{Recommendation for Schools of Education}

The results of this study point to the need foster a better understanding of developing pre-service teachers' beliefs on their role of providing a democratic classroom. Utilizing case studies and group discussions of issues within education, schools of education might utilize such experiences to foster critical reflection. According to Ladson-Billings (2001) beginning teachers have to come into the profession with the understanding that for them to be success teachers of students of color, they need to believe that students achieve, develop a positive sense of themselves, and develop a commitment to larger social and community concerns. So Ladson-Billings (2001) and Villegas and Lucas (2002) suggest pre-service teaching sites be selected based on the 
school's commitment to developing teacher's cultural humility among their students and staff through the use of the school's diverse community. However, this might be challenge as this study demonstrated when trying to find participants, schools that expect culturally relevant teaching practices are few and even then the teacher's own beliefs drive the development of the teacher's culturally relevant practices. Therefore, these preservice teacher experiences may be fostered in ways beyond the selection of student learning sites by requiring volunteer experiences within the communities, much like the one in Bennett's (2012) study. In Bennett's study half of the participants chose not to interact and immerse themselves with the children in the community center. Unlike Bennett's study, this is the time to challenge a pre-service teacher's thinking and belief system to determine if they can overcome cultural biases before being placed in a culturally diverse school. Ladson-Billings (2001) suggest pre-service teachers may gain more affirming perspectives of students when they have an opportunity to be taught how to critically reflect on their own beliefs when students' respond in a way that the preservice does not understand. These experiences will develop what Gay and Kirkland (2003) call "cultural critical consciousness and self-reflection" (p. 182). The authors argue that conversations of race and justice in itself are not enough to influence a preservice biased thinking. Instead when preservice teachers engage in authentic learning opportunities that confront the emotional component of transforming ideologies, preservice teachers start to question their prejudices towards cultures different from their own. Gay and Kirkland (2003) also call for ways for preservice teachers to make connections between experiences and critical reflection. In this way, the university faculty can guide teachers and ask the hard questions when preservice teachers have not 
developed the capacity. They state, "Turning critical thoughts into transformative instructional actions helps to internalize the process so that it can be replicated in future endeavors" (p. 186).

This study showed that the three participants had personal experiences that allowed willing openness to culturally relevant teaching. All three teachers experienced and reflected on what it meant to be an out casted because of events out of their control. Ladson-Billings (2001) suggest university staff should consider an interview protocol that attempts to determine student's ability to persist and what life experiences they have had that will prepare them to teach diverse students. Budgetary issues can arise from taking professors away from classes and research. So taping into the community stakeholders can help in the interviews of finding preservice teachers that have the beliefs it takes for students of color to find success.

\section{Recommendation for the District of Study}

In the past decade, the district in which this study took place has implemented two different versions of a district-wide strategic plan that all departments align their daily duties. The core values of the plan is to provide students with caring, equity, excellence, respect, individuality, diversity, opportunity, creativity, collaboration, and stewardship. For example, in the professional development department, all PD providers connect their participant learning goals to the strategic plan. Also, when departments interview for leadership positions, applicants are questioned on how they would align the position to the strategic plan. 
In the latest version of the district's strategic plan, there is specific language uniting educators to exposing students to "deeper learning" opportunities in that all students will learn, grow and develop into high performing individuals. The participants in this study did expose their students to deeper learning through the use of higher order thinking reading activities. Claire and Charles presented their students with deeper learning activities by having them create work product that went beyond the textbook. For example, both teachers had students develop pamphlets, short stories, dramas, speeches, and research products that connected their students reading, writing, and social studies content. Stephanie's students had extensive self-chosen writing assignments, in which they chose the structure, to demonstrate what they learned from their reading. All three teachers accepted students' culture background and so when students' work product was directly related to their communities, the three teachers knew their students had mastered the purpose of the reading and writing standards.

The district has a diversity department dedicated to ensuring all students, paying particular attention to those students who are at risk of failing or dropping out, have an equitable educational experience. This department puts on numerous PD throughout the year to educate teachers in strategies that engage students of color, students living in poverty, or reluctant learners. The participants for this study shared how they relied on the diversity department's PD to keep them current with the best practices of teaching students of color.

The diversity department PD roasters provided the sample of potential research participants for this study. Each institute provided learning opportunities to 500 educators. The 2014 - 2016 showed an attendance ranging from 270 to 350 . Once these 
rosters were combined into an Excel document, there were over 1000 fields of possible participants. Then PD participants were sorted and filtered into the parameters of this study; there was a potential of 35 elementary teachers. When these 35 elementary teachers were contacted, none responded. Next, the principals were asked to verify the researcher. Two teachers then returned the phase one email. These teachers were identified as little cultural awareness. These two teachers had attended the diversity institute for three years. Even though these teachers participated in three years of PD to help them implement an educational environment based on caring, equity, excellence, respect, individuality, diversity, opportunity, creativity, collaboration, and stewardship, these two teachers felt they were not able to do so because parents and students prevent successful implementation of a school reform. As stated earlier in this study, Young (2011) found her research did not have the wanted effects because of teachers' cultural bias that kept them from implementing the theory of culturally relevant instruction. community.

A review of the research literature identified many potential problems when a school or district try to implement culturally relevant practices as it relates to deeper learning activities. Lareau and Horvat (1999) stated many plans to improve student learning focuses on curriculum or learning style but when it comes to culturally relevant deeper learning activities school districts have to see that teachers are reluctant or unable to look past their basis to see students of color cultural capital. Milner (2010) also added that district reforms minimal positive effects of providing an equitable learning opportunity for students of color in that the reforms do not tackle the teacher's beliefs and how those beliefs affect student learning. A district cannot hold each teacher accountable 
for his or her teaching decisions. The responsibility falls to the school leadership to make sure teachers overcome their prejudices and give students of color an equitable learning opportunity through the use of their culture. Also it is up to the district to hire principals that value and demand culturally relevant deeper learning activities from their teachers if students of color are to reach their full potential.

\section{Recommendation for School Leaders' Practice}

Culturally relevant teaching can be sustained if professional development is connected to the teacher's personal and classroom needs. The federal government made statements in support of equal education for all through ESEA and its subsequent reauthorizations. Specifically, NCLB held states accountable to provide an equal education for all. CCSS, for their part, represented the first policy to be financially supported at the federal government that has sought to assure all students of the same higher-order thinking instruction. Now that ESSA is moving away from greater federal involvement, it is up to schools to ensure that teachers are given the opportunity to develop their understanding of what it means to teach a challenging curriculum and that their students learn and can apply what is learned.

As revealed in this study, culturally aware teachers want all students to succeed so they adapt their curriculum to the individual needs of their classroom. The participants valued the high standards of CCSS and purposefully sought out professional development that would build their teaching craft to make the standards relevant to their students of color. Stosich (2017) contends, "Standards are intended to foster excellence and equity in student learning by institutionalizing high expectations for all students while allowing educators to have professional discretion in determine how to meet these goals" (p. 539). 
CCSS arose out of the needs set by The Council of Chief State School Officers and the National Governors Association (Kendall, 2011). Forty-eight states, 2 territories, and the District of Columbia committed to the work of bettering the educational experience for U.S. students (Kendall, 2011). CCSS sought to bring high expectation standards to the same high level nationwide, but were met with increasing controversy and moves away from the standards (Jochim \& McGuinn, 2016). The present study found that the participants accepted the standards at face value. Their schools' principals accepted the standards and required PLCs to guide their decisions based on those standards. Stosich (2017) found when principals came from the perspective of a learning frame, teachers and students engaged with the CCSS educational content. Regardless if the states keep CCSS, adapt them for specific state needs, or replace them with new student expectations, the way the teacher sees their role in teaching the content to the students, affects the way the students engage in the learning. The participants in this study embraced the standards as-is, and were intentional in the materials they used to engage their students in learning.

Reflecting on how more equitable teaching approaches might be encouraged, Charles offered several suggestions, placing the impetus for change on school leaders. He noted how initiatives such as publisher basal programs and mandated meetings focusing on district assessments caused teachers to focus on teaching and not on students. He believed that when the teachers were given the room to take chances and not follow the basal program, they would build relationships with their students. Also, if teachers were required to reflect on various student outcomes as evidence of needed teacher growth rather than using deficit thinking, then students would reap the benefits of changing 
teacher practice. Charles reported that he had attained his principal certification in the hope of making schools more beneficial to African American students. As each participate shared the strengths of their PLC, when teachers are given the time to talk about their practice, students benefit. So as part of culturally infused professional development, teachers need the time to discuss what it means to embrace a culturally relevant pedagogy.

Participants of this study reported several limitations for the openness of many of their colleagues adapting their curriculum and instruction to be more culturally relevant. Their discussion included the overreliance on standardized testing and justifying approaches that encouraged use of a basal series without the benefit of supplemental materials. This study found that classroom teachers who embrace their students' cultural capital and use it as a resource reported a low number of behavioral incidents, higher levels of engagement, and increased student comfort in using their voice to make a difference in the community. Even though these teachers felt an obligation to do what was needed for all their students to find success, they shared that teachers in their buildings did not see the benefits of culturally infused instruction as valuable as they did.

The first step on having professional development that can sustain the rigor introduced by CCSS is for the principal to develop their own social justice identity and commit to diversity and social justice and provide their teachers with opportunities to better their craft for all their students (Kose, 2009). Principals should provide and participate in the same professional development as their teachers and model what it means to plan with students' culture in mind (Kose, 2009). Next, equity, diversity, and social justice should be fused into the professional development experience regardless of 
the content area. Teachers should be able to reflect and learn cooperatively on what it means to value students culture as a strategy for student engagement (Kose, 2009). Lastly, a professional development vision statement should be develop to analyze if professional develop opportunities align with the diversity needs of the building (Kose, 2009; Stemler et al., 2011).

Going forward, school leaders should continue to be held accountable for all their students' learning. To this end, principals must be able to identify hidden biases related to the perceived academic ability of students of color. Stephanie reflected on her lack of autonomy, which in part was the product of her high-functioning PLC. She noted that race, community events, and performance of students of color at lower levels - at timesthan their White peers were not addressed when her PLC talked about the results of their formative assessments. Stephanie welcomed the frequent formative assessments, as they informed her teaching, but she was concerned about her team's beliefs that assessments needed to be like accountability testing. She felt authentic real-world assessments were the true test if her students could apply the standards. However, she did understand why it was important to prepare students for the state assessment. All these examples reveal a need to foster transformative learning experiences at all levels across the school. For school leaders to be prepare their teachers to teach all students, a focus on cultural humility rather than proficiency could be adopted. Accordingly, Helsing, Howell, Kegan, and Lahey (2008) argue that professional development should address the contradictions between leaders' intended goals and their actual behaviors.

The results of this study indicated a strong support by local school leaders for teachers to participate in professional learning communities in which teachers planned, 
implemented, analyzed, and reflected on their instructional practices and student outcomes. Participants expressed several limitations within their school context including limited discussions of the sociocultural context of education, a since of using formative assessments as a way of labeling students by ability level instead of using assessments to address instructional methods, and a punitive sense of classroom management rather than empowering approaches to transforming learning. These examples suggest the need to foster culturally relevant learning experiences at all levels across in a school. In order for school leaders to be prepared for task of getting into a teachers instructional belief system, a focus on cultural humility rather than proficiency may be one approach. Demands placed on a school leader as a manager and instructional leader can cause a leader to feel as if they are being pulled in many directions. However when a school leader has clear vision of what they want for their school, teachers, and students, it is easier to know what is essential for their school's success. Theoharis (2007) gave suggestions to school leaders on how to better build a school beneficial to all students:

- a climate dedicated on diversity,

- end pullout programs,

- all learners have exposure to higher-order thinking activities,

- strengthen core teaching and curriculum, and make sure that all students had access to s challenging curriculum

- assure marginalized students of the same vibrant academic and social opportunities as were available to all other students,

- demand equal success of every child,

- help students achieve together, 
- and emphasize that everyone is part of the same school community, A school leader who approaches education for all students and the implementation of the standards as a challenge for teachers and students are more "likely to close the gap between existing practice and the goals of policy" (Stosich, 2017, p. 539). A school leader has to lead their school and be prepared to resist what has always been done and the complicity of allowing students of color to not reach their full academic potential (Theoharis, 2007). A school leader who focuses on requiring teachers to reflect on their practices, to question instruction effectiveness, and have a sense of responsibility towards every individual student needs starts the process of teachers becoming culturally relevant as those found in Ladson-Billings (2009).

Culturally relevant pedagogy is pedagogy of resistance (Ladson-Billings, 2009). Historically, politicians and program leaders designed curriculum with a color-blind perspective (Ladson-Billings, 1998). The school leader must be prepared and knowledgeable of the specific cultures of different ethnic groups in their schools. They have to also have to be aware of how designers determine what is taught. Also, principals need to prepare teachers to understand what it means to have an effective learning environment that encourages the different ethnic groups to have positive learning behaviors (Gay, 2002). Plus, principals need to expect and model what it means to have classroom interactions and instruction that embraces the differences of ethnic groups (Gay, 2002). A culturally relevant principal makes students' culture part of the school vision because "culture strongly influences the attitudes, values, and behaviors that students and teachers bring to the instructional process, it has to likewise be a major determinant of how the problems of underachievement are solved" (Gay, 2002, p. 114). 
Stemler, Bebell, and Sonnabend (2011) found that principals perceive mission statements as an essential tool to develop practice and communicate core values to teachers, students, and community. So a principal dedicated to their students' culture and the expectation that teachers use their students' cultures are a resource will make it part of their person belief system and the school's mission statement.

\section{Recommendation for Individual Teacher's Practice}

Even though teachers are held to guidelines set by individuals outside of the school building and classroom, the final choice of what is taught, how it is taught, and the buy-in of why it is being taught, is up to the teacher. All teachers go through a relative training experience when they study to be a teacher. However, no two universities communities are exactly the same. So no two teachers will see their responsibility as an educator the same. This leads to no two classrooms being exactly the same. Consequently, what the teachers perceives as their role in the learning process is what happens in their classroom. The teachers in this study believed an inclusive classroom culture was essential for all students to find academic success. The participants became the students and learned what made each of their students successful; as well as, each teacher bridged relationships among students so they could support each other academically. When participants reflected on the interview process, they enjoyed discussing topics they did not often have the opportunity to among colleagues. Claire confided that during her lunch between interviews, she shared her thoughts with colleagues on materials used in her classroom based on her answers she gave during the first part of her interview. She affirmed our discussion reassured her in her purpose as an educator. Participants felt what they were doing was the right thing for all their students 
based on the classroom climate they had developed as compared to their fellow teachers. Charles left the interview saying he knew he got on his PLC nerves because he would not follow the program. He felt since his students performed as expected, it did not matter. This was also observed by the amount of times students laughed, smiled, agreed, and pleasantly disagreed about what they were learning. There was a feeling a friendship in all three participants' classrooms.

The participants' classroom environment did not develop this way on its own. It was a process that the teachers strategically planned and taught. For a teacher to develop these systems, first, they need to use students' individual cultures as a way to develop a common vision for learning in their classrooms. Also, the classroom teacher should teach students how to be professional learners as observed in this study. The students talked, listened, responded, and supported each other with respect. Second, a classroom teacher should continuously reflect on if their students were being successful. If they are not, it is the responsibility of the classroom teacher to adjust instruction to meet the needs of their students. Reflecting on practice can escape teachers who are pulled in many different directions when their work environment is affected by standardized testing. Critically reflecting takes the different directions teachers are forced to face, and urges reflection based on purpose and consequence of classroom decisions. While districts are pushing down mandates and school leaders provide resources for teachers to help their students meet expectations, teachers are capable of educating themselves too. Howard (2003) suggests that teachers have the capacity to think more deeply about teaching to the needs of their students. As the participants in this study, they demonstrated their power to learn about their students' likes, dislikes, loves, fears, family, and the best way to engage 
them in the learning process. Teachers should be weary of initiatives that place the burden for change solely on their shoulders or that suggest quick fixes to complex issues. As the teachers in this study, decisions came from student assessments based on the standards. Charles believed not one basal series was sufficient for his multinational, multi-ability, and multiple interests' students. He pulled resources from different publishers, different text sources, and if he needed created his own. Claire students were observed reading different chapter books based on reading level and interest. Even though Stephanie's students read the same text, each student was able to express their comprehension in their own way. A teacher should approach equitable teaching from a stance of continuous learning of their students' interest and continually reflect on their own cultural humility. Cochran-Smith (2004) insists that teaching is a political activity in which the teacher plays a part that influences a student's outcome. Teachers have the power to silence or affirm the importance of adopting a pedagogical approach that embraces students' individuality.

All three participants approached reading instruction as an essential component of teaching different content areas. The participants selected texts with the intention of supporting content taught in writing, science, or social studies. During the observations, all texts students were reading allowed students to use information learned in science or social studies to support or encouraged to challenge the author they were reading. The participants shared to get students engaged in the learning process, students needed to see the relevance of the instruction. So a classroom teacher should find a way for students to find relevance in what they are learning. Also, students should be taught how to develop an argument based on their beliefs and given the opportunity to defend those beliefs. The 
participants used different time period texts and scientific topics for students to explore their voice. Students were encouraged and expected to disagree with the author if the message was contrary to their community. Participants found students agreeing or disagreeing prepared them to be critical readers of the community surrounding them. Thus, a classroom teacher should establish an environment where students are encouraged to disagree with published science and social studies authors. This allows students to feel they can make a difference through their reading, writing, and speech when a contrary event affects their community. Also, cross-curricular reading allows students frequent reading experiences. The participants included frequent writing and talking with the reading as a way to develop their students' skills to participate in a democratic society. Lastly, the participants' environment, instructional techniques, and reflective practices caused students to be successful when exposed to higher order thinking and rigorous activities of the Reading CCSS. The participants did not exclude students from activities based on their reading ability. During the observations, all students were engaged in what they working on and there were no obvious differences in what students were reading. So a teacher can have a classroom where all students can be challenged regardless of students' academic ability. As these participants felt it was their responsibility to follow the CCSS, in which they all believed prepared students for their future. So a classroom teacher needs to establish a strong foundation of classroom climate, assessments that allow for critical reflection, cross-curricular reading activities, that prepare their students to be successful in accomplishing rigorous and higher order thinking activities.

\section{Recommendations for Future Research}


In consideration of the finding and limitations of this study, further research may address the following. First, a mixed-methods research approach, including a survey in which teachers respond to their culturally relevant beliefs, standardized test scores of students, and case studies may result in a deeper understanding if the way a teacher sees and uses culturally relevant pedagogy can influence student academic outcomes. Second, a larger study including teachers and principals across grade levels, with a range of teaching experiences, may yield a broader range of perspectives. Finally, while participants shared many stories of their practice and were observed teaching during a reading block, there remains the possibility of disconnects between what they expressed and their actual practice. Spending more time in classroom and observing students' behavior throughout the day might illuminate a study in which students are the participants.

\section{Final Reflection on the Study}

These three participants are exemplars of Ladson-Billing's theory of culturally relevant teaching belief that teaching is an art form. Their teaching practice revealed how they respected the power of their school's PLC process, how they followed the common formative assessments created by their PLC, and how they used intervention programs to give their struggling students additional academic support. However, participants did not view their pedagogical choices through a technical lens that needed to be followed. Instead, they used the relationships they had built with their students to determine what was needed to engage their students in the learning process. They did not have a one-sizefits-all belief in a system or material that would reach all students. 
Learning to teach in more equitable ways is an ongoing process of learning for these teachers. This was evident by the participants' responses and can be seen in their attendance to the diversity's department professional development opportunities. With varying backgrounds that led these teachers to see the strengths that all students bring with them to the classroom, all were engaged along a continuum of developing awareness, critically examine their practices and the educational structures that privilege some members of society, as well as acting within their own area of influence.

Several factors enabled these teachers to develop an understanding and advocate for their instructional decisions that benefited their culturally diverse classrooms. These included their belief in critical reflection and dialogue regarding dilemmas of practice. They were proud of their students' outcomes and shared their successes with their PLC. Also they took advantage of the district's diversity department's professional development opportunities to enhance their understanding of what it means to be an effective teacher of students of color. These findings indicate that while culturally relevant teaching arguable can transform the way we look at what is needed to educate students of color, the process of learning for teachers and students to adopt this ideology is an ongoing process and should never be considered completed or mastered. 


\section{REFERENCES}

Afflerbach, P., Cho, B. Y., \& Kim, J. Y. (2015). Conceptualizing and assessing higherorder thinking in reading. Theory Into Practice, 54(3), 203-212.

Ainsworth, L., \& Viegut, D. (Eds.). (2006). Common formative assessments: How to connect standards-based instruction and assessment. Thousand Oaks, CA: Corwin Press.

Anfara, V. A., Brown, K. M., \& Mangione, T. L. (2002). Qualitative analysis on stage: Making the research process more public. Educational Researcher, 31(7), 28-38.

Athanassiou, N., McNett, J. M., \& Harvey, C. (2003). Critical thinking in the management classroom: Bloom's taxonomy as a learning tool. Journal of Management Education, 27(5), 533-555.

Atwater, S. A. C. (2008). Waking up to difference: Teachers, color-blindness, and the effects on students of color. Journal of Instructional Psychology, 35(3), 246-254.

Au, K., \& Jordan, C. (1981). Teaching reading to Hawaiian children: Finding a culturally appropriate solution. In H. True, G. Guthrie, \& K. Au (Eds.), Culture and the bilingual classroom: Studies in classroom ethnography (pp. 139-152). Rowley, MA: Newbury House.

Au, K. H., \& Kawakami, A. J. (1994). Cultural congruence in instruction. Teaching diverse populations: Formulating a knowledge base, 24. 
Bean, T. W., \& Moni, K. (2003). Developing students' critical literacy: Exploring identify construction in young adult fiction. Journal of Adolescent \& Adult Literacy, 46(8), 638-648.

Bennett, S. V. (2012). Effective facets of the field experience that contributed to eight preservice teachers' developing understanding about culturally responsive teaching. Urban Education, 48(3), 380-419.

Boyd, C. D. (2011). Charlie Pippin. New York: Simon \& Schuster Books for Young Readers.

Boyd, M. P., \& Markarian, W. C. (2011). Dialogic teaching: Talk in service of a dialogic stance. Language and Education, 25(6), 515-534.

Brown, K. M., \& Mangione, T. L. (2002). Qualitative analysis on stage: Making the research process more public. Educational Researcher, 31(7), 28-38.

Cazden, C., \& Leggett, E. (1981). Culturally responsive education: Recommendations for achieving Lau remedies II. In H. True, G. Guthrie, \& K. Au (Eds.), Culture and the bilingual classroom: Studies in classroom ethnography (pp. 69-86). Rowley, MA: Newbury House.

Cochran-Smith, M. (2004). Walking the road: Race, diversity, and social justice in teacher education. New York, NY: Teachers College Press.

Common Core State Standards Initiative. (2010). Common Core State Standards. Available from http://www.corestandards.org/the-standards Conley, D. T. (2007). The challenge of college readiness. Educational Leadership, 64(7), 23-29. 
Creswell, J. W. (2013). Qualitative inquiry and research design: Choosing among five approaches (3rd ed.). Thousand Oaks, CA: Sage Publications.

Creswell, J. W. (2014). Research design, qualitative, quantitative, and mixed methods approaches (4th ed.). Thousand Oaks, CA: Sage Publications.

Creswell, J. W., \& Miller, D. L. (2000). Determining validity in qualitative inquiry. Theory Into Practice, 39(3), 124-130.

Crocco, M. S., \& Costigan, A. T. (2007). The narrowing of curriculum and pedagogy in the age of accountability urban educators speak out. Urban Education, 42(6), $512-535$.

Debnam, K. J., Pas, E. T., Bottiani, J., Cash, A. H., \& Bradshaw, C. P. (2015). An examination of the association between observed and self-reported culturally proficient teaching practices. Psychology in the Schools, 52(6), 533-548.

Dee, T. S., Jacob, B. A., Hoxby, C. M., \& Ladd, H. F. (2010, Fall). The impact of No Child Left Behind on students, teachers, and schools (Comments and discussion). Brookings Papers on Economic Activity, 149-207. Retrieved from https://www.brookings.edu/wp-content/uploads/2010/09/2010b_bpea_dee.pdf

Delgado, R., \& Stefancic, J. (2012). Critical race theory: An introduction (2nd ed.). New York, NY: University Press. [Kindle DX]. Retrieved from www.amazon.com Delpit, L. (2006). Other people's children: Cultural conflicts in the classroom (2nd ed.). New York, NY: The New Press.

Delpit, L. D. (2012). "Multiplication is for white people": Raising expectations for other people's children. New York, NY: The New Press. 
Department of Education, Office of Planning, Evaluation and Policy Development (2010). A blueprint for reform: The reauthorization of the Elementary and Secondary Education Act. Retrieved May 7, 2017 from https://www2.ed.gov/policy/elsec/leg/blueprint/blueprint.pdf

Desimone, L. (2002). How can comprehensive school reform models be successfully implemented? Review of Educational Research, 72(3), 433-479. http://dx.doi.org/10.3102/00346543072003433

Doorey, N. A. (2012). Coming soon: A new generation of assessments. Educational Leadership, 70(4), 28-34.

Drake, S. M., \& Burns, R. C. (2004). Meeting standards through integrated curriculum. St, Alexandria, VA: ASCD.

Duncan-Andrade, J. M., \& Morrell, E. (2008). The art of critical pedagogy: Possibilities for moving from theory to practice in urban schools. New York, NY: Peter Lang.

Elmore, R. F. (2002). Bridging the gap between standards and achievement: The imperative for professional development in education. In Secondary lenses on learning, participant book: Team leadership for mathematics in middle and high schools (pp. 313-344). Thousand Oaks, CA: Corwin Press.

Eng, N. (2013). The impact of demographics on 21 st century education. Social Science and Public Policy, 50, 272-282. http://dx.doi.org/10.1007/s12115-013-9655-z

Every Student Succeeds Act (ESSA). (n.d.). Retrieved June 10, 2017, from https://www.ed.gov/ESSA

Feiman-Nemser, S. (2008). Teacher learning: How do teachers learn to teach? In S. Cochran-Smith, S. Feiman-Nemser, \& D. McIntyre (Eds.), Handbook of research 
on teacher education: Enduring questions in changing contexts (pp. 697-705). New York, NY: Routledge.

Fernandez, M., \& Hauser, C. (2015). Texas mother teaches textbook company a lesson on accuracy. The New York Times. Retrieved from https://www.nytimes.com/2015/10/06/us/publisher-promises-revisions-aftertextbook-refers-to-african-slaves-as-workers.html

Ford, Y. F., \& Kea, C. D. (2009). Creating culturally responsive instruction: For students and teachers' sakes. Focus on Exceptional Children, 41(9), 1-16.

Frankenberg, E. (2009). The segregation of American teachers.Education Policy Analysis Archives, 17(1). Retrieved May 7, 2017 from http://epaa.asu.edu/epaa/v17n1/

Freire, P. (2011). Pedagogy of the oppressed (30th anniversary ed.; M. B. Ramos, trans.). [Kindle DX]. Retrieved from www.amazon.com

Freire, P., \& Macedo, D. (2005). Literacy: Reading the word and the world. New York: Routledge.

Gardner, D. P. (1983). A nation at risk.

Garrett, H. J., \& Segall, A. (2013). (Re)considerations of ignorance and resistance in teacher education. Journal of Teacher Education, 64(4), 294-304.

Gay, G. (2000). Culturally responsive teaching theory, research, and practice. New York, NY: Teachers College Press.

Gay, G. (2002). Preparing for culturally responsive teaching. Journal of Teacher Education, 53(2), 106-116. 
Gay, G. (2010). Acting on beliefs in teacher education for cultural diversity. Journal of Teacher Education, 61(1), 143-152.

Gay, G., \& Kirkland, K. (2003). Developing cultural critical consciousness and selfreflection in preservice teacher education. Theory Into Practice, 42(3), 181-187.

Glidden, H. (1998). Making standards matter 1998: An annual fifty-state report on efforts to raise academic standards [Descriptive report]. Washington, DC: American Federation of Teachers.

Gokhale, A. A. (1995). Collaborative learning enhances critical thinking. Journal of Technology Education, 7(1), 22-25.

Goldenberg, B. M. (2014). White teachers in urban classrooms: Embracing non-White students' cultural capital for better teaching and learning. Urban Education, $49(1), 111-114$.

Griner, A. C., \& Stewart, M. I. (2012). Addressing the achievement gap and disproportionality through the use of culturally responsive teaching practices. Urban Education, 48(4), 585-621.

Hasty, M. M., \& Fain, J. G. (2014). Emergent understandings: Multilingual fourth grade students generating close reading and multimodal responses to global and informational texts. Perspectives on Urban Education, 11(2), 10-20.

Heck, R. (2009). Teacher effectiveness and student achievement: Investigating a multilevel cross-classified model. Journal of Educational Administration, 47(2), $227-249$. 
Helsing, D., Howell, A., Kegan, R., \& Lahey, L. (2008). Putting the “development” in professional development: Understanding and overturning educational leaders' immunities to change. Harvard Educational Review, 78(3), 437-465.

Hochschild, J., \& Scovronick, N. (2003). The American dream and the public schools. New York, NY: Oxford University Press.

Holmes, K., Powell, S., Holmes, S., \& Witt, E. (2007). Readers and book characters: Does race matter? The Journal of Educational Research, 100(5), 276-281, 328.

Howard, T. C. (2003). Culturally relevant pedagogy: Ingredients for critical teacher reflection. Theory Into Practice, 42(3), 195-202.

Howard, T. C. (2010). Why race and culture matter in schools: Closing the achievement gap in America's classrooms. NY: Teachers College Press.

Hoy, A. W., \& Spero, R. B. (2005). Changes in teacher efficacy during the early years of teaching: A comparison of four measures. Teaching and Teacher Education, $17(7), 343-356$.

Hursh, D. (2007). Assessing No Child Left Behind and the rise of neoliberal education policies. American Educational Research Journal, 44(3), 493-518.

Irvine, J. J. (1990). Black students and school failure. Policies, practices, and prescriptions. Greenwood Press, Inc., 88 Post Road West, Box 5007, Westport, CT 06881 .

Irvine, J. J., \& Armento, B. J. (2001). Culturally responsive teaching: Lesson planning for elementary and middle grades. Education Review.

Jaquith, A., Mindich, D., Chung Wei, R., \& Darling-Hammond, L. (2010). Teacher professional learning in the United States: Case studies of state policies and 
strategies-summary report. Retrieved from

http://www.learningforward.org/docs/pdf/2010phase3report.pdf

Jochim, A., \& McGuinn, P. (2016). The politics of the Common Core assessments. Education Next, 16(4), 44-52.

Kendall, J. (2011). Understanding the Common Core State Standards. Alexandria, VA: ASCD.

King, J. E. (1991). Dysconscious racism: Ideology, identity, and the miseducation of teachers. The Journal of Negro Education, 60(2), 133-146.

Kose, B. W. (2009). The principal's role in professional development for social justice: An empirically-based transformative framework. Urban Education, 44(6), 628663.

Kozol, J. (1991). Savage inequalities. New York, NY: Crown Publishers.

Ladson-Billings, G. (1992). Reading between the lines and beyond the pages: A culturally relevant approach to literacy teaching. Theory Into Practice, 31(4), $312-320$.

Ladson-Billings, G. (1995). But that's just good teaching! The case for culturally relevant pedagogy. Theory Into Practice, 34(3), 159-165.

Ladson-Billings, G. (1998). Just what is critical race theory and what's it doing in a nice field like education? Qualitative Studies in Education, 11(1), 7-24.

Ladson-Billings, G. (2001). Crossing over to Canaan: the journey of new teachers in diverse classrooms. San Francisco: Jossey-Bass.

Ladson-Billings, G. (2005). The evolving role of critical race theory in educational scholarship. Race Ethnicity and Education, 8(1), 115-119. 
Ladson-Billings, G. (2006a). From the achievement gap to the education debt:

Understanding achievement in U.S. schools. Educational Researcher, 35(7), 3-

12.

Ladson-Billings, G. (Ed.). (2006b). Yes, but how do we do it? White teachers/diverse classrooms: A guide to building inclusive schools, promoting high expectations, and eliminating racism. Sterling, VA: Stylus.

Ladson-Billings, G. (2009). The dreamkeepers (2nd ed.). San Francisco, CA: JosseyBass.

Ladson-Billings, G. (2014). Culturally relevant pedagogy 2.0: a.k.a. the remix. Harvard Educational Review, 84(1), 74-84.

Ladson-Billings, G., \& Tate, W. (1995). Toward a critical race theory of education. Teachers College Record, 97(1), 47-68.

Lareau, A., \& Horvat, E. (1999). Moments of social inclusion and exclusion: Race, class, and cultural capital in family-school relationships. Sociology of Education, 72, 37-53.

Lawrence, S. M. (2005). Contextual matters: Teachers' perceptions of the success of antiracist classroom practices. The Journal of Educational Research, 98(6), 350365.

Lewis, A., \& Smith, D. (1993). Defining higher order thinking. Theory Into Practice, $32(3), 131-137$.

Love, A., \& Kruger, A. C. (2005). Teacher beliefs and student achievement in urban schools serving African American students. The Journal of Educational Research, 99(2), 87-99. 
Lynn, M. (2006). Education for the community: Exploring the culturally relevant practices of Black male teachers. The Teachers College Record, 108(12), 24972522.

Lynn, M., Johnson, C., \& Hassan, K. (1999). Raising the critical consciousness of African American students in Baldwin Hills: A portrait of an exemplary African American male teacher. Journal of Negro Education, 68(1), 42-53.

Marshall, C., \& Rossman, G. B. (2011). Designing qualitative research (5th ed.). Thousands Oaks, CA: Sage Publications.

Mathis, W. J., \& Trujillo, T. M. (2016). Lessons from NCLB for the Every Student Succeeds Act. Retrieved from http://nepc.colorado.edu/files/publications/ PB\%20Mathis-Trujillo \%20ESSA_0.pdf

McDaniel, C. (2004). Critical literacy: A questioning stance and the possibility for change. The Reading Teacher, 57(5), 472-481.

McDonnell, L. M., \& Weatherford, M. S. (2013). Evidence use and the Common Core State Standards movement: From problem definition to policy adoption. American Journal of Education, 120(1), 1-25.

McLaughlin, M., \& DeVoogd, G. (2004). Critical literacy as comprehension: Expanding reader response. Journal of Adolescent \& Adult Literacy, 48(1), 52-62.

Merriam, S. B. (1988). Case study research in education: A qualitative approach. San Francisco, CA: Jossey-Bass.

Miles, M. B., Huberman, A. M., \& Saldana, J. (2014). Qualitative data analysis: A methods sourcebook(3rd ed.). Thousand Oaks, CA: Sage Publications. 
Milner, H. R. (2007). Race, culture, and researcher positionality: Working through dangers seen, unseen, and unforeseen. Educational Researcher, 36(7), 388-400.

Milner, H. R. (2010). What does teacher education have to do with teaching? Implications for diversity studies. Journal of Teacher Education, 61(1-2), 118131.

Mohatt, G., \& Erickson, F. (1981). Cultural differences in teaching styles in an Odawa school: A sociolinguistic approach. In H. Treba, G. Guthrie, \& K. Au (Eds.), Culture and the bilingual classroom: Studies in classroom ethnography (pp. 105119). Rowley, MA: Newbury House.

NAEP - 2015 Mathematics \& Reading Assessments. (2015). Retrieved March 09, 2016, from https://www.nationsreportcard.gov/reading_math_2015/ \#reading/state/scores?grade $=4$

Natesan, P., \& Kieftenbeld, V. (2013). Measuring urban teachers' beliefs about African American students: A psychometric analysis. Journal of Psychoeducational Assessment, 31(1), 3-15. http://dx.doi.org/10.1177/0734282912448243

National Center for Education Statistics. (2017, May 10). NAEP overview. Retrieved from http://nces.ed.gov/nationsreportcard/about/

Nelson, S. W., \& Guerra, P. L. (2014). Educator beliefs and cultural knowledge: Implications for school improvements efforts. Educational Administration Quarterly, 50(1), 67-95. http://dx.doi.org/10.1177/0013161X13488595

Nieto, S. (2010). The light in their eyes: Creating multicultural learning communities. New York, NY: Teachers College Press. 
Ogawa, R. T., Sandholtz, J., Martinez-Flores, M., \& Scribner, S. (2003). The substantive and symbolic consequence of a district's standards-based curriculum. American Educational Research Journal, 40, 147-176.

Payne, C. M. (2013). So much reform, so little change: The persistence of failure in urban schools. Cambridge, MA: Harvard Education Press.

Pewewardy, C. D., \& Willower, D. J. (1993). Perceptions of American Indian high school students in public schools. Equity \& Excellence in Education, 26(1), 5255.

Porter, R. E., Fusarelli, L. D., \& Fusarelli, B. C. (2015). Implementing the Common Core: How educators interpret curriculum reform. Educational Policy, 29(1), 111-139.

Rozansky-Lloyd, C. (2005). African Americans in schools: Tiptoeing around racism. Western Journal of Black Studies, 29(3), 595-604.

Saldana, J. (2013). The coding manual for qualitative researchers (2nd ed.). Thousand Oaks, CA: Sage Publications.

Schmidt, W., \& Houang, R. T. (2012). Curricular coherence and the common core state standards for mathematics. Educational Researcher, 41(8), 294 -308. http://dx.doi.org/10.3102/0013189X12464517

Seidman, I. (2013). Interviewing as qualitative research: A guide for researchers in education and the social sciences. New York, NY: Teachers College Press. Shor, I., \& P. Freire, (1987). What is the 'dialogical method' of teaching? Journal of Education, 169 (3), 11-31. 
Siwatu, K. O. (2011). Preservice teachers' sense of preparedness and self-efficacy to teach in America's urban and suburban schools: Does context matter? Teaching and Teacher Education, 27(2), 357-365.

Sleeter, C. E. (2011). An agenda to strengthen culturally responsive pedagogy. English Teaching: Practice and Critique, 10(2), 7-23.

Sleeter, C. E. (2012). Confronting the marginalization of culturally responsive pedagogy. Urban Education, 47(3), 562-584.

Sleeter, C., \& Stillman, J. (2005). Standardizing knowledge in a multicultural society. Curriculum Inquiry, 35(1), 27-46.

Smith-Maddox, R. (1998). Defining culture as a dimension of academic achievement: Implications for culturally responsive curriculum, instruction, and assessment. The Journal of Negro Education, 67(3), 302-317.

Song, K. H. (2006). Urban teachers' beliefs on teaching, learning, and students: A pilot study in the United States of America. Education and Urban Society, 38(4), 481499. http://dx.doi.org/10.1177/0013124506289030

Spindler, G. D. (1997). Education and cultural process: anthropological approaches. Prospect Heights, IL: Waveland Press.

Stemler, S. E., Bebell, D., \& Sonnabend, L. A. (2011). Using school mission statements for reflection and research. Educational Administration Quarterly, 47(2), 383420.

Stiggins, R. (2007). Assessment through the student's eyes. Educational Leadership, 64(8), 22-26. 
Stosich, E. L. (2017). Leading in a time of ambitious reform: Principals in high-poverty urban elementary schools frame the challenge of the common core state standards. Elementary School Journal, 117(4), 539-565.

Stoll, L., Bolam, R., McMahon, A., Wallace, M., \& Thomas, S. (2006). Professional learning communities: A review of the literature. Journal of educational change, $7(4), 221-258$.

Strauss, V. (2014, September 16). How Common Core's recommended books fail children of color. The Washington Post. Retrieved from https://www.washingtonpost.com/blogs/answer-sheet/wp/2014/09/16/howcommon-cores-recommended-books-fail-children-of-color/

Taylor, B. M., Pearson, P. D., Peterson, D. S., \& Rodriguez, M. C. (2003). Reading growth in high-poverty classrooms: The influence of teacher practices that encourage cognitive engagement in literacy learning. The Elementary School Journal, 104(1), 3-20.

Theoharis, G. (2007). Social justice educational leaders and resistance: Toward a theory of social justice leadership. Educational Administration Quarterly, 43(2), 221-258

Ujifusa, A. (2013, February 4). Pressure mounts in some states against Common Core. Education Week. Retrieved from http://www.edweek.org/ew/articles/2013/02/06/20commoncore_ep.h32.html.U.

U.S. Department of Education Non-Regulatory Guidance (2016, September 27). Nonregulatory guidance for Title II, Part A: Building systems of support for excellent teaching and leading. Retrieved from https://www2.ed.gov/policy/elsec/leg/ essa/essatitleiipartaguidance.pdf 
Vaisey, S. (2010). What people want: Rethinking poverty, culture, and educational attainment. Annals of the American Academy of Political and Social Sciences, 629, 75-101.

Villegas, A. M. (1991). Culturally Responsive Pedagogy for the 1990s and Beyond. Trends and Issues Paper No. 6. ERIC Clearinghouse on Teacher Education, One Dupont Circle, NW, Suite 610, Washington, DC 20036-1186.

Villegas, A. M., \& Lucas, T. (2002). Preparing culturally responsive teachers: Rethinking the curriculum. Journal of Teacher Education, 53(1), 20-32.

Vogt, L. A., Jordan, C., \& Tharp, R. G. (1987). Explaining school failure, producing school success: Two cases. Anthropology \& Education Quarterly, 18(4), 276286.

Vanlommel, K., Van Gasse, R., Vanhoof, J., \& Van Petegem, P. (2017). Teachers' decision-making: Data based or intuition driven? International Journal of Educational Research, 75-83.

Walker, K. L. (2011). Deficit thinking and the effective teacher. Education and Urban Society, 43(5), 576-597.

Ward, A., Stoker, H. W., \& Murray-Ward, M. (1996). Achievement and ability tests: Definition of the domain. Educational Measurement, 2, 2-5.

Warren, C. J. E. (1954). Brown v. board of education. United States Reports, 347(1954), 483.

Watson, D. (2012). Norming suburban: How teachers talk about race without using words. Urban Education, 47(5), 983-1004. 
Weinstein, C., Curran, M., \& Tomlinson-Clarke, S. (2003). Culturally responsive classroom management: Awareness into action. Theory Into Practice, 42(4), 269276.

Yin, R. K. (2014). Case study research: Design and methods (5th ed.). Thousand Oaks, CA: Sage Publications.

Young, E. (2010). Challenges to conceptualizing and actualizing culturally relevant pedagogy: How viable is the theory in classroom practice? Journal of Teacher Education, 61(3), 248-260. 


\section{APPENDIX A}

\section{INTERVIEW PROTOCOL}

\begin{tabular}{|c|c|c|}
\hline \multicolumn{3}{|c|}{ Teacher Interview Protocol } \\
\hline \multirow{2}{*}{\multicolumn{3}{|c|}{$\frac{\text { RESEARCH QUESTIONS }}{1 . \text { What practices do elementary culturally relevant teachers use to ensure academic }}$}} \\
\hline & & \\
\hline \multirow{2}{*}{\multicolumn{3}{|c|}{$\begin{array}{l}\text { success, develop their cultural competency, and teach critical consciousness? } \\
\text { 2. How do teachers develop a critical consciousness with which to better serve the needs } \\
\text { of diverse students? } \\
\text { 3. How do teachers develop a critical consciousness with which to address the lack of } \\
\text { diversity in the CCSS? }\end{array}$}} \\
\hline & & \\
\hline Interview Question & $\begin{array}{c}\text { Relationship } \\
\text { to Research } \\
\text { Question }\end{array}$ & $\begin{array}{c}\text { Relationship to } \\
\text { Theoretical Framework }\end{array}$ \\
\hline \multicolumn{3}{|l|}{ What led you to become a teacher? } \\
\hline \multicolumn{3}{|l|}{$\begin{array}{l}\text { Can you recall a school memory, experience, or } \\
\text { teacher that had an impact on you? What about } \\
\text { the experience, the person, or your reaction that } \\
\text { led to that impact? }\end{array}$} \\
\hline $\begin{array}{l}\text { When you hear the term "culturally relevant } \\
\text { teaching," what comes to mind? }\end{array}$ & 1 & $\begin{array}{l}\text { Academic Success } \\
\text { Cultural Competency } \\
\text { Critical Consciousness }\end{array}$ \\
\hline $\begin{array}{l}\text { What level of autonomy do you have in the } \\
\text { classroom? }\end{array}$ & $1,2,3$ & $\begin{array}{l}\text { Cultural Competency } \\
\text { Critical Consciousness }\end{array}$ \\
\hline How would you describe your students? & 1,2 & Cultural Competency \\
\hline $\begin{array}{l}\text { Can you explain what a "normal" student looks } \\
\text { like, sounds like, hears like, and learns like? }\end{array}$ & 1,2 & Cultural Competency \\
\hline $\begin{array}{l}\text { How do you take your cultural characteristics and } \\
\text { match them with the culture of your students of } \\
\text { color? }\end{array}$ & 1 & $\begin{array}{l}\text { Cultural Competency } \\
\text { Critical Consciousness }\end{array}$ \\
\hline $\begin{array}{l}\text { Describe how you use formative and summative } \\
\text { assessments to drive your instruction. }\end{array}$ & 2,3 & Academic Success \\
\hline $\begin{array}{l}\text { Take me through your reflection process as you } \\
\text { analyze formative assessments based on Common } \\
\text { Core State Standards. }\end{array}$ & 1 & $\begin{array}{l}\text { Academic Success } \\
\text { Critical Consciousness }\end{array}$ \\
\hline $\begin{array}{l}\text { How do you prepare your lessons to meet } \\
\text { individual student needs? }\end{array}$ & 2,3 & $\begin{array}{l}\text { Academic Success } \\
\text { Critical Consciousness }\end{array}$ \\
\hline How do you incorporate critical thinking and & 2,3 & Academic Success \\
\hline
\end{tabular}




\begin{tabular}{|l|l|l|}
\hline higher-order thinking activities into your lessons? & & Critical Consciousness \\
\hline $\begin{array}{l}\text { How do you use the Common Core State } \\
\text { Standards to teach children they can make a } \\
\text { difference in the world? }\end{array}$ & 2,3 & $\begin{array}{l}\text { Academic Success } \\
\text { Critical Consciousness }\end{array}$ \\
\hline $\begin{array}{l}\text { Discuss with me a lesson/unit in which you used } \\
\text { culturally relevant teaching strategies while using } \\
\text { the Common Core State Standards as the } \\
\text { benchmark for achievement. }\end{array}$ & $1,2,3$ & $\begin{array}{l}\text { Academic Success } \\
\text { Cultural Competency } \\
\text { Critical Consciousness }\end{array}$ \\
\hline $\begin{array}{l}\text { How do you encourage and enable students to } \\
\text { challenge mainstream curriculum materials and } \\
\text { media? }\end{array}$ & $1,2,3$ & $\begin{array}{l}\text { Academic Success } \\
\text { Cultural Competency } \\
\text { Critical Consciousness }\end{array}$ \\
\hline $\begin{array}{l}\text { How do your students' cultures influence the } \\
\text { literature you choose to teach reading CCSS? }\end{array}$ & 23 & $\begin{array}{l}\text { Academic Success } \\
\text { Cultural Competency }\end{array}$ \\
\hline $\begin{array}{l}\text { How do you use literature to respond to the } \\
\text { cultural differences of your students? } \\
\text { neighborhood? Global? }\end{array}$ & 2,3 & $\begin{array}{l}\text { Academic Success } \\
\text { Cultural Competency } \\
\text { Critical Consciousness }\end{array}$ \\
\hline $\begin{array}{l}\text { What are topics an elementary teacher can use to } \\
\text { teach author's point of view and critical } \\
\text { consciousness? What about teaching materials? }\end{array}$ & 2,3 & $\begin{array}{l}\text { Academic Success } \\
\text { Cultural Competency } \\
\text { Critical Consciousness }\end{array}$ \\
\hline $\begin{array}{l}\text { How can a teacher have and teach critical } \\
\text { consciousness? }\end{array}$ & $1,2,3$ & Critical Consciousness \\
\hline $\begin{array}{l}\text { What are issues in your students' school, } \\
\text { neighborhood, and global community that lend } \\
\text { itself as a catalyst for critical consciousness? }\end{array}$ & 1,2 & Critical Consciousness \\
\hline $\begin{array}{l}\text { What type of classroom reading environment is } \\
\text { needed to discuss issues related to students' } \\
\text { culture? }\end{array}$ & 2,3 & $\begin{array}{l}\text { What are the limitations a teacher faces while } \\
\text { trying to have and teach critical consciousness? }\end{array}$ \\
\hline $\begin{array}{l}\text { Describe how you determine your professional } \\
\text { development needs. }\end{array}$ & $1,2,3$ & $\begin{array}{l}\text { Academic Success } \\
\text { Critical Consciousness }\end{array}$ \\
\hline
\end{tabular}




\section{APPENDIX B}

\section{STEPHANIE'S STUDENT WORK SAMPLE}

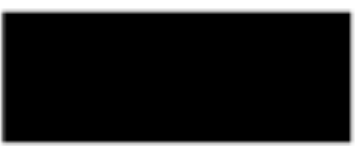

December 6, 2016

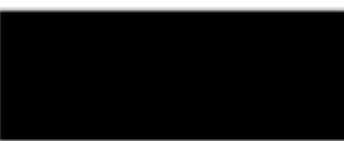

Frankfort KY 40601

Dear

I am a 4 grader at

Slementary. I make straight $A$ 's and try very hard every day in sthool. I want to grow up to be an engineer. I like math. My teacher always tells me how there is never a problem that I can not fix. I know she is right because $\mathrm{I}$ help my dad and mom fix things at the house and the car. Sometimes I have to use math to help them.

I was born in America. My dad and mom came to America when they were little kids. They did not know each other when they came to America but they lived in the same community. They liked each other and they got married. The both work jobs. They take care of me and my sister. My mom is a good cook and she helps people in the apartments. My dad knows how to fix things and he helps people to.

I want you to know me, my sister, my dad, and my mom. Donald Trump says he is going to send people to Mexico. My mom is scared. My dad says it is going to he ok. But my mom is still scared. I do not hurt people. My dad and mom do not hurt people. I want to help people. I do not want to go to Mexico. My dad and mom want to stay in America. Please tell Donald Trump we are gond and follow the rules. We do not hurt people. We want to help.

Sincerely,

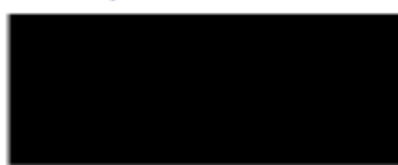


APPENDIX C

STEPHANIE'S STUDENT WORK SAMPLE
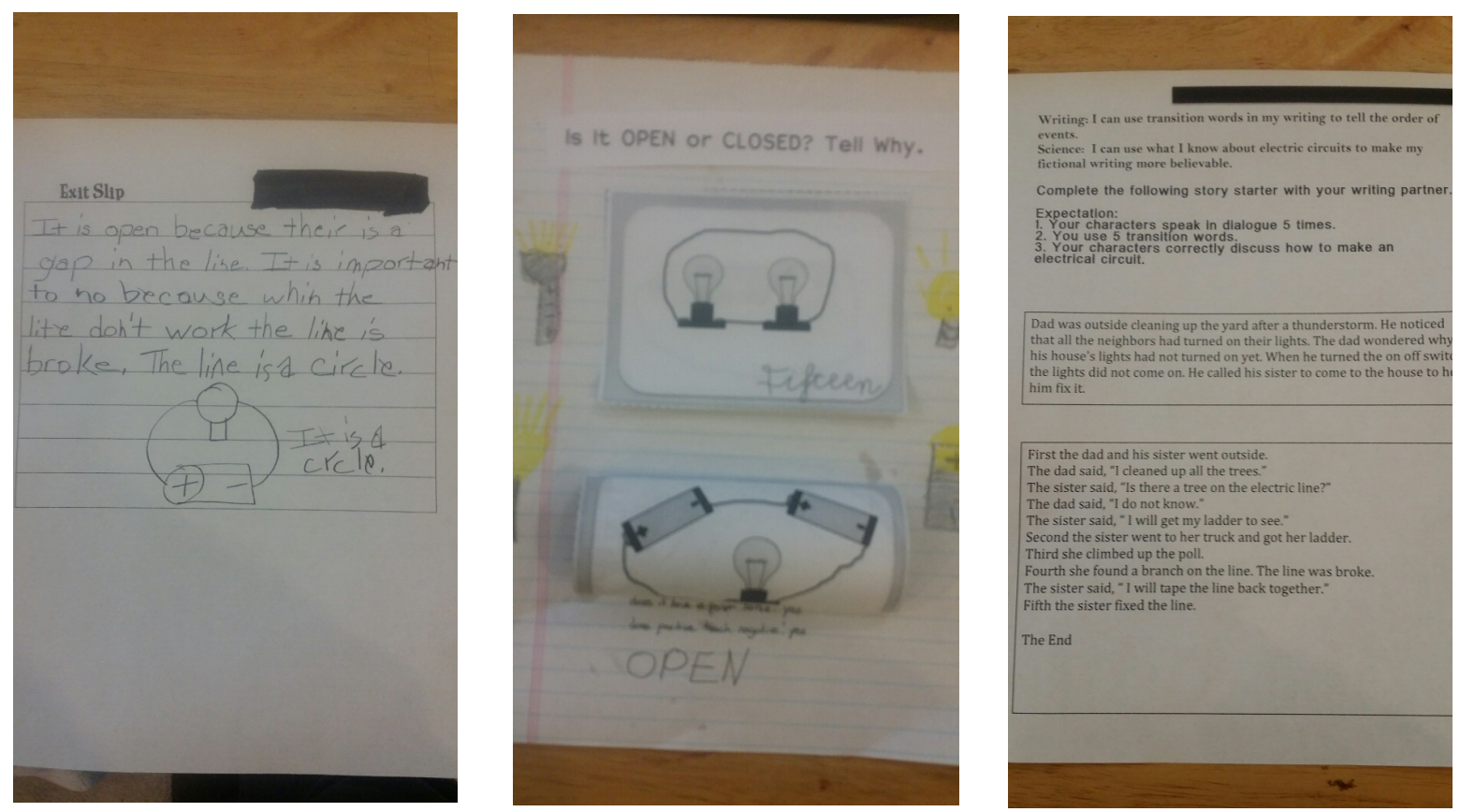
APPENDIX D

CLAIRE'S STUDENT WORK SAMPLE
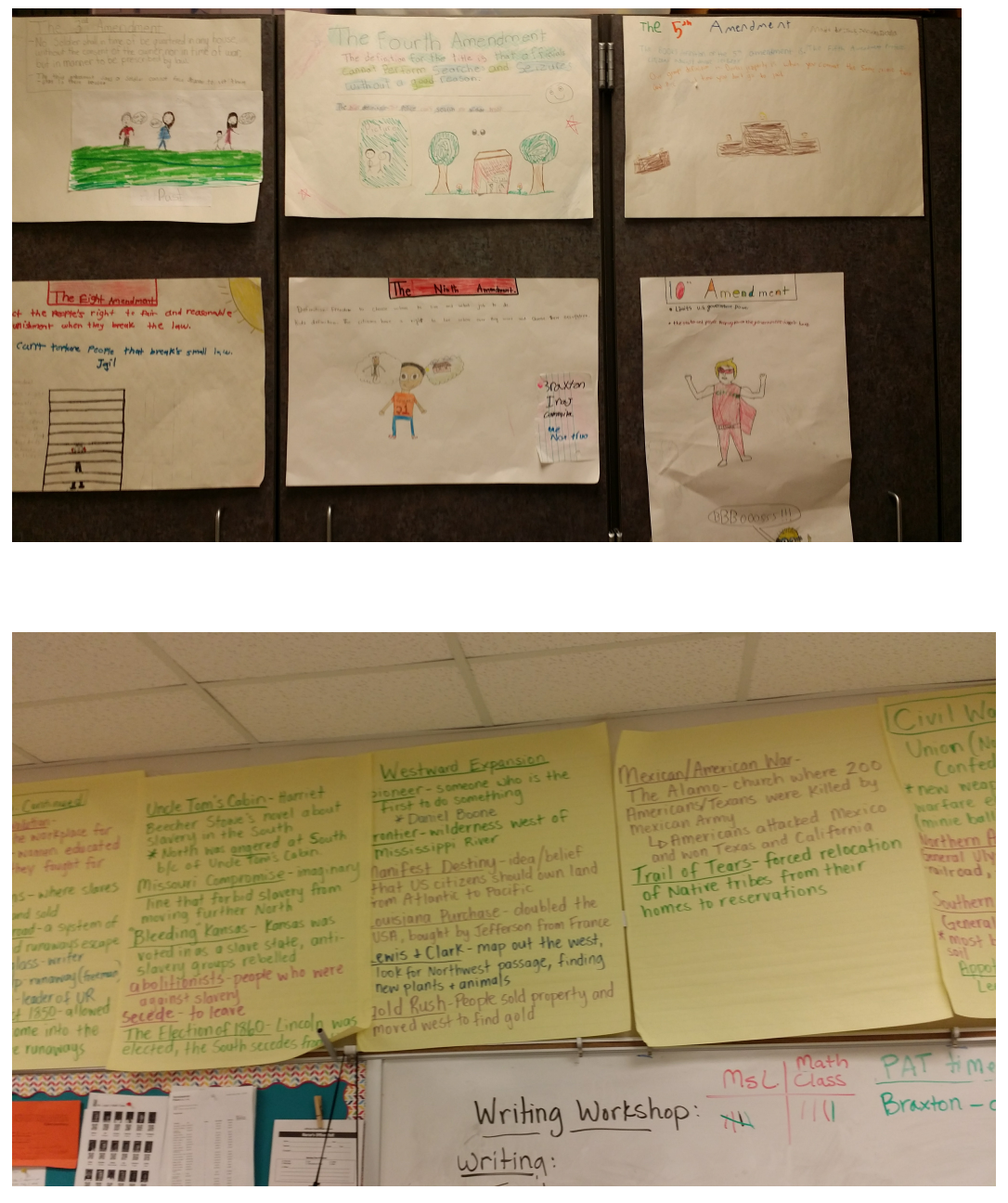


\section{APPENDIX E}

\section{CLAIRE'S STUDENT WORK SAMPLE}

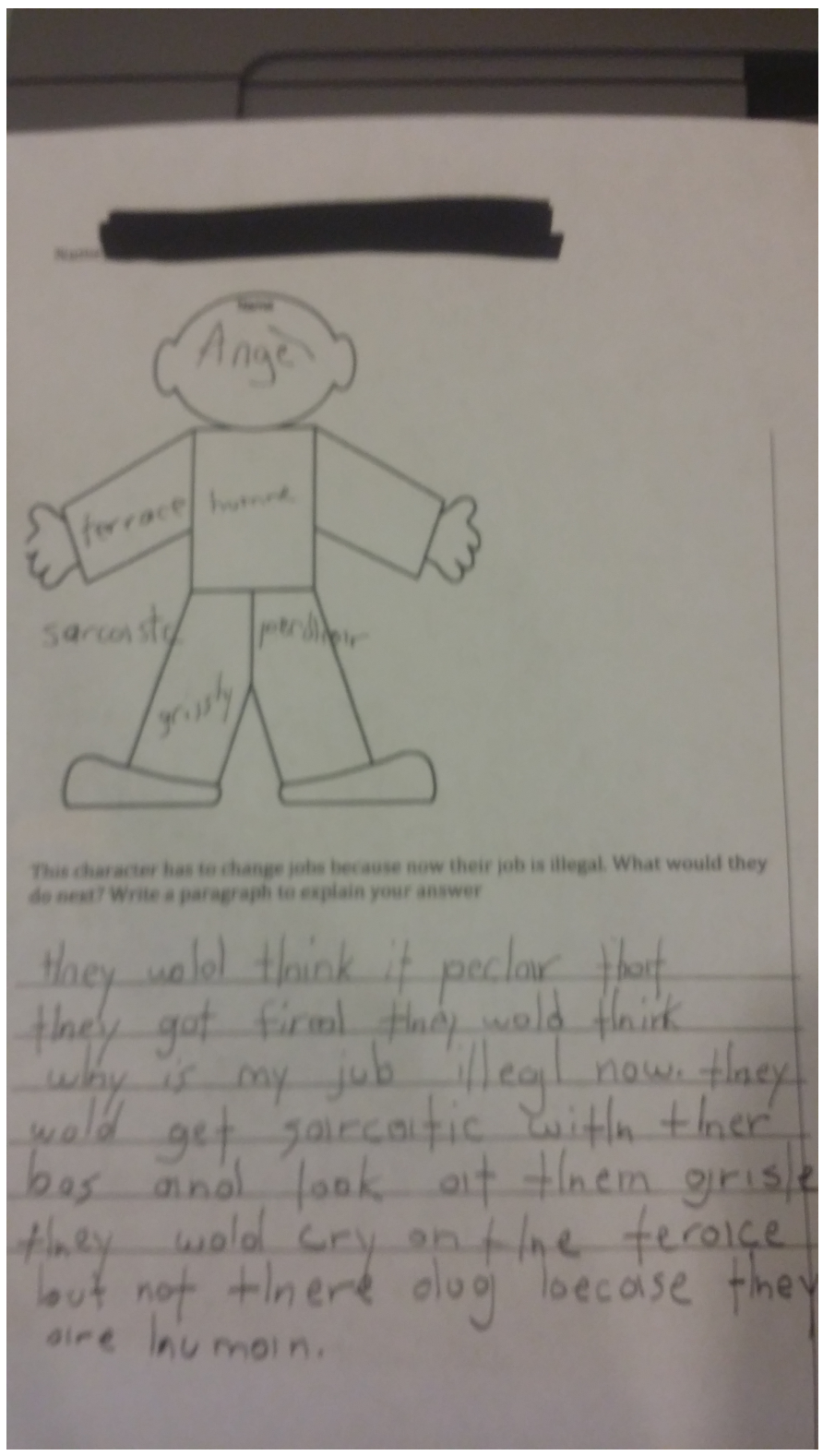




\section{APPENDIX F}

CHARLES'S STUDENT WORK SAMPLE
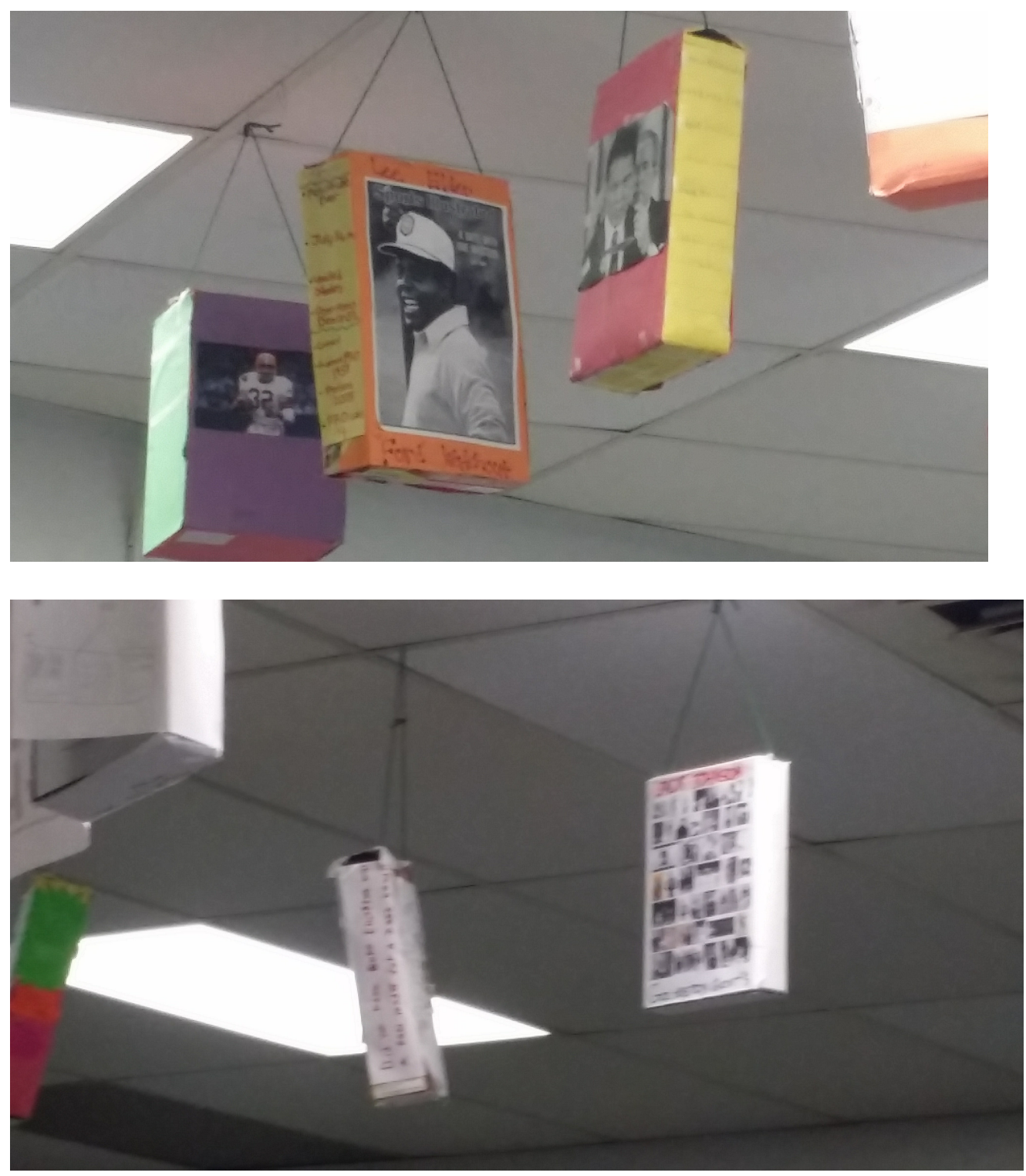


\title{
APPENDIX G
}

\section{INFORMED CONSENT}

\author{
Informed Consent for Research Participants
}

[Date]

Dear Participant,

1 am a teacher in

as well as a doctoral candidate at the

University of Louisville in Louisville, KY. 1 am currently working on my dissertation, which centers on culturally relevant teachers. You are being invited to participate in my research based $\infty$ your interest in the $\square$. Diversity, and \_ Institute held by $\square$ You are being invited to participate in a writing prompt. As well as, you possibly might be asked to participate in an interview and classroom observation for a dissertation research project. This project is required in partial fulfillment of the degree of EDD in Urban Leadership through the University of Louisville. The interview aims to document teacher perceptions regarding their experiences and beliefs in using students' culture as a catalyst for teaching the Common Core State Standards. In particular this research aims to explore how you kesp a critical consciousness while selecting materials and topics to teach the Common Core State Standards.

Your participation first entails answering two short writing prompts. If you are selected to move to the next phase, you will participzte in one 45 - 60 minute interview and a reading lesson observation. The interviews will be audio recoeded. The writing prompt responses, interview recording and interview transcript materials will be stored in the researcher's home office on a personal password-protected computer. Your responses are strictly confidential and they will not be disclosed individually to anyone. Your name will not be connected to any of your answers. Participants will be identified by their positions and will be assigned pseudonyms. The schools described will also be assigned pseudonyms. Summaries of initial findings will be peovided for your review in order to report accurate information.

Participation in this study is voluntary and you may withdraw at any time with no negative consequences. By transmitting a writing prompt response, you are agreeing to participate in this study. Additionally, if there is an interview question you would prefer not to answer, you have no obligation to do so. If you would like additional information, or if you have any questions about this study, you may email me at angela.pleasantia

You may receive a summary of the final report at your request.

I appeceiate your willingness to give your time to this study. If you have any questions or concerns regarding your rights as a research participant or with any aspect of the project, you may report them to my doctocal study supervisor,

Sincerely,

Angela Pleasant

Candidate for EDD, Urban Leadership

University of Louisville 


\section{APPENDIX H}

\section{PARENTAL CONSENT}

Date

Dear Parent/Guardian

My name is Angela Pleasant, and I am conducting a research project in your child's class. I am interested in studying teachers who use culturally responsive materials and teach their students to think critically while teaching reading curriculum related to the Common Core State Standards. The teachers I'm studying teach their students to question what they read. For example, when students read a fictional book, critical teachers teach students to think why certain characters behave the way they do. Also, these teachers ask students to examine and discuss the author's interpretation of characters and settings based on the information given in the text. The teacher encourages their students to use their prior knowledge and the text to agree or disagree with the author's depiction or analysis.

I will be in your child's class on While in the classroom, I will observe and take notes of the teacher's instructional methods. I will not record your child's name or any other materials that would identify your child. I may collect copies of your child's writing samples, but the teacher will remove your child's name before copies are given to me. Your child will not do anything outside of his or her normal classroom activities, and there is no risk to you or your child.

If you have any questions or concerns about the study, or if you would like to withdraw your child from the study, please contact me at:

Angela Pleasant anglea.pleasant@jefferson.kyschools.us

If you have questions about your rights as a research participant, please contact my doctoral chairs,

Sincerely,

Angela Pleasant

Candidate for EDD, Urban Leadership University of Louisville 


\section{CURRICULUM VITA}

NAME: $\quad$ Angela Lee Pleasant

ADDRESS: 720 Crescent Ridge Dr.

Taylorsville, KY 40071

DOB: $\quad$ Louisville, KY - October 17, 1973

EDUCATION

\& TRAINING: $\quad$ B.S., Political Science University of Louisville $1992-1996$

M.Ed., Instructional Technology

University of Louisville 2000-2001

Ed.D., Educational Leadership and Organizational Development

$2013-2017$

AWARDS: Carl Perkins Contributor to Special Education 2013

Ashland Oil Teacher Achievement Award 2014

Elementary Teacher Semi-Finalist for Ashland's Kentucky Elementary Teacher of the Year 2014

PROFESSIONAL SOCIETIES: Alpha Kappa Alpha Sorority: Eta Omega Graduate Chapter

International Reading Association 
Kentucky Reading Association

Greater Louisville Alliance of Black School Educators

Louisville Writing Project 